Universidade de São Paulo Instituto de Química

\title{
DESENVOLVIMENTO E AVALIAÇÃO DE SISTEMA ENVOLVENDO INTERFACE DE ANÁLISE POR INJEÇÃO EM FLUXO COM ELETROFORESE CAPILAR
}

FABIANO SOUZA PALGROSSI

Dissertação de Mestrado

ORIENTADOR: IVANO GEBHARDT ROLF GUTZ

São Paulo, 26 de novembro de 2002 
“... A criação não é uma alegria no sentido vulgar. É uma servidão, uma terrível escravidão voluntária - e a alegria se assemelha muito às das grandes vitórias, tem um perfume de melancolia."

Albert Camus

"...Nem sempre faço o que é melhor pra mim, Mas nunca faço o que não "tô a fim de fazer."

Humberto Gessinger (Engenheiros do Hawaii)

À minha amada, Erika, pela dedicação, compreensão, carinho e por ter transformado minha vida em um mundo de amor e alegria, te amo.

Ao meu Pai, Osvaldo (meu herói), pelo amor e apoio em todo meu viver. À minha Mãe, Cleuza (In Memorian) que nesse momento está radiante de alegria, por mais esta etapa cumprida.

À minha Tia, Maria Helena, que foi como uma mãe para mim ao ter, ao modo dela, me incentivado nesta jornada. 
Agradeço à minha irmã, por todo carinho e incentivo.

Ao meu orientador, Professor Ivano Gebhardt Rolf Gutz, meu pai científico, pela paciência e amizade.

Aos professores Claudimir Lúcio do Lago e Lúcio Agnes pelo apoio científico e financeiro (pelas tantas FUVESTs).

Ao meu amigo Flávio Rocha, um exemplo a ser seguido como pesquisador e pessoa.

Ao amigão Tacio Philip Sansonovisk que sempre me acompahou nas fotografias, aventuras radicais e acampamentos.

À minha amiga Adriana De Donato (minha irmã científica) por sempre permanecer ao meu lado nos momentos de dificuldade, mesmo estando fora da academia.

Ao Amigo, Escoteiro e Sacerdote Monsenhor Danilo de Oliveira Ohl pela orientação moral, cívica e espiritual.

Ao amigo José Alberto Fracassi pela herança tecnológica (equipamento $\mathrm{CE})$.

Ao amigo Jairo pela minha iniciação à pesquisa científica.

Aos companheiros de laboratório: Alexandre, Andrea, Carlos, Carol, Dosil, Escobar(Rodrigo), Giza, Heron, Osmar, Lúcia, Daniela, Eduardo, Márcio, Sérgio, Vitor, Zé Geraldo, Zé Maria, pelas brincadeiras e discussões infindáveis que só vieram a acrescentar conhecimento em minha trajetória acadêmica.

Aos técnicos: Ricardo e Fernando e ex-técnico: Rogério pela correria a procura de reagentes, cotações e compras.

À secretária Marlene por nunca esquecer um de meus recados.

Aos compositores e cantores: Humberto Gessinger, Marisa Monte, Roberto Frejat, Elis Regina, Zé Ramalho, Cazuza, Thedy Correa, Herbert Vianna, entre muitos outros que me ajudaram a escrever, alegrando esta difícil jornada com suas músicas.

À Fapesp e ao CNPq pelo apoio financeiro. 
ABREVIATURAS UTILIZADAS .....................................................................i

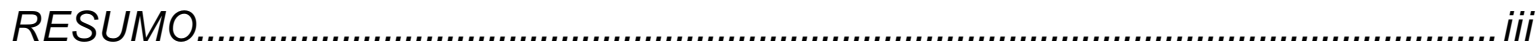

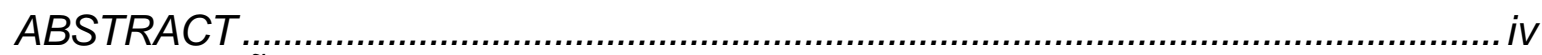

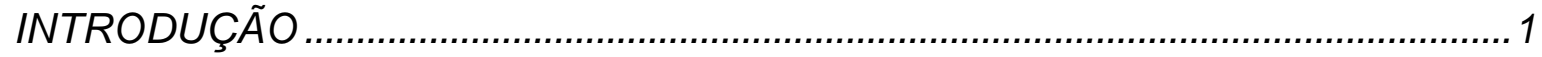

DESENVOLVIMENTO DE COMPONENTES DO SISTEMA …............................

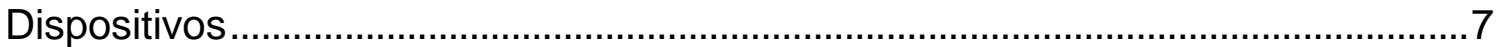

Equipamento de Eletroforese Capilar ...........................................................

Circuitos Eletrônicos .......................................................................................10

Sistema de termostatização .......................................................................10

Fontes de alta tensão .................................................................................11

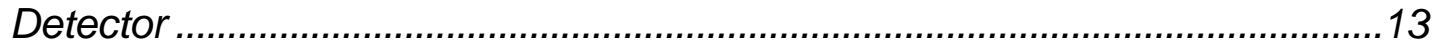

Pressiostato para transferência hidrodinâmica ................................................15

Circuito de controle da Bomba de Vácuo ..........................................................17

Válvula multicanal para múltiplos eletrólitos .....................................................18

Circuito de alimentação para válvula multicanal...............................................18

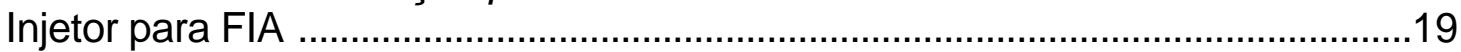

Circuito de alimentação do injetor FIA.......................................................23

Detector condutométrico sem contato para FIA ................................................24

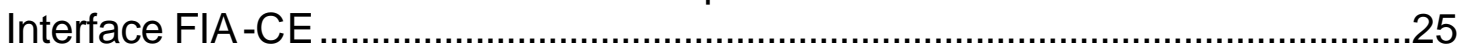

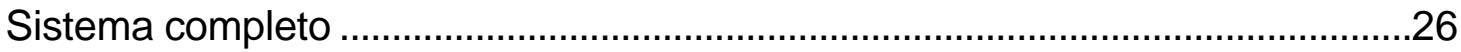

Interfaceamento com microcomputador …………………………………...27

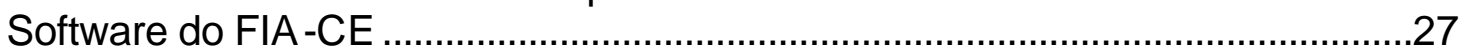

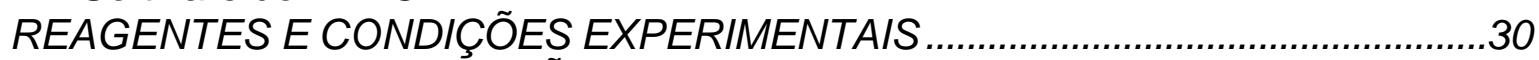

RESULTADOS E DISCUSSÃO..........................................................................

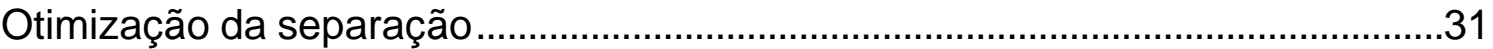

Avaliação da repetibilidade do injetor FIA ...............................................................33

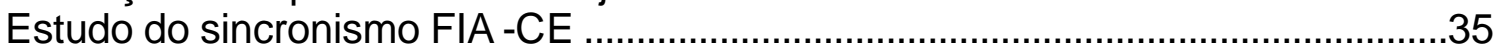

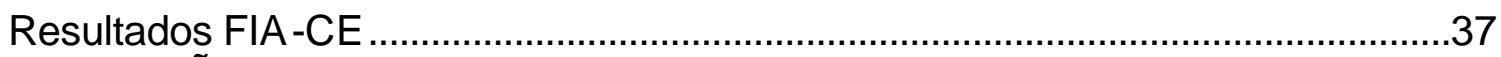

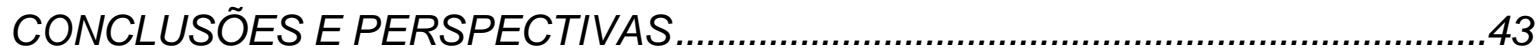

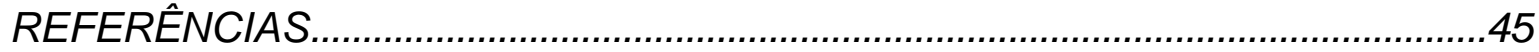

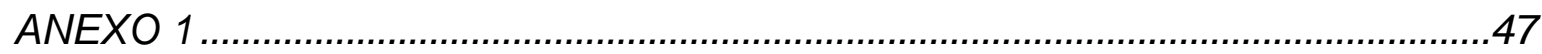

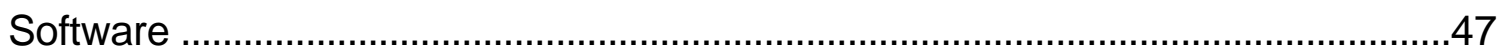

Program EletroforeseCapilar_Praia; .............................................................47

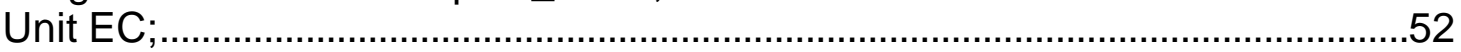

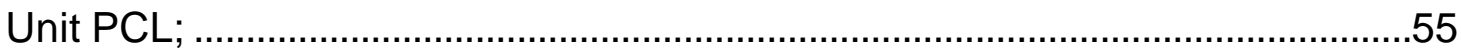

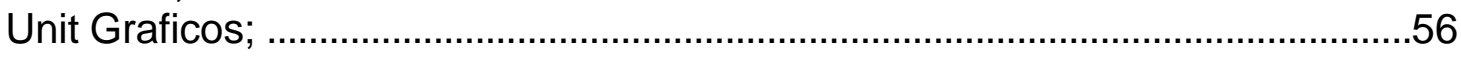

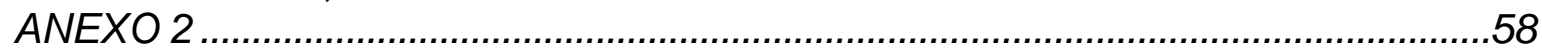

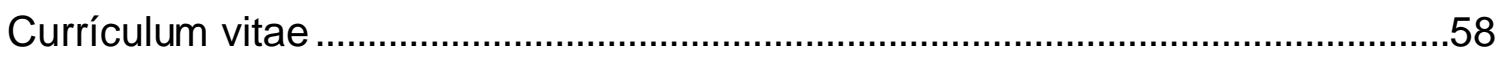


$\phi-$ Vazão

$\Delta \mathrm{P}$ - Diferença de Pressão

A/D - conversor analógico/digital

AT - Alta Tensão

CE - Capillary Electrophoresis (Eletroforese Capilar)

Conversor i/e - Conversor corrente em tensão

d.c. - Corrente contínua

D/A - conversor digital/analógico

DCE - dupla camada elétrica

DCSC - Detector condutométrico sem contato ou detector oscilométrico

d.e. - Diâmetro Externo

DI - Entrada digital

d.i. - Diâmetro Interno

DPR - Desvio padrão relativo

DO - Saída digital

EOF - electroosmotic flow (Fluxo eletroosmótico)

FIA - Flow Injection Analysis (Análise por Injeção em Fluxo)

His - Histidina

HLact - Ácido Láctico

HPLC - High Performance Liquid Chromatography (Cromatografia Líquida de Alta Performance)

IC - integrated circuit (Circuito integrado)

MES - Ácido 2-(N-morfolino)etanosulfônico

MTBF - tempo médio antes de falha (de um componente ou equipamento)

s - Estimativa do Desvio Padrão Relativo

SMD - Surface mounted device (componentes de montagem em superfície)

u.a. - Unidade arbitrária

V dc - Tensão contínua 
A combinação sinérgica da análise por injeção em fluxo com eletroforese capilar, FIA-CE, é um novo campo em rápida expansão, que se estende da simples justaposição de equipamentos (FIA-CE at-line) ao verdadeiro interfaceamento ou hifenação (FIA-CE in-line ou on-line). Tipicamente, circuitos FIA construídos nos laboratórios são interfaceados com equipamentos comerciais de eletroforese capilar providos com detecção espectrofotométrica UV-Vis, e operam sob injeção (ou melhor, transferência) eletrocinética de amostra do circuito FIA para o capilar, vez que esta é mais simples para implementar que a transferência hidrodinâmica. Um novo sistema FIA-CE que combina a detecção condutométrica sem contato elétrico, DCSC, com transferência hidrodinâmica ou eletrocinética de amostra foi projetado e construído no laboratório utilizando-se material de baixo custo, além de uma fonte de alta tensão, uma bomba peristáltica e um microcomputador. No circuito FIA, utilizou-se um único solenóide na construção de injetor multicanal com válvulas de estrangulamento de dimensões reduzidas. O DCSC foi anteriormente desenvolvido por outros componentes do grupo. A interface FIA-CE consiste de uma agulha hipodérmica de aço inoxidável conectada à saída do circuito FIA, atuando como eletrodo aterrado, traspassada pelo capilar. Quatro diferentes eletrólitos podem ser chaveados por intermédio do microcomputador para alimentar o circuito FIA. Na CE, três níveis de pressão podem ser aplicados ao reservatório contendo o eletrodo ao qual se aplica a alta tensão, correspondente ao extremo do capilar mais próximo do detetor: a) potente aspiração, durante o procedimento de limpeza rápida; b) pequena pressão subambiente (ajustada com um pressiostato simples) para a transferência sincronizada de amostra da interface; e c) pressão ambiente, durante a aquisição de dados do eletroferograma. O sistema opera sob controle de um flexível software de código aberto, aceitando procedimentos FIA usuais. As avaliações mostraram, afora a comodidade de uso do sistema, freqüência analítica maior, limites de detecção similares e melhor repetibilidade da área e posição dos picos em comparação a CE operada manualmente. 
The synergistic combination of flow injection analysis with capillary electrophoresis, FIA-CE, is a new and rapidly evolving field, comprising juxtaposition of equipments (at-line FIA-CE) and true interfacing or hyphenation (in-line or on-line FIA-CE). Typically, FIA circuits assembled in the laboratory are interfaced to commercial electrophoresis equipments provided with UV-Vis detection and operated under electrokinetic sample injection (or better, transfer from the FIA circuit), that is simpler to implement than hydrodynamic tansfer. A new FIA-CE system that combines contactless conductivity detection, CCD, with hydrodynamic and electrokinetic sample transfer was designed and constructed in the laboratory from low cost parts, besides a high voltage supply, a peristaltic pump and a PC. In the FIA circuit, a solenoid actuated multi-channel pinch-valve injector was downsized from a previous prototype. The oscillometric CCD was formerly developed by other components of the group. The interface consists of a hypodermic needle, connected to the FIA circuit and serving as grounded electrode, trespassed by the capillary. Four different electrolytes can be switched by the PC and three levels of pressure can be applied to the vial with the HV electrode and the tip of the capillary near the detector (opposite to the FIA-CE interface): a) strong aspiration, during fast cleansing procedure; b) slightly subambient pressure (adjusted with a simple pressurestat) for synchronized sample transfer at the interface; and c) ambient pressure, during data acquisition of the electropherogram. The system runs under control of flexible, open-code software, accepting usual FIA procedures. Evaluations showed, besides convenience of use, higher analytical frequency, similar detection limits and better repeatability of peak positions and areas in comparison with manually operated CE. 
Em duas décadas e meia, os métodos de análise em fluxo assumiram grande importância, como se pode aquilatar pelos mais de 11.000 artigos relacionados ao assunto, mais de uma dúzia de livros e pela instituição de duas conferências internacionais especializadas (International Conference on Flow Analysis e International Conference on Flow Injection Analysis) ${ }^{[1,2]}$. No Brasil, onde foram realizados vários trabalhos pioneiros, 1/4 dos trabalhos científicos em química analítica publicados nos últimos anos, faz uso de análise em fluxo, em geral, com detecção espectrofométrica ${ }^{[3]}$. Entretanto, alguns grupos, como, por exemplo, o do orientador desta dissertação, trabalham preferencialmente em combinação com técnicas eletroanalíticas ${ }^{[4-8]}$ ou mesmo, espectroeletroanalíticas $^{[9]}$. O crescente interesse na análise em fluxo se deve principalmente devido: à relativa facilidade de obtenção de uma alta freqüência analítica, ao pequeno consumo de amostra/reagentes, ao maior isolamento do sistema de interferências externas e à facilidade de automação, diminuindo assim a influência do operador e minimizando desvios nos resultados.

A eletroforese é uma técnica de separação baseada na migração diferenciada de compostos iônicos ou ionizáveis sob efeito do campo elétrico, ou seja, baseia-se em separação não cromatográfica (apesar de haver variantes em que esta distinção deixa de ser nítida). A paternidade da eletroforese convencional é atribuída a Tiselius que, no inicio da década de trinta, introduziu o método de fronteira móvel, empregado na separação de algumas proteínas do soro sangüíneo. Essas pesquisas renderam-Ihe o prêmio Nobel de $1948^{[10]}$. Mas foi somente na década de 80 , com a implementação das técnicas capilares, que a eletroforese passou a encontrar ampla utilização na pesquisa e em análises de rotina devido, entre outros fatores, à sua elevada capacidade de separação, ao baixo custo da instrumentação, ao menor tempo de análise e ao menor consumo de reagentes frente a HPLC ${ }^{[11]}$.

O material tipicamente utilizado na fabricação dos capilares é a sílica fundida, que lhes confere muitas propriedades interessantes, como dimensões 
precisas, alta condutividade térmica, boa resistência mecânica, maleabilidade, resistência ao ataque químico, alta transmitância óptica (190 a 900 nm) e, principalmente, um conveniente processo de transporte de massa, o fluxo eletroosmótico, que se estabelece sob campo elétrico em ampla faixa de $\mathrm{pH}$.

A sílica fundida é caracterizada por possuir em sua superfície grupos silanol, os quais em contato com meio aquoso podem ser desprotonados, tornando-se negativamente carregados. Os grupos desprotonados são chamados de grupos silanolatos. O resultado de tal ocorrência é o surgimento da dupla camada elétrica, DCE, região na qual há uma distribuição espacial não homogênea de carga ${ }^{[12,13]}$.

O modelo combinado de Gouy-Chapman-Stern-Grahame descreve a região imediatamente adjacente à superfície interna do capilar, onde predominam os grupos silanolatos. Cátions hidratados aproximam-se da superfície do capilar a uma distância correspondente ao raio de hidratação, sendo que o centro destes íons define o plano externo de Helmholtz, delimitando a camada compacta da dupla camada elétrica. As camadas mais externas de cátions, menos atraídas eletrostaticamente e sob efeito do movimento térmico aleatório, apresentam concentração que decai com a distância, formando a camada difusa, que se estende até o ponto em que a concentração se confunde com a do âmago da solução.

Quando um campo elétrico intenso é imposto ao capilar, seu efeito sobre a DCE coloca em movimento cátions da camada difusa (mas não da camada compacta) em direção ao eletrodo de carga negativa. Na distância em que uma fração da camada difusa consegue escapar às forças de atração da superfície pode-se atribuir a passagem de um plano teórico denominado plano de cisalhamento. O processo resultante, conhecido como fluxo eletroosmótico, decorre do fato de os cátions da camada difusa arrastarem consigo não somente a sua esfera de solvatação mas todo o conteúdo do tubo capilar cilíndrico. Como decorrência, a velocidade linear do fluxo é similar em toda a seção do capilar, afora a interface, razão pela qual a dispersão causada é muito menor que quando o líquido é deslocado hidrodinamicamente por efeito de uma bomba (como no FIA) ou da gravidade. 
O fluxo eletroosmótico é utilizado, via de regra, para acelerar a corrida, estando direcionado no sentido do detector. Eventualmente, pode servir para aumentar a eficiência de separação das substâncias a serem analisadas, quando no sentido contrário ao detector (às custas do aumento do tempo de separação).

Para se inverter o fluxo eletroosmótico inverte-se a polaridade dos eletrodos e/ou modifica-se a carga efetiva da superfície do capilar, tipicamente (mas não exclusivamente) pela adsorção de uma bicamada de moléculas de tensoativo ou micelas carregadas positivamente.

Cabe observar que a análise por injeção em fluxo não abrange, por convenção ${ }^{[14]}$, a cromatografia nem a eletroforese capilar, apesar destas duas famílias de técnicas se basearem em fluxo de soluções.

No entanto, é evidente que a implementação de sistemas combinando FIA e técnicas de separação têm enormes potencialidades, pois assim eúnem-se procedimentos analíticos implementados em fluxo, facilmente automatizáveis e realizados com alta repetibilidade e rapidez - tais como acumulação (préconcentração), diluição, transferência de fases, condicionamento, adição de reagentes, reações - com um estágio posterior de separação altamente eficiente, possibilitando incrementar, principalmente, a seletividade frente à análise em fluxo empregada isoladamente.

Por ser um campo ainda muito novo, há somente cerca de 4 dezenas de trabalhos na literatura sobre FIA-CE, quase todos surgidos na segunda metade da década de 90, mas já reunidos em revisões sobre o assunto ${ }^{[15,16,17,18]}$. Trabalhos como a diálise in vivo para o monitoramento da ação de fármacos em ratos ${ }^{[19]}$, a pré-concentração de metais em coluna $\mathrm{C} 18^{[20]}$ ou de troca iônica ${ }^{[21,22]}$, monitoramento de dissolução de medicamentos ${ }^{[23]}$, separação de espécies voláteis com unidade de difusão gasosa ${ }^{[24]}$, extração de polifenóis de chá por microondas $^{[25]}$, ou amostragem por extração da fase gasosa ${ }^{[26]}$. Naturalmente, existem amplas possibilidades de inovação neste campo em expansão.

Pode-se constatar que a introdução de amostras nos instrumentos de eletroforese capilar, CE, constitui uma etapa crítica e, portanto, limitante especialmente nas aplicações de rotina, vez que envolve a troca do recipiente (vial) de eletrólito pelo de amostra e vice-versa. Esta operação requer cuidado 
especial, pois uma das extremidades do frágil capilar, juntamente com um dos eletrodos, devem ser imersos na solução, cujo nível também precisa ser ajustado. Para aplicações de rotina com grandes séries de amostras, existem no mercado intercambiadores automáticos, de custo expressivo em relação ao restante da instrumentação e muito dependentes de dispositivos adicionais para realizar qualquer tratamento prévio das amostras.

Historicamente, o primeiro passo rumo ao interfaceamento entre sistemas em fluxo e a eletroforese remonta ao trabalho de Tsuda e Zare em $1991^{[27]}$ no qual, para evitar a manipulação em torno do capilar da CE durante a introdução de amostra, os autores introduziram uma técnica designada de "split injector" (termo emprestado da cromatografia de gás com coluna capilar). Este consiste em bombear um plugue de amostra até o capilar, onde a maior parte desta é descartada, enquanto apenas uma porção mínima de alguns nanolitros é transferida para o capilar. Por envolver uma válvula de injeção e uma bomba propulsora para movimentar a amostra até a interface, não demorou para que tal arranjo fosse designado como FIA-CE por Hogan et al., em trabalho que já compreende diálise em fluxo, precedendo a interface ${ }^{[19]}$. Apesar do uso da terminologia FIA-CE ser discutível neste caso, visto que a determinação analítica dos componentes da amostra passa a dar-se após sua separação eletroforética, o termo FIA-CE vem se propagando, sendo apenas eventualmente substituído por FI-CE.

Contudo, em todos os trabalhos subseqüentes, com uma exceção ${ }^{[28]}$, na a transferência de amostra do circuito em fluxo para o capilar se utilizam da assim chamada injeção eletrocinética (que, no contexto FIA-CE, pode ser mais precisamente designada como transferência eletrocinética de amostra).

A maneira pela qual a amostra é introduzida no capilar tem implicação direta na análise quantitativa. Na transferência eletrocinética, um gradiente de potencial é estabelecido ao longo do comprimento do capilar por um período de tempo conhecido. Já na transferência hidrodinâmica utiliza-se uma diferença de pressão que pode ser estabelecida por diferentes mecanismos: pressurização ou vácuo em um dos reservatórios de solução nos extremos do capilar, ou por 
gravidade (desnivelamento dos dois reservatórios), sendo a amostra introduzida por sifonagem.

A transferência eletrocinética é a alternativa mais prática, pois pode ser realizada sem interrupção da aplicação da alta-tensão entre os extremos do capilar, deixando assim, de ser imprescindível o sincronismo perfeito entre a posição da amostra no sistema FIA e a transferência ao capilar. Entretanto, dependendo da aplicação, a transferência hidrodinâmica apresenta vantagens sobre a eletrocinética, por ser menos dependente da composição da matriz e inteiramente não discriminatória ao analito, conduzindo à obtenção de eletroferogramas mais reprodutíveis. Preferencialmente, ambas as opções deveriam ficar disponíveis, para que o químico analítico possa escolher a modalidade mais apropriada a cada circunstância de análise. Assim, a implementação da transferência hidrodinâmica mereceu atenção no sistema FIA CE desenvolvido, vez que a eletrocinética rão depende de recursos adicionais aos dispositivos usados.

Com relação à etapa de detecção, nos trabalhos disponíveis de FIA-CE, invariavelmente, foram utilizados métodos ópticos, especialmente a absorção na região do visível ou UV (direta ou indireta) e, eventualmente, a fluorescência induzida por laser ${ }^{[19]}$. Não foram considerados ainda os métodos eletroquímicos, entre os quais se mostra particularmente atraente a oscilometria, modalidade de condutometria em que os eletrodos não entram em contato com a solução.

A oscilometria opera com freqüências da ordem de centenas de $\mathrm{kHz}$ a $\mathrm{MHz}$, bastante superiores às freqüências usualmente utilizadas na condutometria convencional, para a qual a faixa de $60 \mathrm{~Hz}$ a $1000 \mathrm{~Hz}$ é típica. A oscilometria tem como principal vantagem o fato dos eletrodos não entrarem em contato com o eletrólito, ou seja, de poderem ser instalados do lado externo do recipiente de material dielétrico dentro do qual se encontra a amostra. Assim, esta técnica é bastante difundida em medições on-line em processos industriais, quando as matrizes são constituídas de componentes que podem causar a contaminação ou deterioração dos eletrodos (que não precisam mais ser feitos de Pt). Justifica-se, também, o nome preferencial de condutometria "sem contato", CSC. 
A utilização de freqüências relativamente altas na oscilometria minimiza a reatância capacitiva (das paredes do recipiente que acomoda a amostra), que se apresenta em série com a solução e permite que variações de condutividade e permissividade possam ser registradas.

Visto que a detecção condutométrica é simples, econômica e particularmente favorável para a determinação de íons em geral, independentemente de serem coloridos ou não, levando em conta que o melhor detector oscilométrico disponível para CE foi desenvolvido por pesquisadores do IQ-USP ${ }^{[29,30]}$, escolheu-se este detetor para o sistema FIA-CE de que trata a dissertação. Naturalmente, outros detetores podem ser utilizados quando necessário, sem necessidade de modificações significativas no restante do sistema. 


\section{Dispositivos}

\section{Equipamento de Eletroforese Capilar}

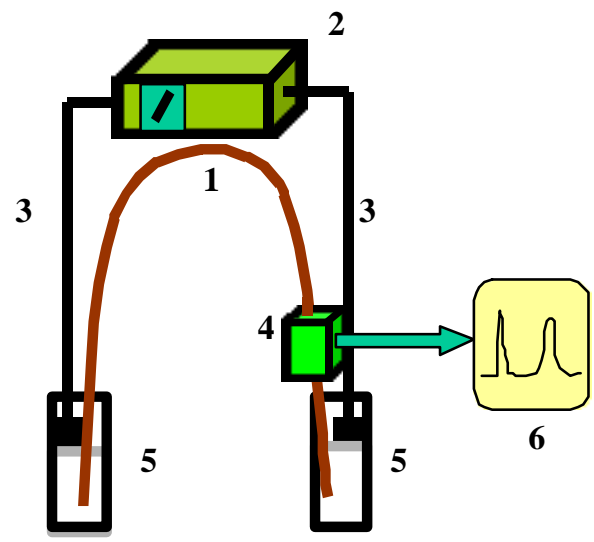

Figura 1 - Esquema do Equipamento de CE: 1-capilar; 2-fonte de alta tensão; 3eletrodos; 4-detetor; 5-vials; 6-eletroferograma.

O equipamento de CE utilizado neste projeto foi planejado e confeccionado com base em protótipo desenvolvido por A. Fracassi \& C. L. do Lago ${ }^{[29,30]}$. Este compreende essencialmente (figuras 1 e 2), sob condições típicas: 1) um capilar de sílica $(50 \mathrm{~cm}$ de comprimento, DI de $75 \mu \mathrm{m}$, adquirido da J\&W Scientific Incorporated) externamente revestido de poliimida (do mesmo tipo utilizado para as colunas capilares da cromatografia de gás), no qual ocorre a separação dos componentes da amostra; 2) uma fonte de alta tensão d.c. ajustável ( 0 até $30 \mathrm{kV}$, resolução $0,1 \mathrm{kV}$ ), para a aplicação de uma diferença de potencial entre os extremos do capilar que, para tanto, são imersos em dois pequenos recipientes (1,5mL cada) contendo eletrólito (ou amostra) e eletrodos ligados à fonte; 3 ) um detector condutométrico de tipo oscilométrico. Este dispositivo será descrito em detalhes nas próximas páginas. 


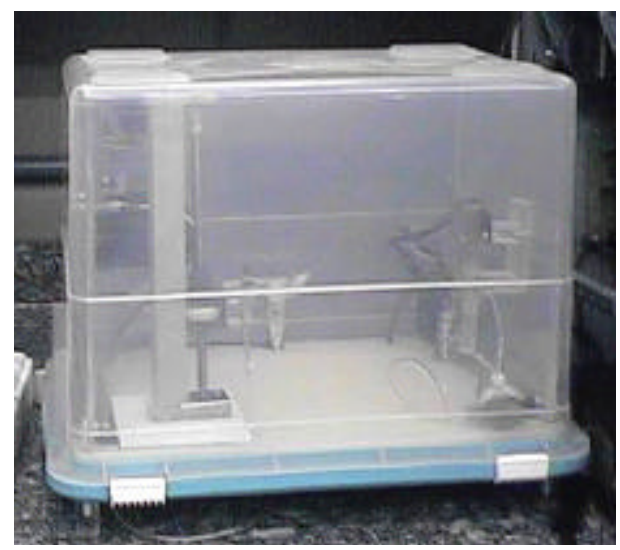

Figura 2 - Foto do Equipamento de CE construído:

Vista Frontal, com cúpula instalada.

A aparelhagem foi distribuída em dois módulos: 1) módulo termostatizado o capilar, os reservatórios das soluções, o detector e os transdutores do sistema de termostatização (aquecedor, constituído de resistência de chuveiro elétrico sub-alimentada, e sensor de temperatura) foram acomodados dentro de um recipiente plástico de 17 litros, em forma de paralelepípedo $(25 \times 35 \times 25 \mathrm{~cm})$, marca Plasútil@. Este recipiente foi usado em posição invertida e a tampa foi reforçada para servir de base, à qual foram afixados todos os componentes, facilitando a remoção da "cúpula"; 2) módulo não termostatizado - as fontes de alimentação dos circuitos e alta tensão, os circuitos de termostatização, conversão de corrente/tensão e oscilador foram instalados sob a base (figura 3).

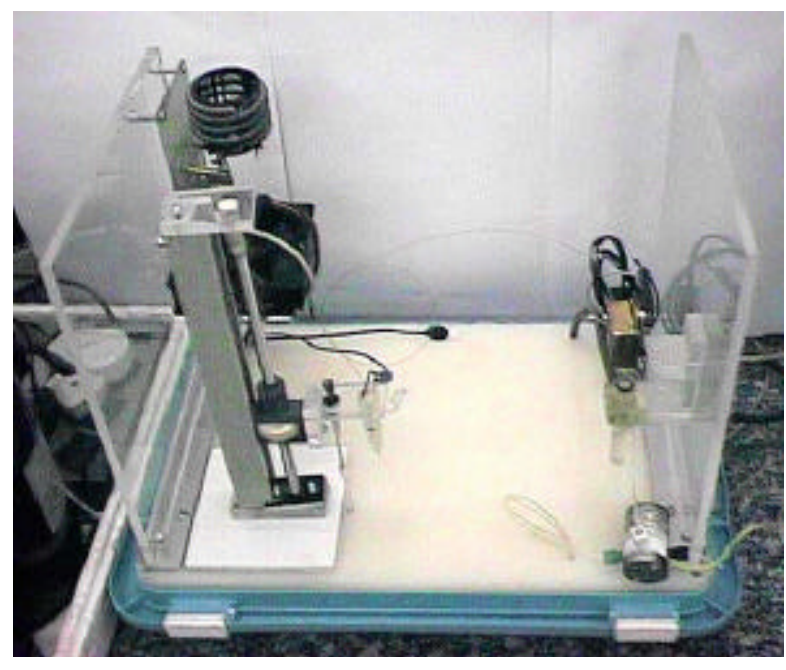

Figura 3 - Vista interna do aparelho CE. 
Em relação a versões anteriores do equipamento ${ }^{[29]}$, foram realizados alguns aperfeiçoamentos, tais como: ajuste fino inicial do nível de líquidos dos reservatórios de solução, com auxílio de uma plataforma (feita de acrílico) acoplada num mecanismo com parafuso de rosca sem fim (figura 4); e construção de uma gaiola de Faraday mais compacta envolvendo o detector, utilizando como material caixa de lamínulas e fita adesiva metalizada (cobre).

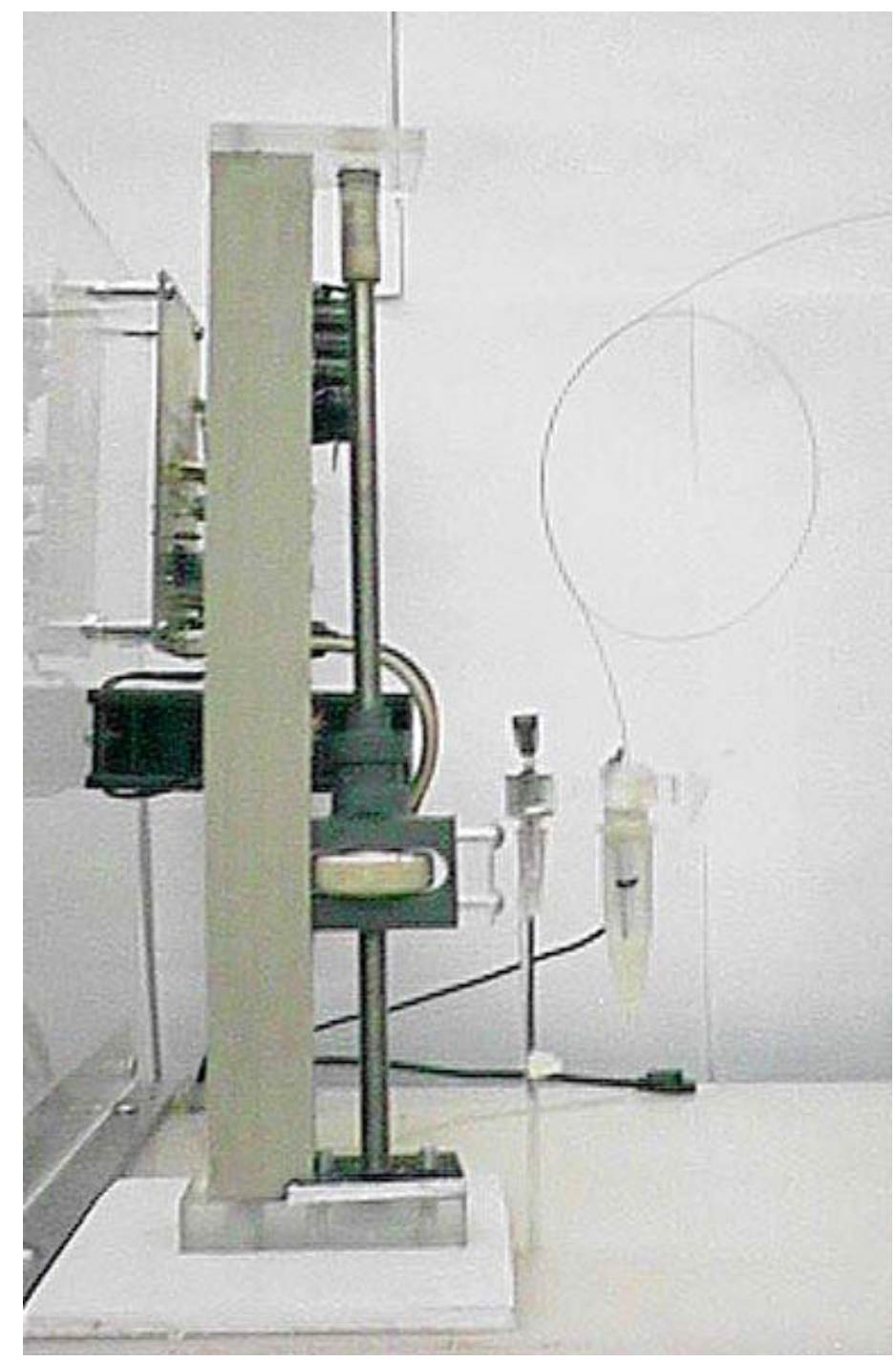

Figura 4 - Dispositivo para ajuste fino do nível de líquido. 


\section{Circuitos Eletrônicos}

Uma modificação importante em relação ao protótipo publicado ${ }^{[29]}$ foi a inversão do extremo do capilar que é mantido aterrado, em relação à alta tensão. Ao invés da prática usual de aterrar o lado do detector (com o intuito de protegê-lo de eventuais fugas), aterrou-se o lado da introdução da amostra, para proteger o circuito FIA a ele interfaceado, vez que o detetor miniaturizado, sem contato com a solução, abre esta alternativa, desde que rigorosamente isolado do eletrodo/eletrólito na extremidade do capilar.

\section{Sistema de termostatização}

O sistema de termostatização utilizado foi similar ao desenvolvido por Fracassi e do Lago ${ }^{[29,30]}$, (figura 5).

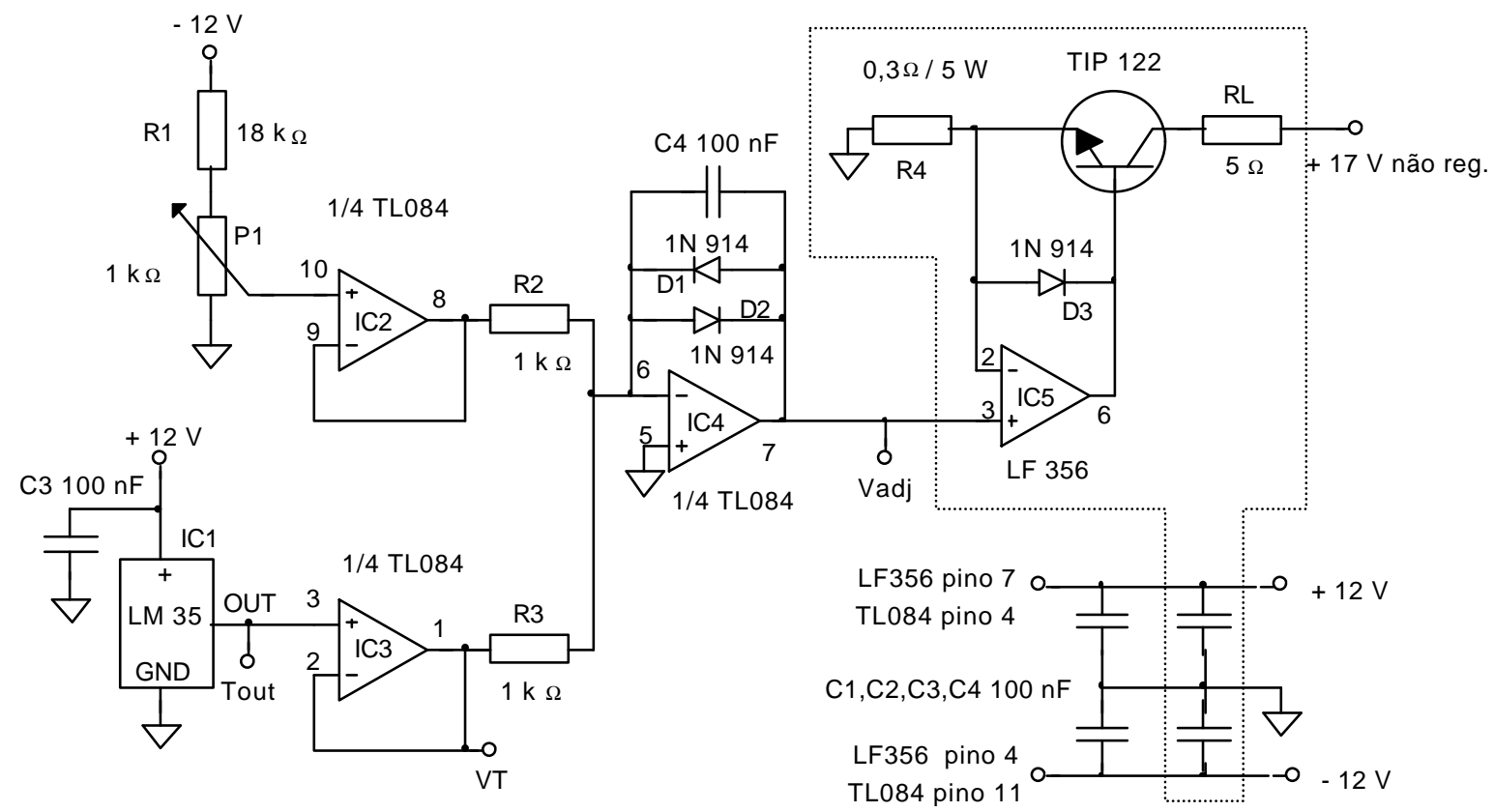

Figura 5 - Circuito do sistema de controle de temperatura ${ }^{[30]}$ : A parte tracejada encontra-se dentro da câmara termostática.

Utilizou-se um sensor de temperatura linear, LM35 $(10 \mathrm{mV} / \mathrm{C})$ interligado a um canal $A / D$ da placa de interfaceamento $A-8111$, para monitoramento da temperatura dentro da cúpula do equipamento CE. 
Para o controle da potência aplicada à resistência aquecedora instalada na cúpula, ao invés de um simples comparador para desligar ou ligar a plena potência à resistência, ou um circuito de controle proporcional, em que a potência é diretamente proporcional ao sinal de erro, foi utilizada amplificação logarítmica do sinal de erro. Assim, ao ligar o equipamento, a temperatura estará bem abaixo da estabelecida e a potência aplicada se aproximará da máxima, acelerando o aquecimento do ar no interior da cúpula; quando a temperatura se aproximar do valor estipulado, a redução na potência será mais drástica que com amplificador linear, assegurando um ajuste mais fino do ponto escolhido.

Um potencial de referência é ajustado através do potenciômetro P1 e é somado ao potencial gerado pelo sensor de temperatura LM35. A soma dos dois sinais é então entregue a um amplificador logarítmico formado pelo IC2, D1 e D2 e, por fim, o sinal na saída do amplificador é aplicado na base de um transistor de potência TIP 122. A resistência de carga utilizada foi uma bobina de fio de $\mathrm{NiCr}$, aproveitada de um chuveiro elétrico, apresentando $5 \Omega$ quando fria. Com a tensão aplicada, de $17 \mathrm{~V}$, a dissipação máxima (transistor saturado) fica ao redor de 50 W, suficiente para aquecer $o$ ar contido na câmara. Próximo à temperatura ajustada, a dissipação é menor e se dá, preponderantemente, no próprio transistor de potência que, por esta razão, é montado dentro da câmara (ver linha tracejada na figura 5), tal como o sensor de temperatura, logo acima de uma ventoinha (12 V dc). A ventoinha assegura a uniformização da temperatura dentro do compartimento e promove a remoção convectiva do calor dissipado pelo capilar.

\section{Fontes de alta tensão (FAT)}

Diferentemente do protótipo de Fracassi e do Lago ${ }^{[29]}$, que utiliza fonte de tensão bipolar, procurou-se alternativa de custo inferior, sem prejuízo do desempenho. Para tanto, compararam-se as características e preços de diferentes marcas do mercado internacional, optando-se pelas fontes da UltraVolt, em particular, o modelo 30A12 que é muito compacto, tem alto MTBF e apresenta o limite superior de tensão e a estabilidade requeridas ( $30 \mathrm{kV}, 0,01 \%$ ), 
ao preço FOB de US\$394,00. Trata-se de fontes unipolares, ou seja, para passar, por exemplo, da análise de ânions para a de cátions, há necessidade de alternar entre a fonte positiva, 30A12-P4, e a fonte negativa, 30A12-N4. Todavia, comparado a outras alterações necessárias ao trocar de método analítico (p. ex., troca de eletrólito e, eventualmente, de capilar), trata-se de um inconveniente pequeno, compensado pela excelente relação custo/benefício.

As fontes utilizadas possuem saídas para monitoramento de corrente e de tensão, de modo que se adaptou o programa de aquisição e controle para aproveitar estes sinais. $\mathrm{O}$ monitor de corrente fornece $6,23 \mathrm{mV} / \mu \mathrm{A}$. Como a corrente máxima fornecida pela fonte de AT é de $114 \mu \mathrm{A}$, a tensão do monitor de corrente varia entre 0 e $0,710 \mathrm{~V}$, intervalo este dentro do limite dos $A / D s$ presentes na placa de interface A8111. Já o monitor de tensão fornece 1V para cada $\mathrm{kV}$ aplicado. Como a máxima tensão aplicada é $30 \mathrm{kV}$ a tensão do monitor de corrente varia entre 0 e $30 \mathrm{~V}$ o que supera muito o limite dos ADs da placa A8111. Para deixar este intervalo dentro do limite dos ADs foi feito um divisor de tensão conforme a figura 6 .

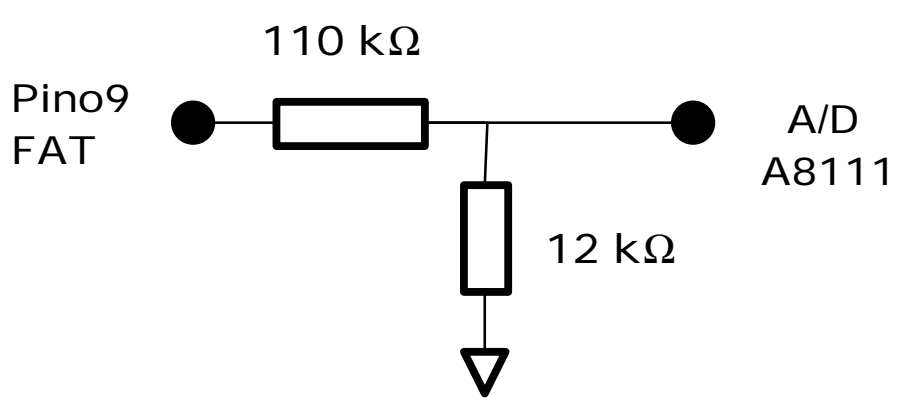

Figura 6 - Divisor de tensão para o monitor de Tensão da Fonte AT.

Para a proteção do usuário contra choques, em caso de abertura da cúpula, foi desenvolvido um circuito para desligar a aplicação da $A T$, visto na figura 7. A presença do pino enable na fonte escolhida facilita deveras esta proteção. Este pino deve ser colocado em nível lógico alto para habilitar a fonte. Somente nas fases da operação em que a AT é requerida, o programa de computador mantém alta a porta lógica que aciona o enable da fonte, sendo que a conexão se dá pelo circuito com uma chave magnética (reed-switch) em série. $O$ 
reed foi instalado na base do equipamento de $\mathrm{CE}$, enquanto o imã está preso à cúpula removível.

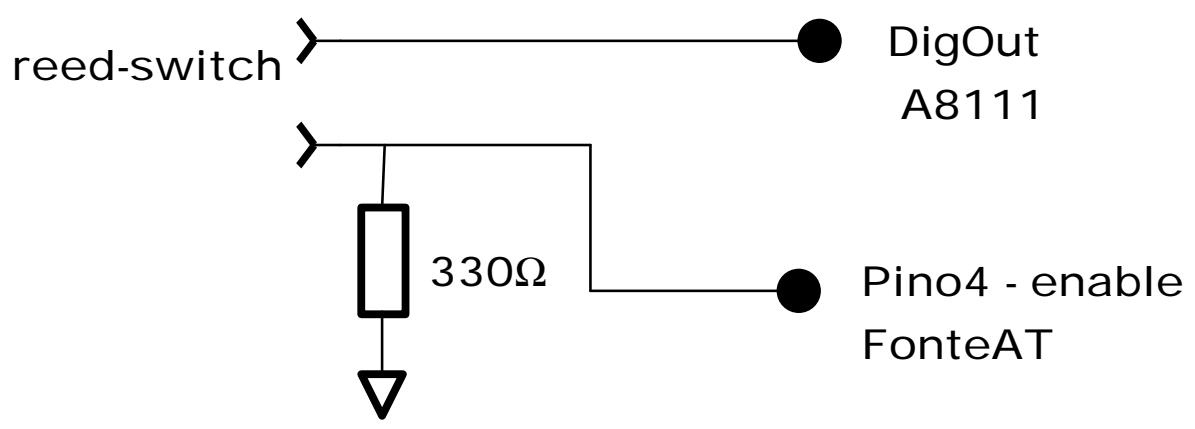

Figura 7 - Circuito de inibição da fonte de alta tensão. DigOut corresponde a uma das saídas lógicas da placa A8111.

\section{Detector}

O detector utilizado foi desenvolvido por Fracassi e do Lago ${ }^{[29,30]}$; trata-se de um detector de condutividade em que os eletrodos não tem necessidade de entrar em contato com a solução eletrolítica, por ser aplicada freqüência superior à empregada em condutivímetros convencionais (60 a $1000 \mathrm{~Hz}$ ), por isto mesmo designada também de oscilometria. Nos experimentos apresentados, a freqüência foi fixada próximo $600 \mathrm{kHz}$. O circuito eletrônico de Fracassi e do Lago é reproduzido na figura 8. 


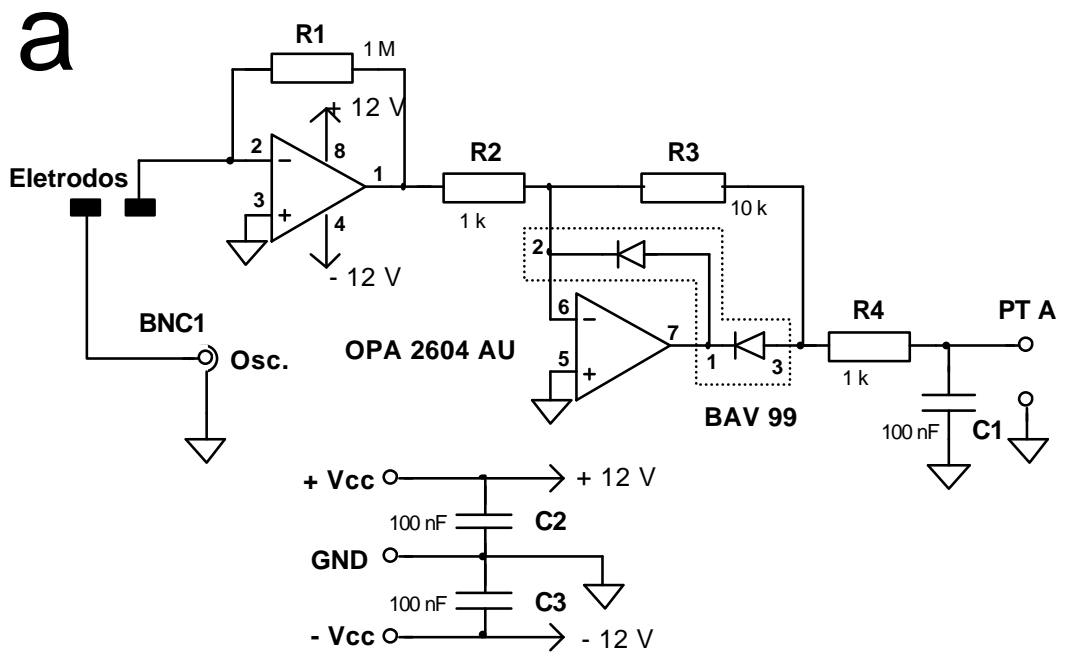

Figura 8a - Circuito eletrônico do DCSC SMD ${ }^{[30]}$.

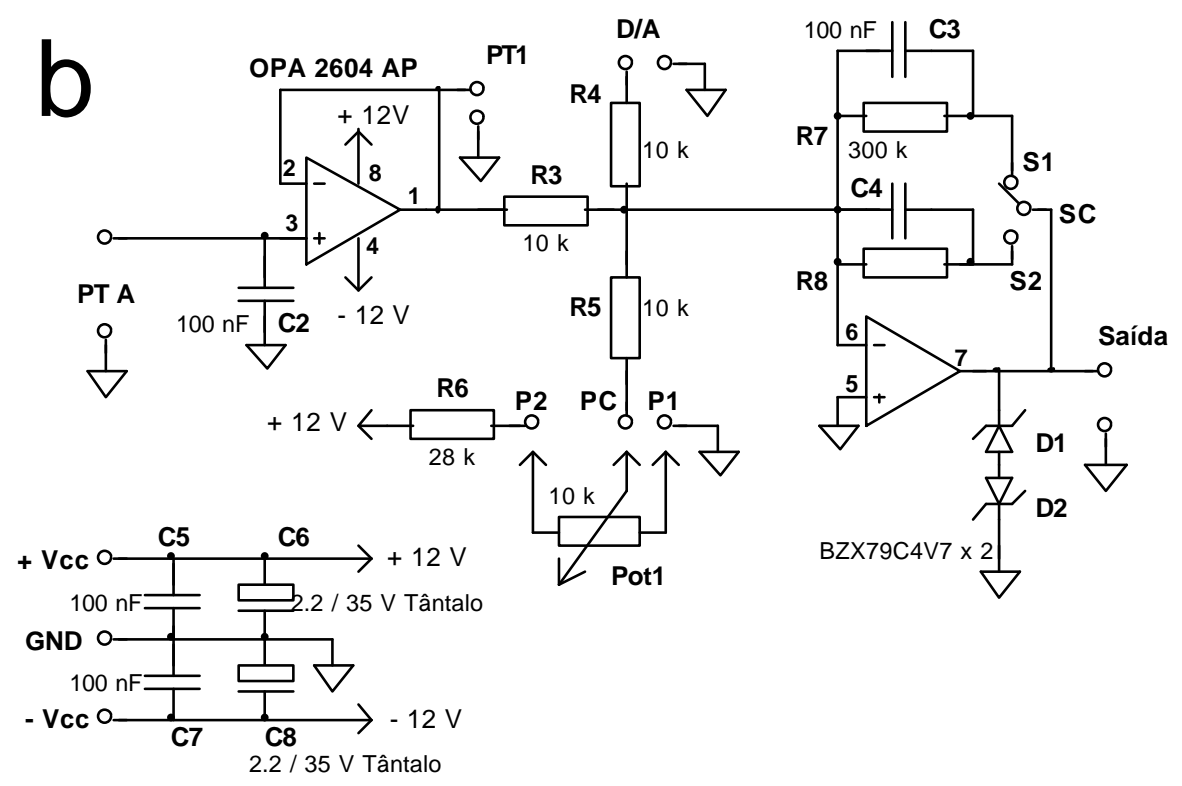

Figura 8b - Circuito eletrônico do DCSC ${ }^{[30]}$, módulo 2.

O oscilador, por ser comercial, não foi representado. A montagem do módulo a foi executada com componentes para SMD, de modo que todo o circuito, incluindo os eletrodos coube numa placa de $3,3 \mathrm{~cm}^{2}$, que foi encapsulada dentro de um invólucro metálico que serve como gaiola de Faraday. 


\section{Pressiostato para transferência hidrodinâmica}

Um aperfeiçoamento importante foi feito para promover a transferência (injeção) hidrodinâmica de amostra de forma compatível com a interface FIA. Ao invés da introdução da amostra no capilar por sifonação (desnivelamento manual ou automático do recipiente, vial, contendo a amostra, no qual está imerso o capilar), preferiu-se fazer vácuo no recipiente correspondente à extremidade do detetor, durante o período de injeção. Para tanto, conectou-se o reservatório, utilizando-se de uma válvula solenóide controlada pelo microcomputador, a um pressiostato ajustado para manter pressão inferior à ambiente em $11 \mathrm{~cm}$ de coluna d'água ( $\mathrm{P}_{\mathrm{amb}}-1080$ Pascal). $\mathrm{O}$ primeiro pressiostato construído compreendia um contato ajustável de $\mathrm{Pt}$ adaptado a uma coluna de $\mathrm{Hg}$ em forma de $U$, que ligava pequena bomba de vácuo (de diafragma, do tipo usado para aeração de aquário) sempre que a pressão sub-ambiente de um reservatório (frasco de vidro de $1 \mathrm{~L}$ ) se elevava. Enquanto a bomba estava desligada, uma válvula de esfera (aproveitada de bico de injeção do carburador do automóvel marca Fiat modelo 147) colocada entre a bomba e o reservatório, impedia a entrada de ar no reservatório. Quando a bomba de vácuo era acionada, a redução na pressão se dava rapidamente, provocando certa pulsação na pressão aplicada ao vial e conseqüente perda de precisão nas injeções. Adicionalmente, devido à alta densidade do $\mathrm{Hg}$ no manômetro e à pequena queda de pressão desejada, o controle era pouco preciso.

Para superar os problemas, ligaram-se dois reservatórios de um litro em série, através de um tubo capilar, configurando um amortecedor pneumático, como pode se observar na figura 9. Adicionalmente, o $\mathrm{Hg}$ do manômetro em forma de $U$, foi substituído por óleo fino e a variação de nível passou a ser feita por acoplador óptico e circuito de controle, representado na figura 10 . Um manômetro de precisão conectado ao vial, revelou desvio padrão relativo de $0,73 \%(N=106)$ na pressão durante uma hora de operação. 


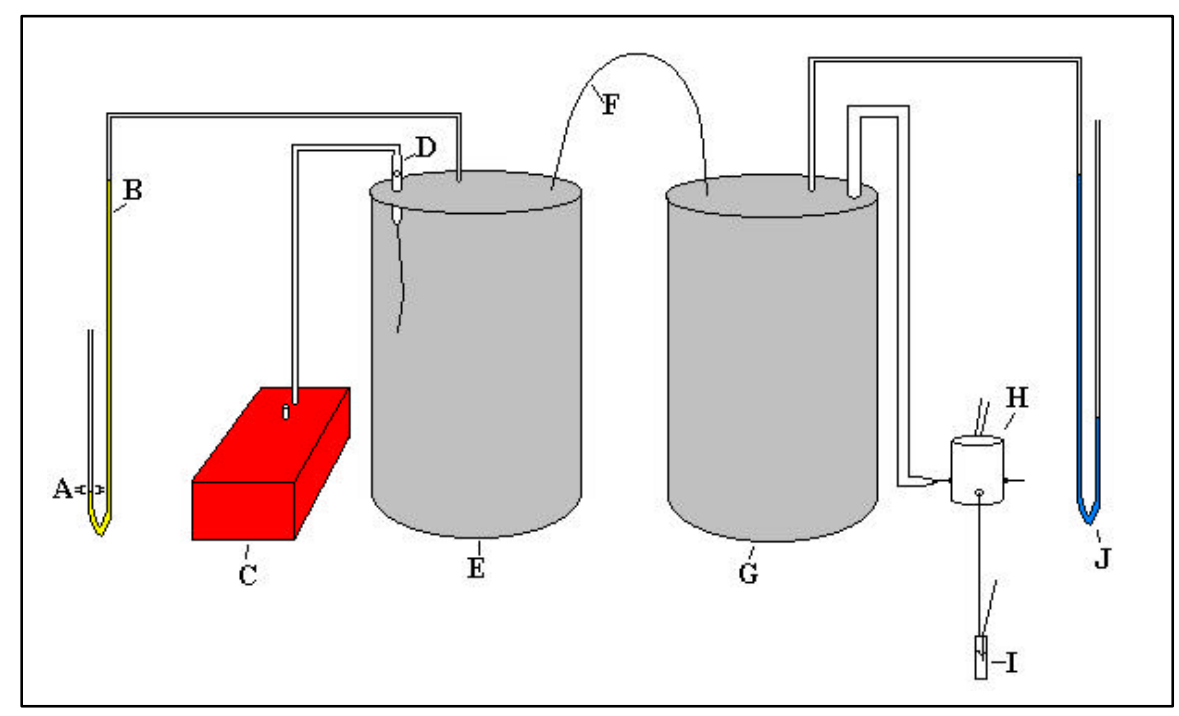

Figura 9 - Pressiostato: A- Acoplador Óptico; B- Manômetro (Tubo em U contendo óleo fino); C- Bomba de Vácuo (bomba aeradora de aquário modificada); D- Válvula de esfera;

E- Reservatório1 (Frasco de um litro reagente Merck); F- Capilar; G- Reservatório 2 (Frasco de um litro); H- Válvula de três vias controlada por computador; I- o vial de um extremo do capilar (detector); J- Manômetro de confirmação da pressão aplicada no vial (Tubo em U contendo água).

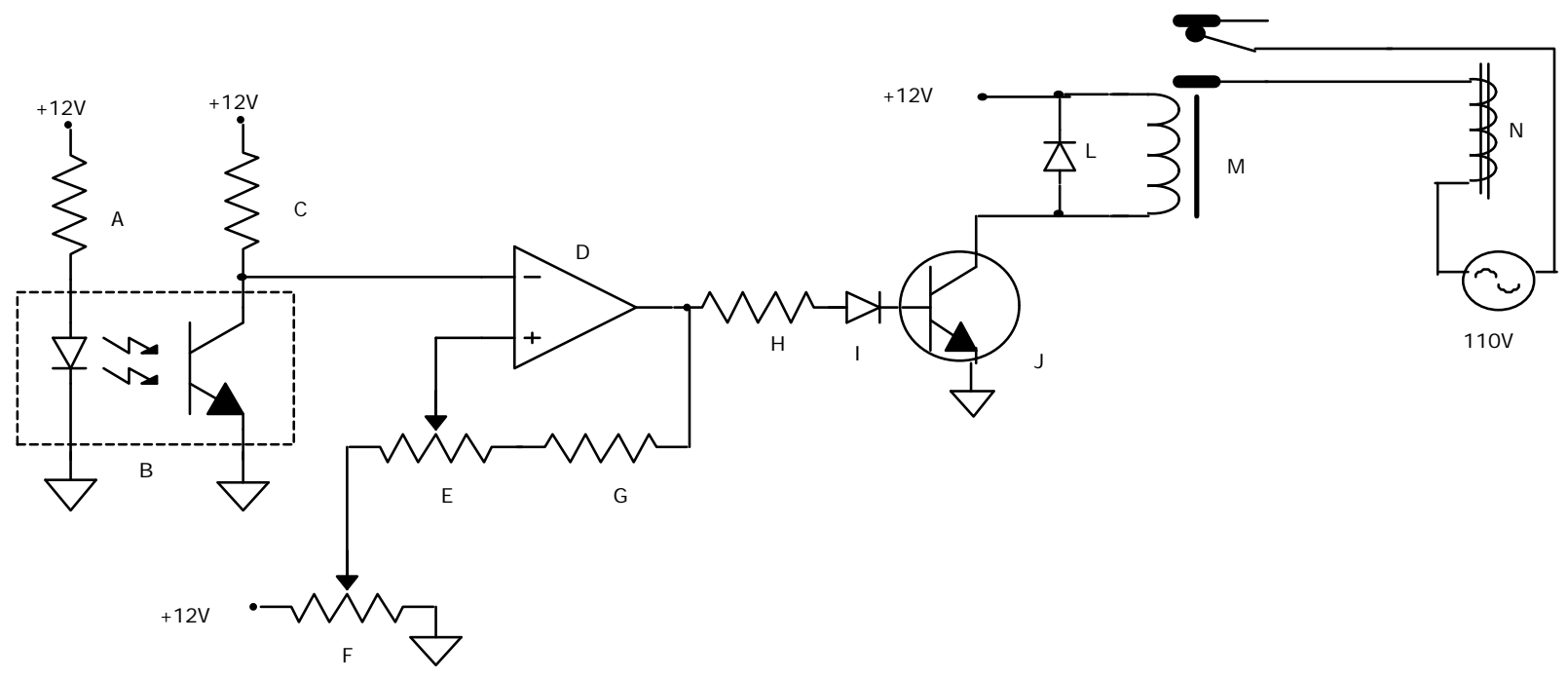

Figura10 - Circuito de controle: A- resistência $1 \mathrm{k} \Omega$; B- Acoplador Óptico; C- resistência $10 \mathrm{k} \Omega$; D- Amplificador Operacional (Cl TL084); E- Potenciômetro $50 \mathrm{k} \Omega$;

F- Potenciômetro $2 \mathrm{k} \Omega$; G- resistência $1 \mathrm{M} \Omega ; \mathrm{H}$ - resistência $5 \mathrm{k} \Omega$;

I e L- diodos 1N4007; J- transistor TIP122; M- relê;

$\mathrm{N}$ - Bomba de vácuo. 


\section{Circuito de controle da Bomba de Vácuo}

Para etapa de limpeza do capilar e de descarga acelerada do capilar utilizou-se um compressor elétrico de nebulizador (modelo: INALEX ${ }^{\circledR}$ marca: NEVONI) modificado para atuar como bomba de vácuo.

O circuito de controle e alimentação, representado na figura 11, é controlado pelo microcomputador que por uma das portas lógicas de saída de um cartão A - 8111 (fabricada pela ICP - DAS Co.) aciona o transistor (cuja finalidade é ampliar a capacidade de corrente) que comuta o relê, ligando a bomba de vácuo.

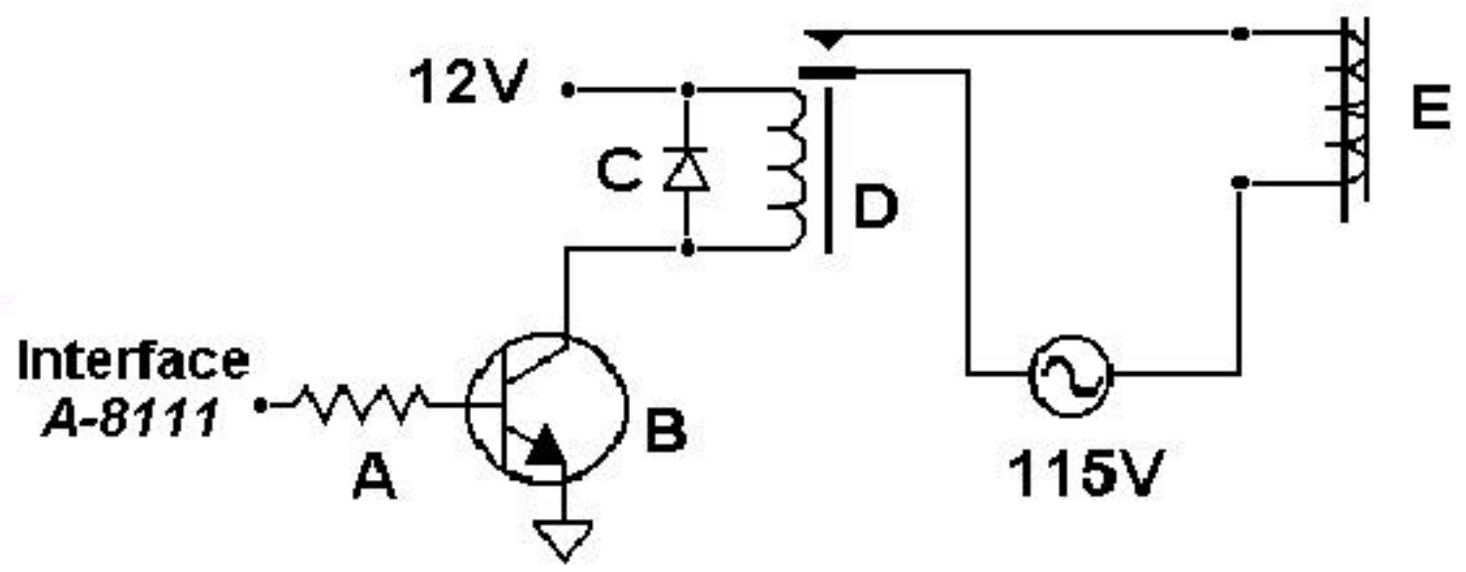

Figura 11 - Circuito de controle e alimentação para a bomba de vácuo, controlada por computador: A - resistor $1,0 \mathrm{k} \Omega$; $\mathrm{B}$ - transistor TIP 122;

C - Diodo 1N2007; D - relê; E - Motor da bomba de vácuo. 


\section{Válvula multicanal para múltiplos eletrólitos}

Utilizou-se de uma "válvula quádrupla" (4 válvulas solenóide com 4 entradas independentes e uma saída comum) para a automação da limpeza do sistema FIA e do capilar do equipamento $\mathrm{CE}$, devido à necessidade de se utilizar alternadamente soluções de $\mathrm{NaOH}$ e tampão, além de água deionizada. Para seu controle rápido e preciso desenvolveu-se um circuito de alimentação controlado pelo microcomputador.

\section{Circuito de alimentação para válvula multicanal}

O circuito de alimentação, representado na figura 12, é controlado pelo microcomputador. Quatro portas lógicas de saída de um cartão A - 8111 (fabricada pela ICP - DAS Co.), acopladas a transistores, permitem acionar qualquer um dos solenóides, abrindo o canal de admissão da solução correspondente.

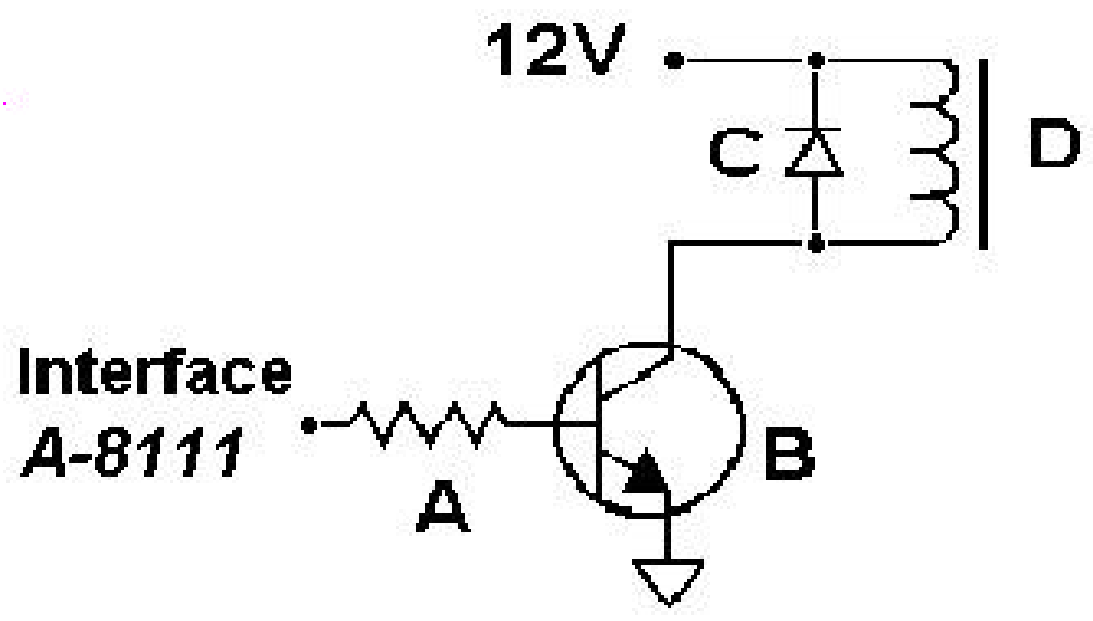

Figura 12: Circuito de alimentação para cada solenóide, controlado por computador: A - resistor 4,7 k $\Omega$; B - transistor TIP 122;

C - Diodo 1N2007; D- Um dos Solenóides da válvula quádrupla. 


\section{Injetor para FIA}

A redução da escala de um injetor multicanal para FIA, anteriormente desenvolvido pelo autor ${ }^{[31]}$, baseado em um solenóide que aciona um conjunto de válvulas de estrangulamento, deu origem ao dispositivo reproduzido na figura 13.

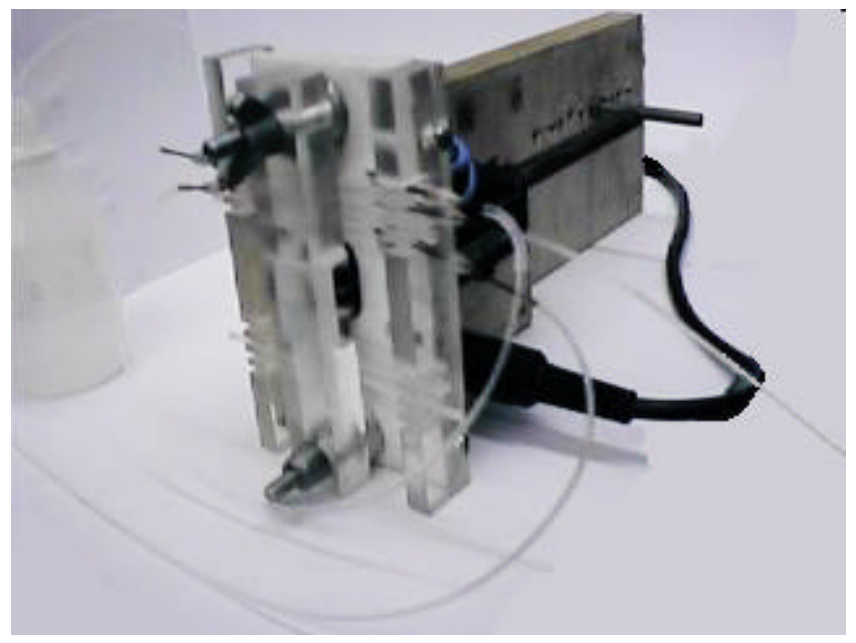

Figura 13 - Injetor multicanal.

No intuito de diminuir o volume interno do circuito do injetor, passou-se a usar nas válvulas de estrangulamento, tubos de silicone muito mais finos e flexíveis ( 0,5 mm de d.i. e $\sim 2,0 \mathrm{~mm}$ de d.e.). Com esta alteração, foi possível reduzir também a capacidade do solenóide, sendo que ao invés do modelo de 4 $\mathrm{Kgf}^{[1]}$, conseguiu-se acionar $\mathrm{O}$ injetor com solenóide de 0,5 Kgf. A haste que pressiona os tubos foi obtida a partir de um parafuso de aço-inox do qual, com auxílio do torno, se removeu a rosca das duas extremidades, conforme a figura 14. A rosca remanescente na parte central possibilita a fixação perpendicularmente ao eixo do solenóide, enquanto as duas extremidades permitem estrangular os conjuntos de tubos de silicone.

Figura 14 - Eixo estrangulador. 
O mecanismo de comutação das válvulas, em número máximo de 16 , é ilustrado na figura 15. Na posição de repouso (mantida por ação de uma mola), o pino estrangula até 8 tubos finos e flexíveis fixados na base de PVC, só pressionando os tubos da face oposta quando a bobina do solenóide estiver energizada, ocasião em que o outro conjunto de válvulas será aberto. A tensão da mola acoplada ao solenóide pode ser ajustada controlando o número de espiras tensionadas, de modo a se conseguir o efetivo estrangulamento de todos os tubos sem pressioná-los excessivamente ou sobrepujar a força do solenóide. Para acionar a bobina do solenóide, foi construído um circuito alimentador adequadamente dimensionado e controlado por microcomputador, que será convenientemente considerado no próximo tópico.

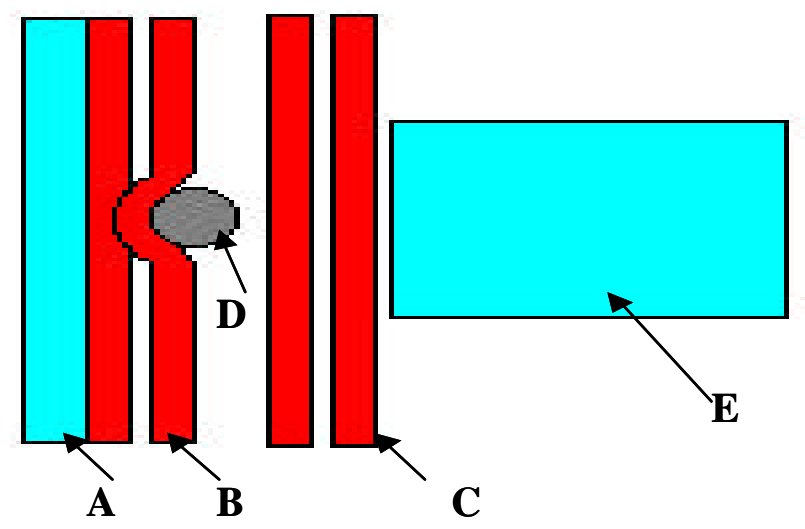

Figura 15 - Corte lateral esquemático do Injetor para FIA: A - Base de PVC; B e C Tubos capilares de Silicone; D - Eixo estrangulador; e E - Contra-base de acrílico. 
A figura 16 traz a configuração do sistema FIA, na situação de descarga da amostra (solenóide desligado), previamente admitida na alça de amostragem com o solenóide ligado. Das até 16 válvulas suportadas pelo comutador, somente 3 normalmente fechadas e 3 normalmente abertas foram utilizadas, servindo uma destas para aspirar ar com auxílio de um dos canais da bomba peristáltica quando não se está carregando a alça com amostra.

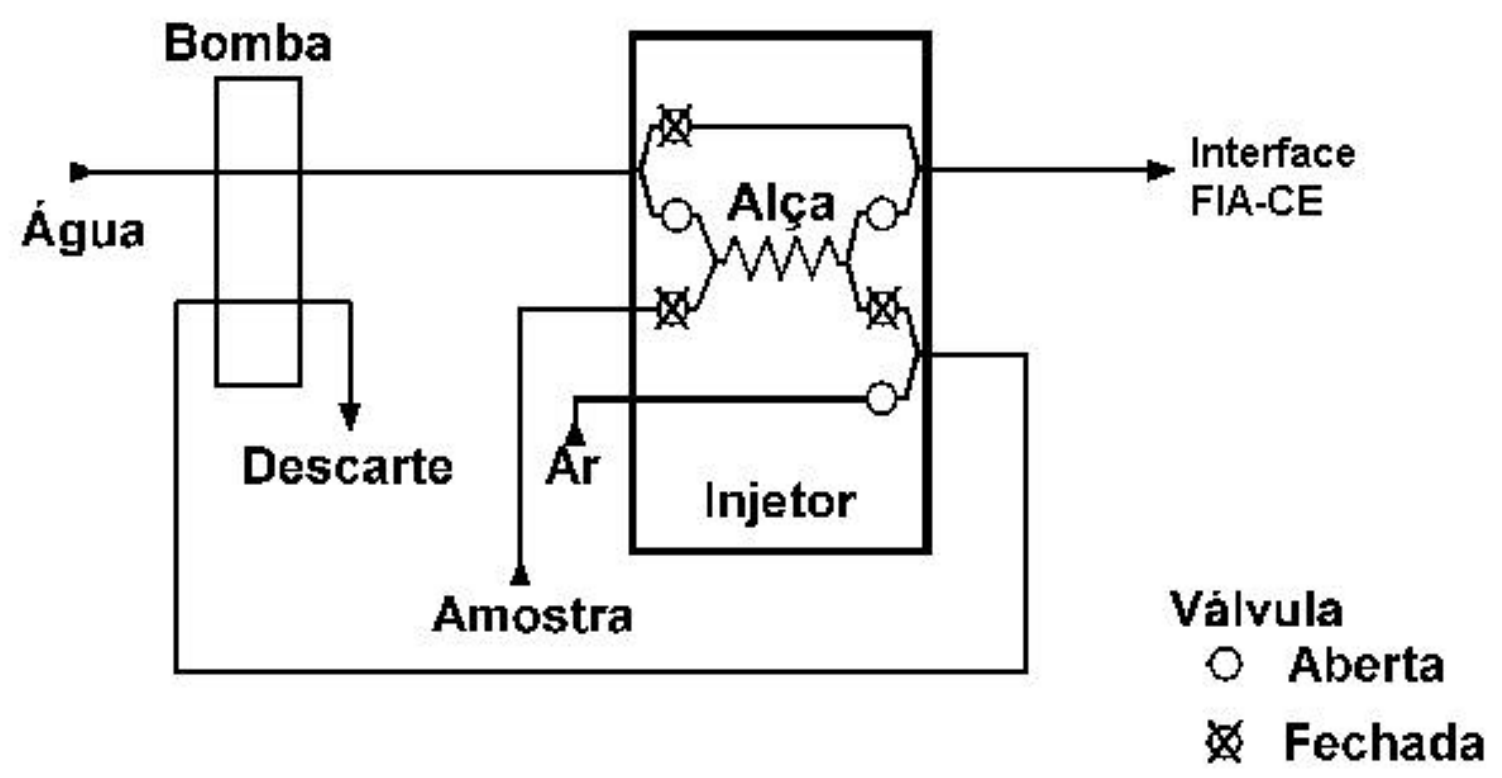

Figura 16 - Configuração do sistema FIA, na posição de descarga da amostra (a posição das válvulas é invertida na admissão de amostra): Bomba - Bomba Peristáltica; Água - Fluido Transportador; Alça - Alça de Amostragem.

Construir as conexões em forma de $\mathrm{Y}$ com baixo volume interno, requeridas na entrada e saída do injetor, não foi tarefa fácil. Para exemplificar, serão citadas somente duas aproximações. 1) Furou-se um pedaço de tubo de silicone com ferramenta preparada a partir de uma agulha de injeção e colou-se, centrado no orifício, outro pedaço de tubo com cola de silicone. Este procedimento se mostrou trabalhoso e pouco eficiente, pois na maioria das vezes a cola escorria e tampava o orifício. 2) Construiu-se confluências utilizando capilares de sílica fundida 
(aproveitado de uma coluna capilar para cromatografia de gás) e ponteiras de pipeta, de polipropileno. Neste modelo, visualizado na figura 17, corta-se uma ponteira de pipeta de $100 \mu \mathrm{L}$ de modo que um pedaço do capilar de sílica fundida (d.i. $=0,5$ e d.e. $=0,7 \mathrm{~mm}$ ) entre justo pela extremidade mais fina; amassa-se a extremidade mais larga do tubo cônico, deixando-o oval, possibilitando a introdução de dois pedaços de capilar de sílica. A vedação entre os componentes foi conseguida com adesivo epóxi (Araldite ${ }^{\circledR} 2 \mathrm{~min}$ ). Esta confluência, de fabricação relativamente simples e custo pequeno, preenche o requisito de apresentar volume morto interno reduzido, sendo que certo cuidado é necessário na montagem e manipulação, devido à fragilidade dos tubos capilares.

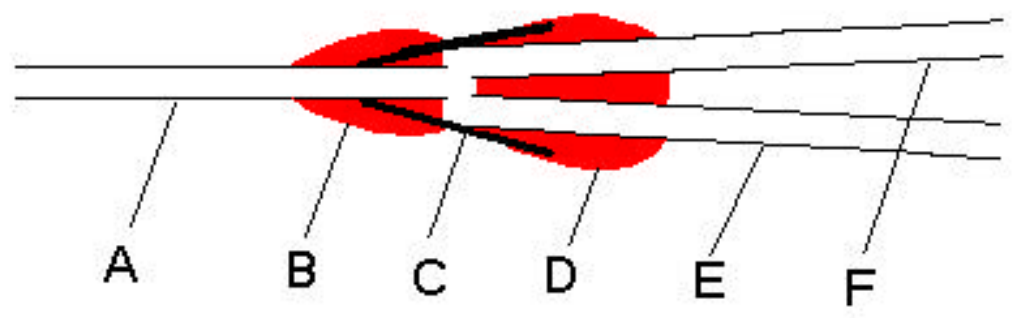

Figura 17 - Micro-confluência: A, E e F - Capilares de Sílica Fundida (d.i. $=0,5$ e d.e. $=0,7 \mathrm{~mm}$ ); B e D - Cola Araldite ${ }^{\circledR}$; - Seção de ponteira de pipeta. 


\section{Circuito de alimentação do injetor FIA}

O circuito de alimentação elétrica do solenóide encontra-se representado na figura 18, tratando-se de adaptação de projeto anterior ${ }^{[31]}$. A tensão da rede foi retificada com auxílio de uma ponte de diodos seguida de um capacitor, cujos bornes alcançavam tensão de aproximadamente $160 \mathrm{~V}$. Em série com a alimentação da ponte de diodos, colocou-se uma lâmpada incandescente de 60 W. Ao ligar-se o solenóide utilizando-se de um relê controlado pelo microcomputador, ocorria, inicialmente, um pico de tensão, visto que o capacitor se encontrava carregado, e a lâmpada, apagada, apresentava resistência interna baixa, da ordem de $19 \Omega$. Em frações de segundo, a lâmpada acendia, elevando sua resistência para mais de $200 \Omega$, e fazia a tensão de manutenção aplicada ao solenóide decair para cerca de $20 \mathrm{~V}$ d.c. Esta tensão mostrou-se apropriada para manter os 8 tubos estrangulados.

Para interfacear o relê de acionamento ao microcomputador, recorreu-se a uma das portas lógicas de saída de um cartão A - 8111 (fabricada pela ICP - DAS Co.), munida de um transistor para aumentar sua capacidade de corrente.

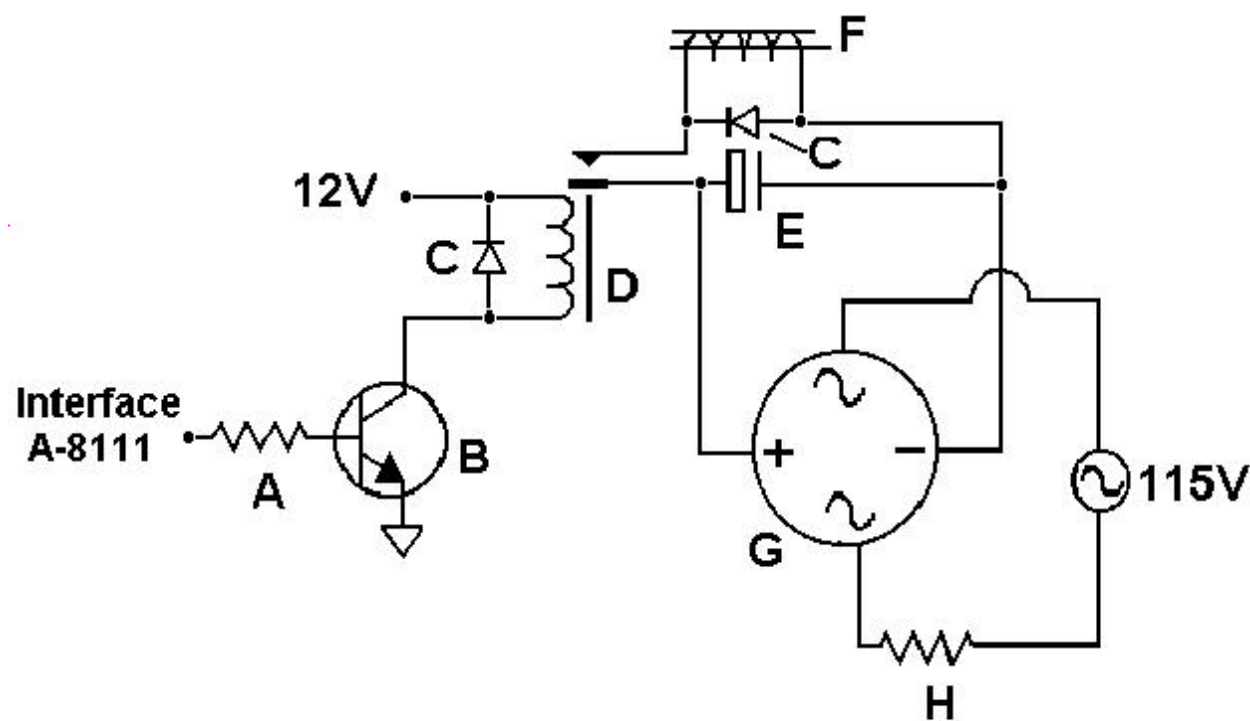

Figura 18 - Circuito de alimentação do solenóide, controlado por computador: A resistor 4,7 k $\Omega$; B - transistor TIP 31; C - Diodo 1N2007; D - relê; E - Capacitor eletrolítico $200 \mu \mathrm{F} 200 \mathrm{~V} ; \mathrm{F}$ - Solenóide do injetor/comutador, bobina de $61 \Omega ; \mathrm{G}$ - Ponte retificadora para $2 \mathrm{~A} ; \mathrm{H}$ - Lâmpada incandescente $115 \mathrm{~V}, 60 \mathrm{~W}$, que acende após a magnetização do solenóide, reduzindo a corrente. 


\section{Detector condutométrico sem contato para FIA}

Para testar o sistema FIA, especialmente 0 injetor, antes do interfaceamento com a CE, aproveitou-se o circuito já construído para o detector do equipamento $\mathrm{CE}$, modificando apenas a dimensão dos eletrodos e o invólucro. Um par de eletrodos em forma de anel foi obtido cortando-se duas seções de 2 $\mathrm{mm}$ de largura de um cilindro de latão de $2 \mathrm{~mm}$ de espessura, previamente furado com broca de 0,7 mm, ou seja, o d.e. do tubo capilar de sílica fundida (o mesmo já utilizado na fabricação das confluências). Os anéis alinhados foram fixados por soldagem à uma placa de circuito impresso, a qual foi montada, por sua vez, no interior do invólucro metálico de um cristal piezoelétrico - convenientemente removido -, como pode ser visto na figura 19. Um dos terminais externos do invólucro foi soldado ao cabo blindado que traz o sinal do oscilador e outro, ao que leva o sinal captado pelo anel detetor ao circuito amplificador/retificador. A figura 19B mostra o detetor encapsulado na gaiola de Faraday, com o tubo capilar inserido através dos anéis. Este detector funciona em paralelo com o detetor para CE (para capilar muito mais fino), mantido inalterado.

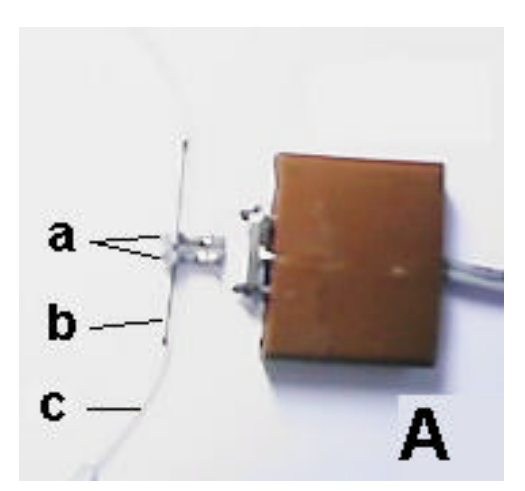

Figura 19A - DCSC p/ FIA s/ o encapsulamento: a - Eletrodos anelares para detecção oscilométrica; $b$ - Capilar de sílica fundida (d.i. $=0,5 \mathrm{~mm})$; c - Tubo de PP (d.i. $=0,5 \mathrm{~mm})$.

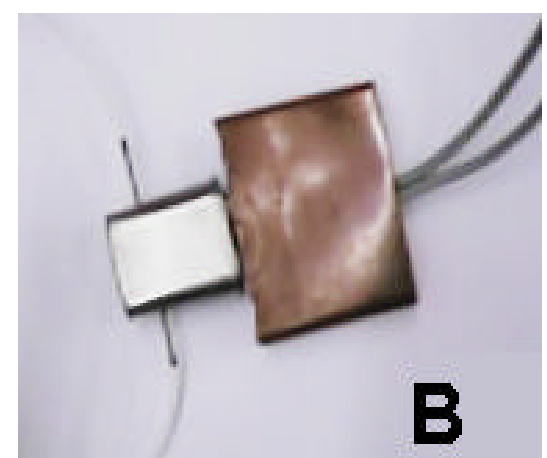

Figura 19B - Gaiola de Faraday obtida aproveitando o encapsulamento retirado de um cristal piezelétrico. 


\section{Interface FIA-CE}

A interface FIA-CE foi construída essencialmente a partir de uma seringa hipodérmica e agulhas de aço inox. Na figura 20 é possível compreender o funcionamento da interface FIA-CE.

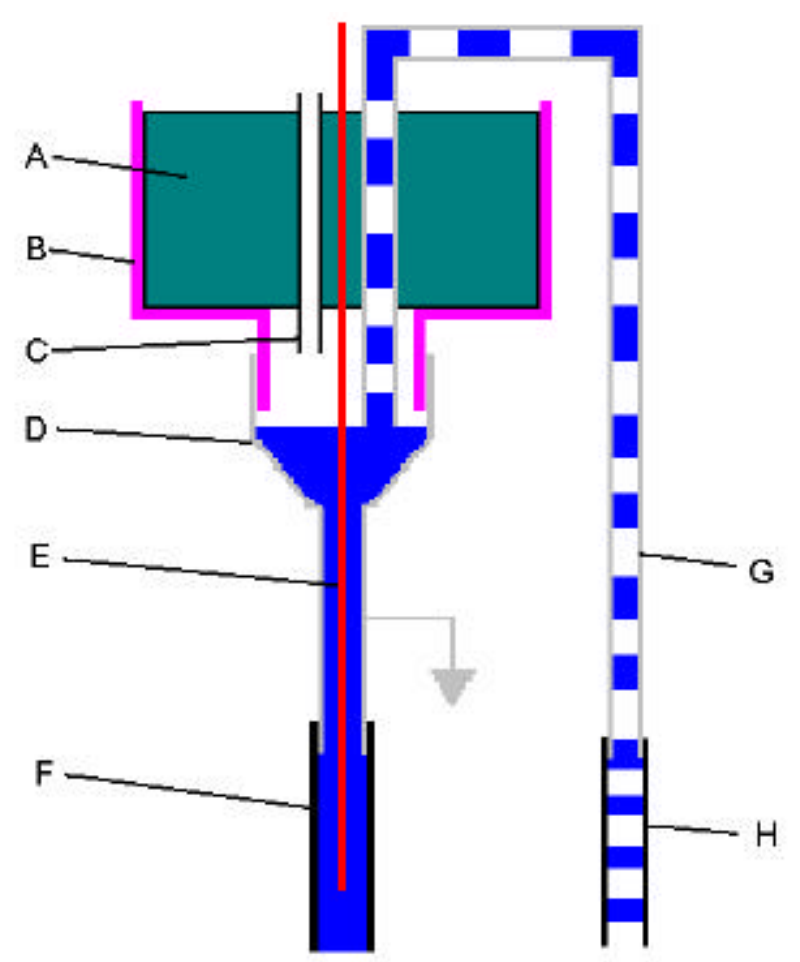

Figura 20 - Interface FIA-CE: A - Tampa (êmbolo da Seringa hipodérmica); B - Adaptador da tampa (corpo de seringa hipodérmica); C - Respiro (agulha de açoinox); D - Eletrodo (agulha hipodérmica com conector Luer-Lock); E - Capilar de Sílica Fundida (d.i. =75 $\mu \mathrm{m}) ; \mathrm{F}-$ Tubo de Tygon (d.i. $=0,5 \mathrm{~mm}$ ) proveniente do circuito FIA; $\mathrm{G}$ - Dreno (Agulha dobrada em $\mathrm{U}$ ); $\mathrm{H}$ - tubo para aspiração pela bomba peristáltica.

A solução, oriunda do percurso FIA, adentra a agulha de inox (D), que serve como eletrodo aterrado da eletroforese capilar. O nível de solução dentro da agulha se mantém constante, devido a um dreno (agulha de aço inox, G). A solução é aspirada com vazão superior à do circuito FIA de alimentação ( $\phi$ do fluido transportador $=2,00 \mathrm{~mL} / \mathrm{min}$ e $\phi$ do dreno $=12,0 \mathrm{~mL} / \mathrm{min}$ ). $O$ nível é ajustado de forma a igualar-se com o do reservatório existente na extremidade oposta do capilar. A coluna capilar da CE $($ d.i. $=75 \mu \mathrm{m})$ (E) encontra-se mergulhada na solução dentro da agulha de aço-inox (D), sendo que a ponta do capilar está 
posicionada dentro de um tubo de $\operatorname{Tygon}^{\circledR}(\mathbf{F})$, situado antes da agulha de aço-inox (D), para, assim, evitar uma possível admissão e interferência de espécies que tenham sido oxidadas ou reduzidas neste eletrodo. Esta interface é compatível tanto com o modo eletrocinético como hidrodinâmico de introdução de amostra (no segundo caso, o controle de pressão é exercido no extremo oposto do capilar).

\section{Sistema completo}

O sistema completo é esquematizado na figura 21, estando sob controle do microcomputador o acionamento de todas as válvulas e da bomba peristáltica, assim como a tensão do FAT, o que confere grande flexibilidade na implementação de métodos mediante reprogramação. Pode-se escolher um entre quatro líquidos para alimentar o circuito (p. ex., tampão, água, $\mathrm{NaOH}$ para limpeza do capilar).

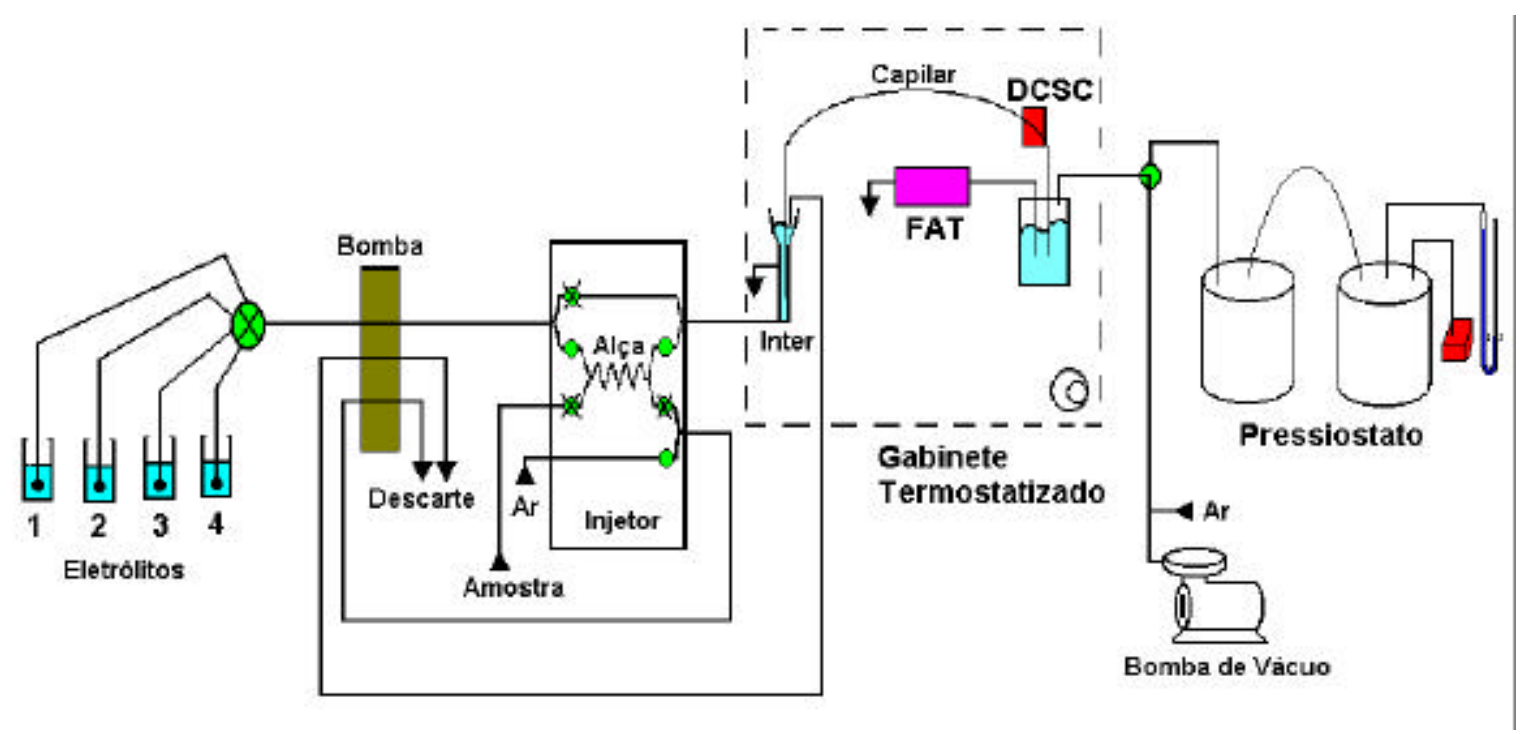

Figura 21 - Sistema Completo FIA-CE: Eletrólitos 1 - Tampão; 2 - $\mathrm{H}_{2} \mathrm{O} ; 3-\mathrm{NaOH} ; 4$ $\mathrm{HCl}$; Bomba - Bomba Peristáltica; Alça - Alça de Amostragem; Inter - Interface FIA-CE;

Capilar - Capilar de sílica $(\mathrm{l}=50 \mathrm{~cm}$, di=75 $\mu \mathrm{m})$; FAT - Fonte de Alta Tenção; DCSC - Detector condutométrico sem contato elétrico; Pressiostato - conjunto de dispositivos para injeção hidrodinâmica; Bomba de Vácuo - para limpeza do capilar.

Para executar uma análise, em linhas gerais, ocorrem as seguintes etapas: liga-se a bomba, aspirando tampão; aciona-se o injetor por tempo suficiente para preenchimento da alça; reverte-se o injetor introduzindo amostra no fluxo, para 
que possa ser submetida a etapas não representadas como diluição, derivatização, acumulação (pré-concentração) e coluna de troca iônica, permeação através de membrana, etc., ou conduzida diretamente à interface FIACE; uma vez estando a interface preenchida com a amostra, o fluxo é suspenso (com desligamento da bomba); para promover injeção hidrodinâmica, a pressão no capilar é reduzida por abertura da válvula de interligação com o pressiostato (p. ex., 20 s); a bomba é ligada para preencher a interface com eletrólito; a FAT é ligada, promovendo a separação eletroforética; os dados gerados pelo detector condutométrico são armazenados; o sistema está pronto para novo ciclo, que pode ser de amostragem ou, periodicamente, de limpeza.

\section{Interfaceamento com microcomputador}

O hardware usado no interfaceamento foi um microcomputador AMD K6-2 475 $\mathrm{MHz}$ e uma placa de interfaceamento A-8111 da ICP DAS (equivalente à PCL-711 da Advantech Co.). Esta placa possui um conversor $A / D$ de 12 bits com 8 entradas endereçáveis e um conversor D/A, também de 12 bits, além de 16 portas digitais de entrada e 16 de saída e 2 contadores ou geradores de pulsos. Os programas de controle da instrumentação e a aquisição de dados foram elaborados em Turbo Pascal, de modo a aproveitar módulos (units) de comunicação com a placa, anteriormente elaborados em Pascal por outros componentes do grupo ${ }^{[29]}$.

\section{Software do FIA-CE}

O programa principal que controla o sistema FIA-CE faz uso das seguintes units (ANEXO 1):

- EC: Sub-rotinas que controlam os equipamentos FIA-CE.

- PCL: "Driver" que controla a placa A-8111 (de interfaceamento A/D e D/A) desenvolvido anteriormente por colaboradores deste Laboratório ${ }^{[29]}$.

- Gráficos: Sub-rotina que controla a parte gráfica do programa. 
Dentre as tarefas que são realizadas pelo programa está:

1) A limpeza e o condicionamento do capilar:

Aciona um dos canais da válvula multicanal $[\mathrm{NaOH}]=0,1 \mathrm{~mol} / \mathrm{L}$

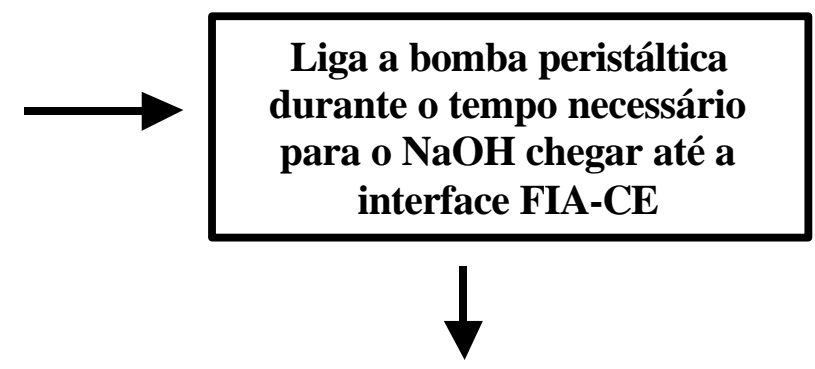

Aciona um dos canais da válvula multicanal ( $\mathrm{H}_{2} \mathrm{O}$ deionizada)
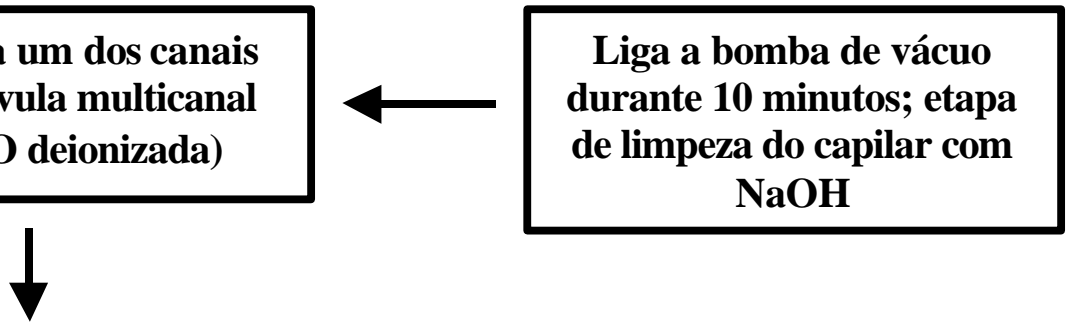

Liga a bomba peristáltica durante o tempo necessário para a $\mathrm{H}_{2} \mathrm{O}$ deionizada chegar na interface FIA-CE

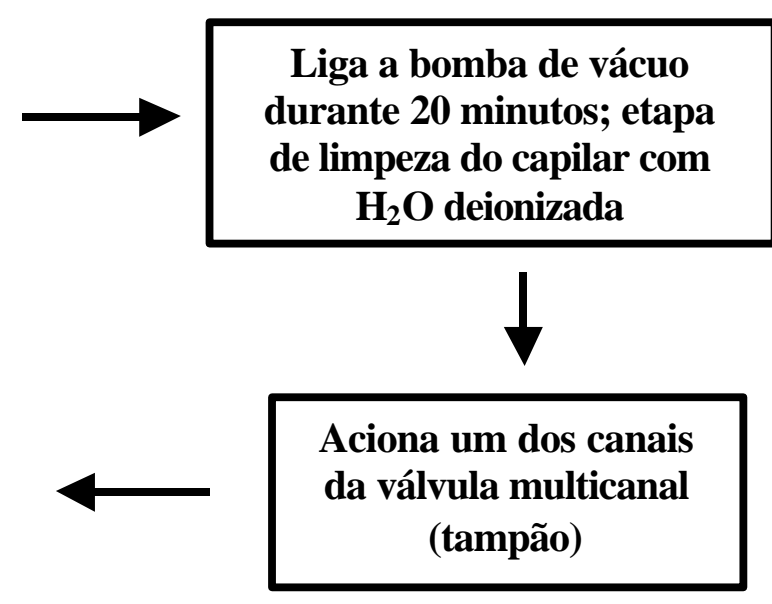

Liga a bomba peristáltica durante o tempo necessário para o tampão chegar até a interface FIA-CE

Aciona um dos canais da válvula multicanal (tampão)

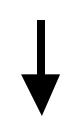

Liga a bomba de vácuo durante 20 minutos, etapa de condicionar o capilar com tampão

Equipamento FIA-CE pronto para análise. 
2) $O$ controle do equipamento FIA-CE e aquisição de dados:

Aciona um dos canais da válvula multicanal

(tampão) e liga a bomba peristáltica
Aciona o solenóide do injetor FIA durante tempo suficiente para preencher a alça com amostra (p. ex. 60s)
Liga a bomba de vácuo durante 1 minuto, etapa de descarga acelerada do capilar

- limpeza do capilar com tampão

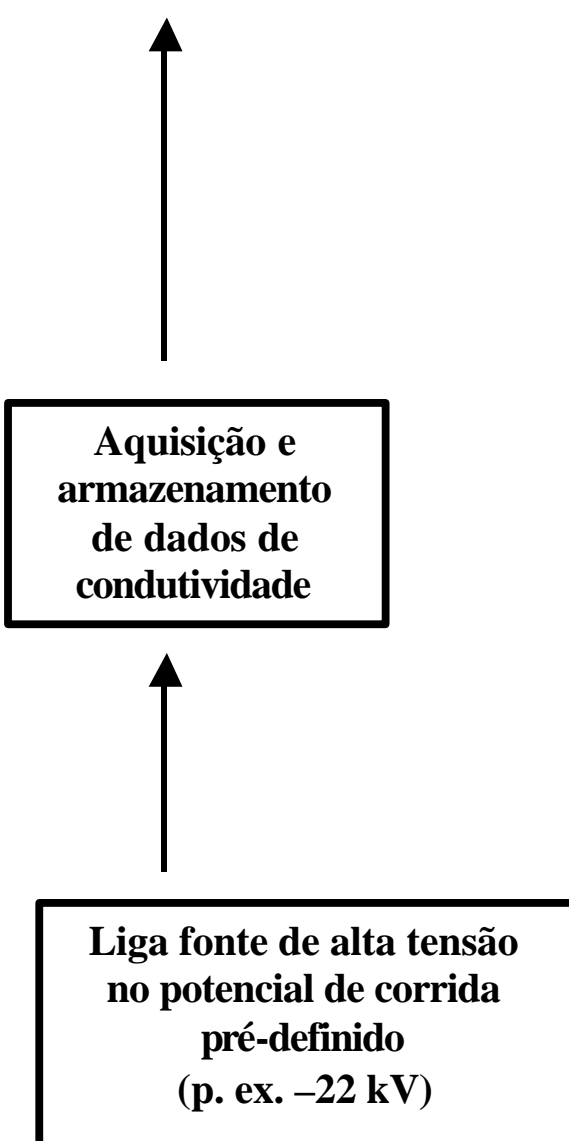

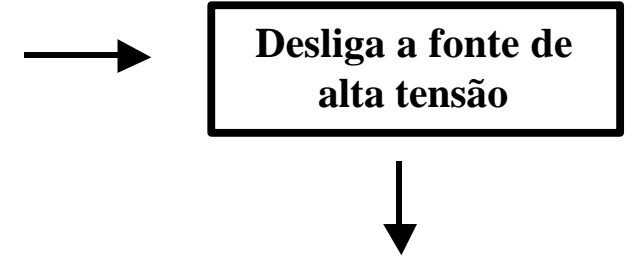

Desliga a bomba peristáltica e válvula multicanal após tempo suficiente para $o$ plugue de amosta chegar na interface FIA-CE

(p. ex. 22s)

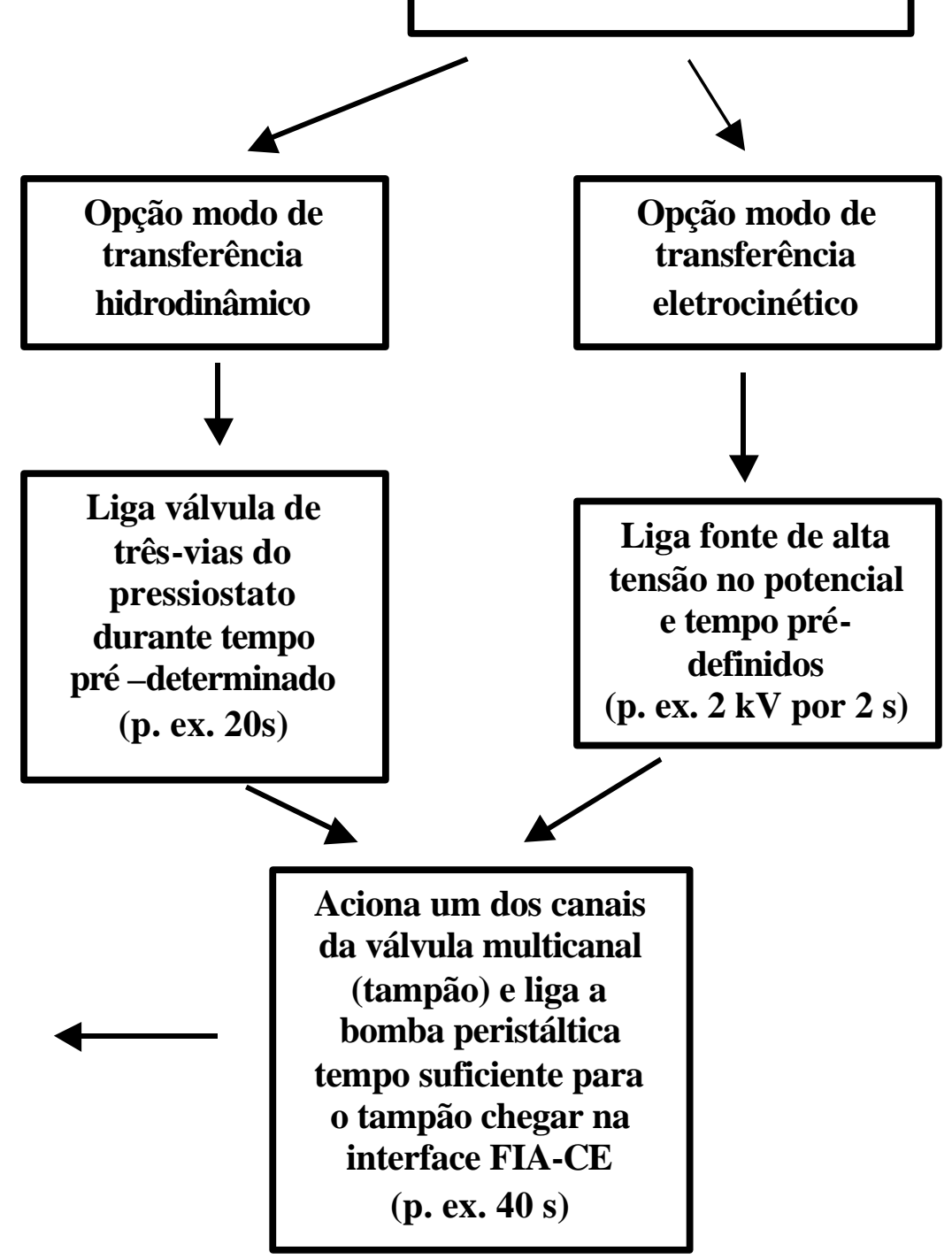


Todos os reagentes utilizados foram de grau analítico ou superior. Todas as soluções utilizadas foram preparadas pela diluição de soluções estoque de concentração $100 \mathrm{mmol} / \mathrm{L}$, com exceção das soluções de $\mathrm{KCl} 0,5 \mathrm{~mol} / \mathrm{L}$ e $1 \mathrm{~mol} / \mathrm{L}$. As diluições e as soluções estoque foram feitas com água deionizada (18 $\mathrm{M} \Omega$ ) e filtrada com filtro de 0,22 $\mu \mathrm{m}$ (NANOpure, Barnstead).

Foram utilizados capilares de sílica fundida (J\&W Scientific,USA) de d.i.= $75 \mu \mathrm{m}$ ou $50 \mu \mathrm{m}$ para CE e d.i. $=0,5 \mathrm{~mm}$ para FIA. O comprimento do capilar foi de $60 \mathrm{~cm}$, sendo $50 \mathrm{~cm}$ entre o ponto de injeção e o detector. $O$ condicionamento do capilar foi feito no início dos experimentos pela passagem de (1) hidróxido de sódio $0,1 \mathrm{~mol} / \mathrm{L}$ por $10 \mathrm{~min}$, (2) água deionizada por $20 \mathrm{~min}$ e (3) tampão de corrida por $20 \mathrm{~min}$, seguido da aplicação do potencial de separação até a estabilização da linha base do sinal do detector. Naturalmente, estes períodos podem ser reprogramados conforme a conveniência. 


\section{Otimização da separação}

Na figura 22 tem-se um dos primeiros exemplos de eletroferograma obtido com o equipamento CE construído.

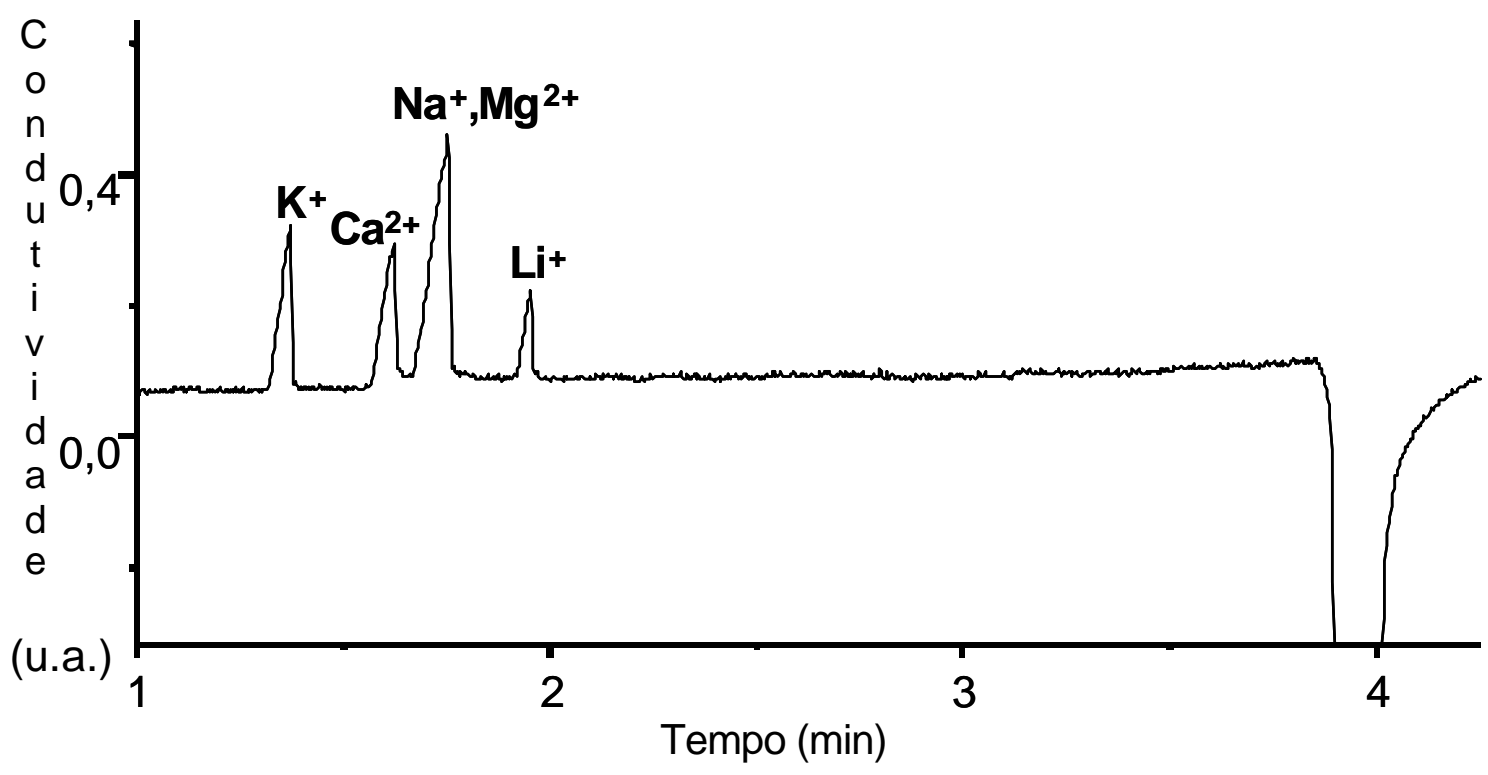

Figura 22 - Eletroferograma de uma amostra sintética: [Cátions]=150 $\mu \mathrm{mol} / \mathrm{L}$; Tampão [MES/HIS]=30 mmol/L; Potencial de Corrida=20 kV; Injeção Eletrocinética - Potencial de Injeção =2 kV; Tempo de injeção =2 s.

Como se pode observar, o sistema de CE já apresentava operação satisfatória, mas não havia separação de todos os componentes da amostra, pois necessitava-se melhorar as condições de corrida e injeção. $O$ pico negativo por volta de 4 minutos é o plugue de água injetado passando pelo detector oscilométrico. 
Com a troca do tampão MES/His por HLac/His conseguiu-se a separação completa de todos os cátions da amostra, como é possível se observar na figura 23.

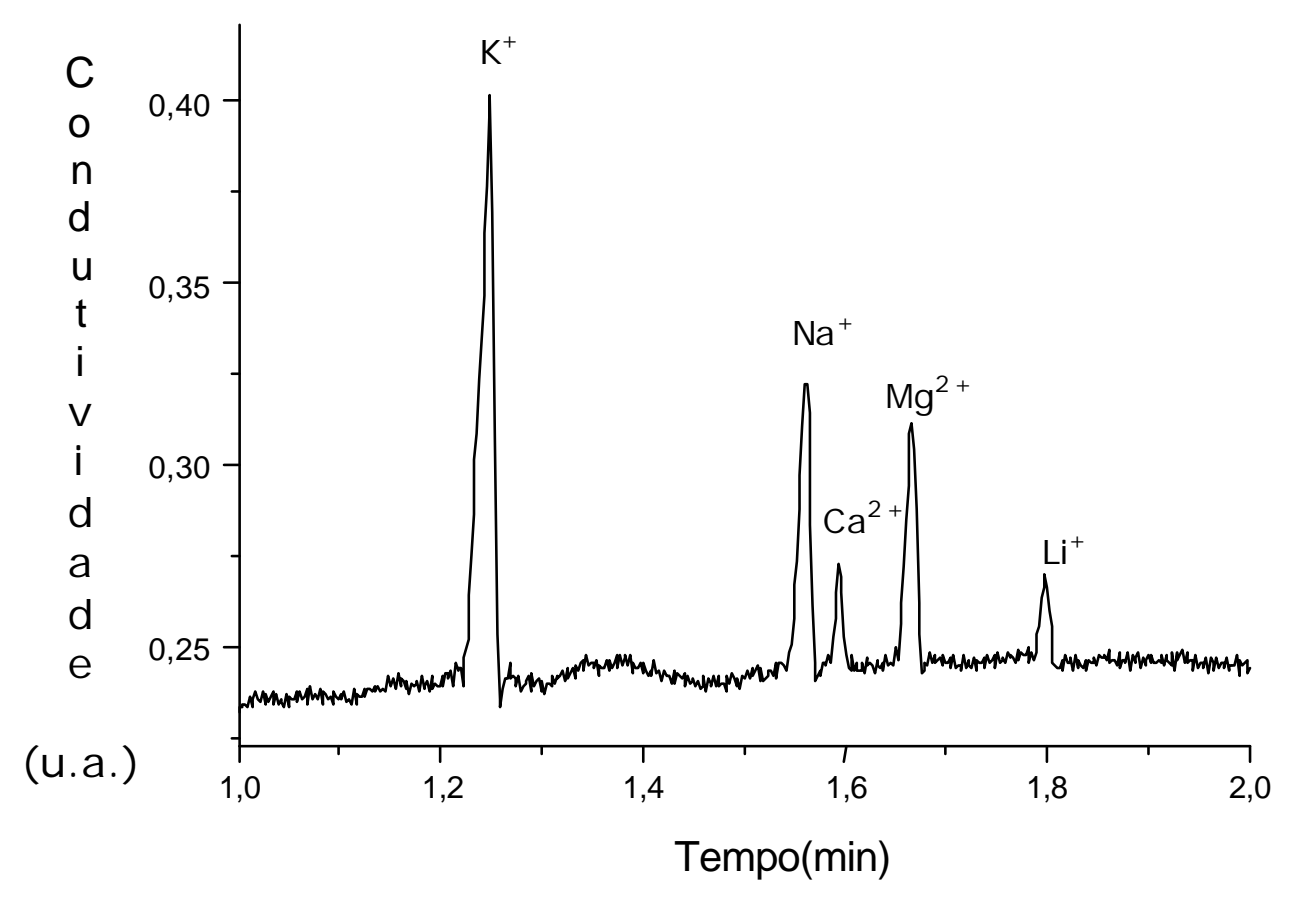

Figura 23 - Eletroferograma de uma amostra sintética: $\left[\mathrm{K}^{+}\right]=70 \mu \mathrm{mol} / \mathrm{L} ;\left[\mathrm{Na}^{+}\right]=50 \mu \mathrm{mol} / \mathrm{L}$; $\left[\mathrm{Ca}^{2+}\right]=10 \mu \mathrm{mol} / \mathrm{L} ;\left[\mathrm{Mg}^{2+}\right]=30 \mu \mathrm{mol} / \mathrm{L} ;\left[\mathrm{Li}^{+}\right]=30 \mu \mathrm{mol} / \mathrm{L} ; \mathrm{Tampão}[\mathrm{HLac} / \mathrm{His}]=20 / 20 \mathrm{mmol} / \mathrm{L}$; Potencial de Corrida $=20 \mathrm{kV}$; Injeção Eletrocinética - Potencial de Injeção $=2$ kV; Tempo de injeção $=2 \mathrm{~s}$. 


\section{Avaliação da repetibilidade do injetor FIA}

Na figura 24 é apresentado o registro expandido de um pico obtido com o injetor construído durante a injeção de solução de $\mathrm{KNO}_{3}$, utilizando-se do DCSC modificado para FIA. Pode-se observar que o pico apresenta um perfil normal, não sendo detectada qualquer anomalia como alargamento da base ou outro sintoma indicativo de oscilação ou vazamento das válvulas.

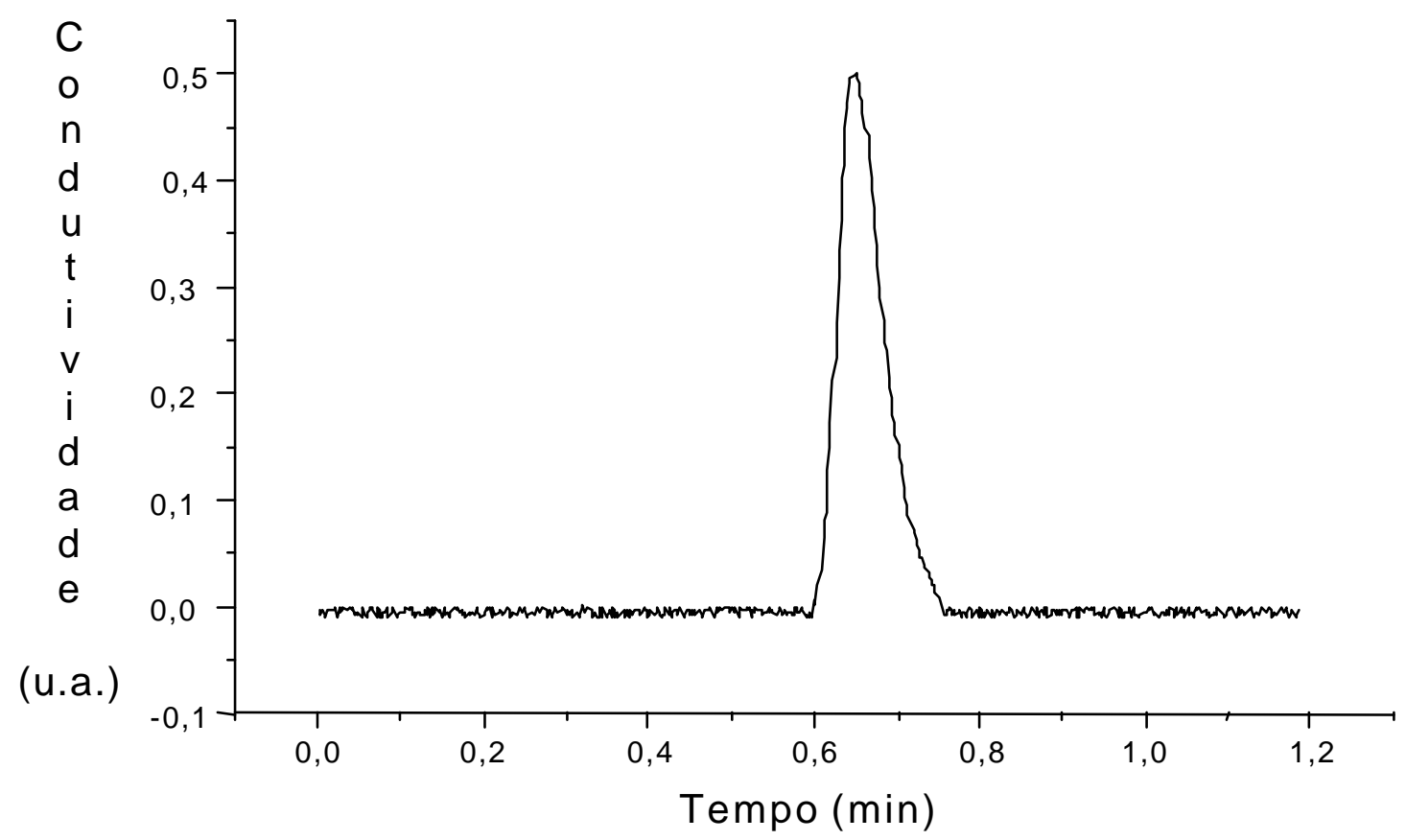

Figura 24 - Fiagrama de uma injeção de uma amostra sintética: $\left[\mathrm{KNO}_{3}\right]=200$ $\mu \mathrm{mol} / \mathrm{L}$; fluido transportador =Água deionizada; $\phi=2,0 \mathrm{~mL} / \mathrm{min}$; Volume da alça de amostragem $=50 \mu \mathrm{L}$. 
A repetibilidade dos picos, mesmo com uma alça de amostragem de volume reduzido $(50 \mu \mathrm{L})$ é muito boa ( $\mathrm{s}=0,6 \%)$, como pode ser apreciado na figura 25 , comprovando não só a qualidade do injetor como também do próprio detector, quando usado diretamente em FIA, tendo como amostra um eletrólito forte na concentração de $200 \mu \mathrm{mol} / \mathrm{L}$. Note-se, ainda, que não foi observada qualquer interferência elétrica do circuito de acionamento do solenóide do injetor/comutador no sinal do DCSC.

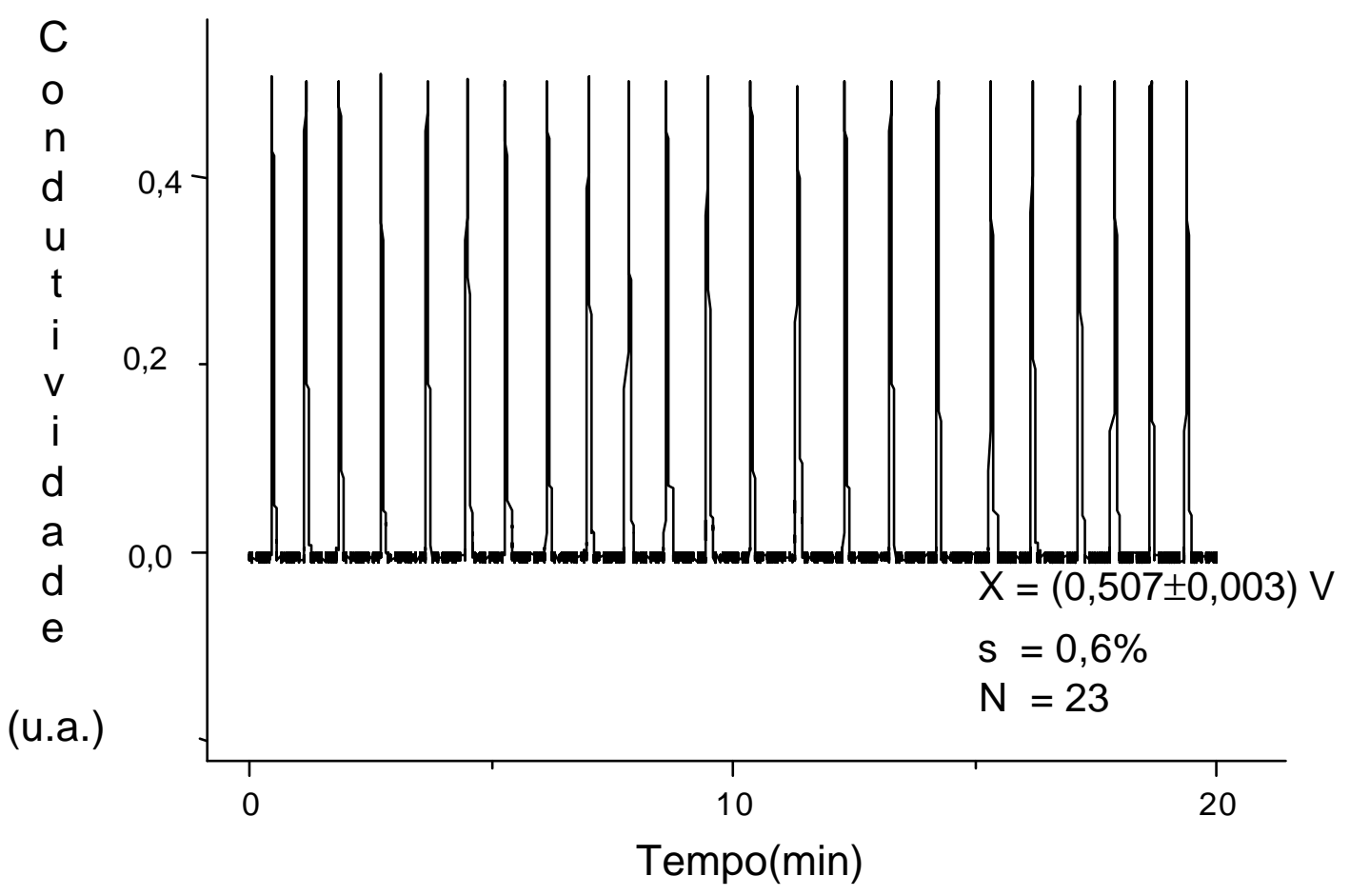

Figura 25 - Fiagrama de 23 injeções de uma amostra simulada: $\left[\mathrm{KNO}_{3}\right]=200 \mu \mathrm{mol} / \mathrm{L}$. Antes do detetor, imergiu-se a serpentina de $30 \mathrm{~cm}$ num banho para uniformização da temperatura. Fluido transportador=Água deionizada, $\phi=2,0 \mathrm{~mL} / \mathrm{min}$, Volume da alça de amostragem $=50 \mu \mathrm{L}, \mathrm{s}=0,6 \%$. 


\section{Estudo do sincronismo FIA-CE}

Para se avaliar o tempo que o plugue de amostra, injetado no sistema FIA, gasta para percorrer o circuito até a interface FIA-CE, utilizou-se do DCSC modificado para FIA e intercambiou-se alças de amostragens de volumes diferentes $(200,300,400$ e $500 \mu \mathrm{L})$.

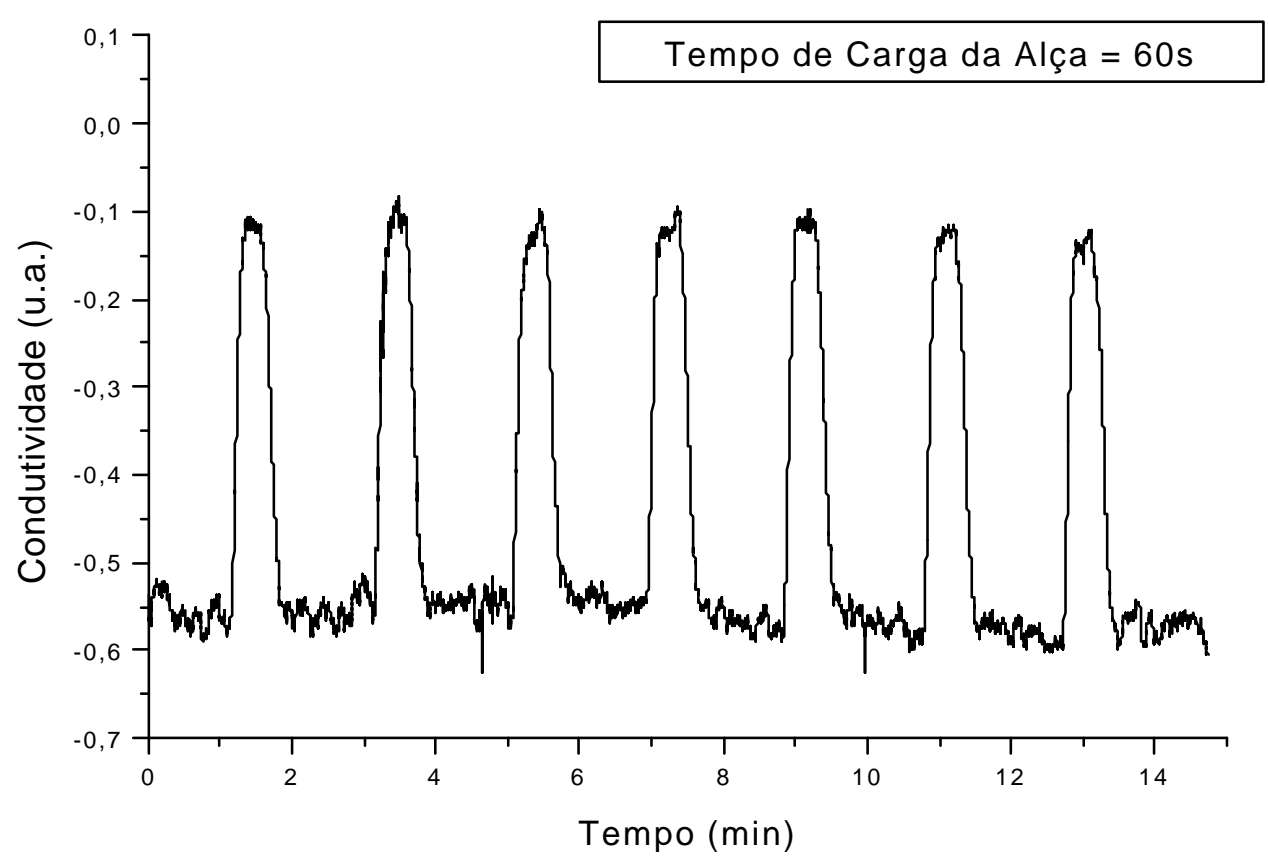

Figura 26 - Fiagrama de 7 injeções de uma amostra simulada: $\left[\mathrm{KNO}_{3}\right]=100 \mu \mathrm{mol} / \mathrm{L}$, Fluido transportador=Água deionizada, $\phi=1,0 \mathrm{~mL} / \mathrm{min}$, Volume da alça de amostragem $=400 \mu \mathrm{L}$. 
Na figura 27 é possível observar o patamar, região do plugue onde a concentração de amostra não varia, ideal para transferência de amostra sem perda de sensibilidade para o equipamento CE. A alça de amostragem de $400 \mu \mathrm{L}$ assegura longo patamar de $18 \mathrm{~s}$, permitindo acomodar variações, p. ex., troca de tubos fatigados da bomba peristáltica. Com alças menores, o sincronismo precisa ser conferido periodicamente.

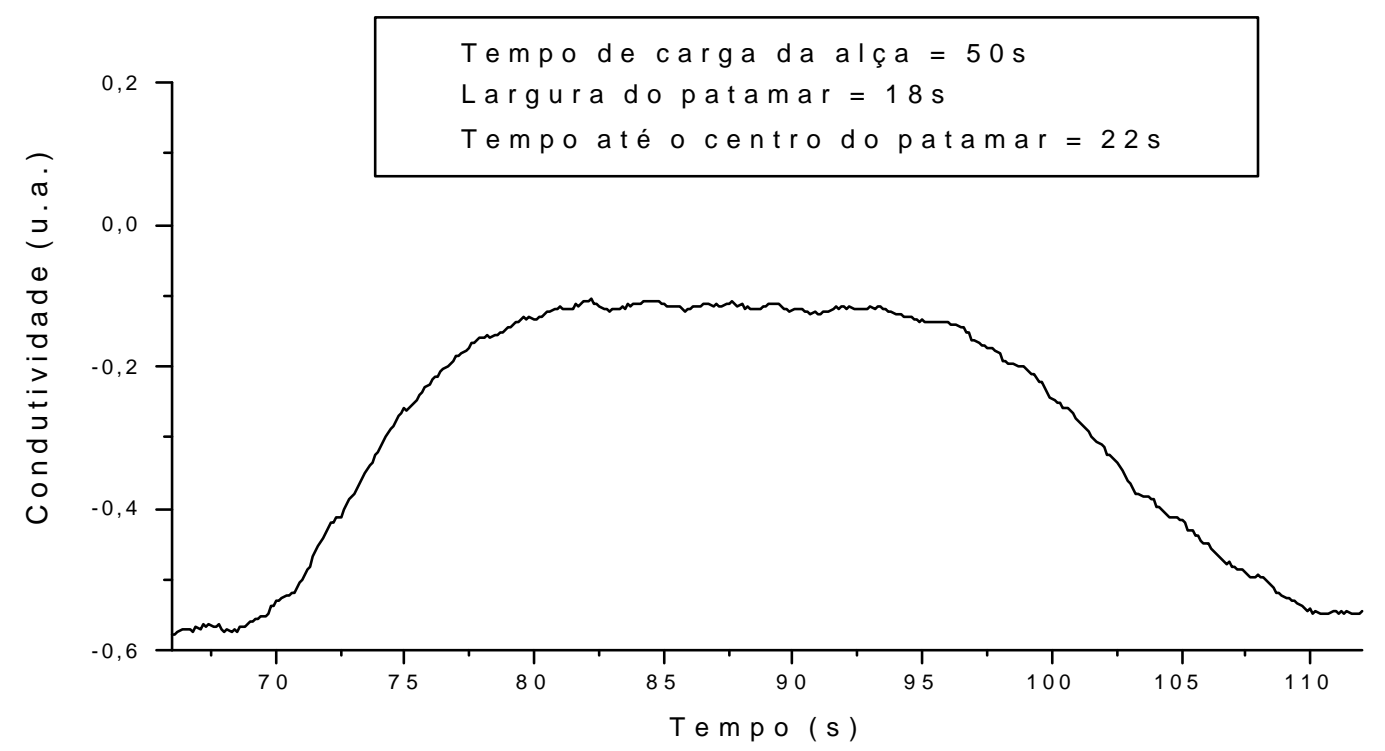

Figura 27 - Fiagrama de uma injeção de uma amostra sintética: $\left[\mathrm{KNO}_{3}\right]=100 \mu \mathrm{mol} / \mathrm{L}$;

Fluido transportador = Água deionizada; $\phi=1,0 \mathrm{~mL} / \mathrm{min}$;

Volume da alça de amostragem $=400 \mu \mathrm{L}$.

$\mathrm{Na}$ tabela 1 são apresentados os resultados obtidos com as diferentes alças de amostragens. Para os testes com a interface FIA-CE a alça escolhida foi a de $400 \mu \mathrm{L}$, por proporcionar estabilização mais longa no patamar (admitindo erros de até $9 \mathrm{~s}$ no sincronismo).

Tabela1 - Resultado do estudo de tempos para sincronismo do sistema FIA-CE.

\begin{tabular}{|c|c|c|c|}
\hline $\begin{array}{c}\text { Volume da alça de } \\
\text { amostragem }(\mu \mathrm{L})\end{array}$ & $\begin{array}{c}\text { Tempo de Patamar } \\
\text { (segundos) }\end{array}$ & $\begin{array}{c}\text { Tempo gasto até a } \\
\text { metade do patamar }\end{array}$ & $\begin{array}{c}\text { Tempo de Limpeza } \\
\text { (segundos) }\end{array}$ \\
\hline 200 & 5 & 13 & 12 \\
\hline 300 & 12 & 18 & 18 \\
\hline 400 & 18 & 22 & 21 \\
\hline 500 & 24 & 26 & 30 \\
\hline
\end{tabular}




\section{Resultados FIA-CE}

$\mathrm{Na}$ figura 28 apresenta-se registro completo de todas as fases de 2 injeções consecutivas de amostra sintética contendo os cátions $\mathrm{K}^{+}, \mathrm{Na}^{+}, \mathrm{Ca}^{2+}$, $\mathrm{Mg}^{2+}, \mathrm{Li}^{+}$. A região útil dos eletroferogramas vai de 13 a15 min e 22 a 24 min.

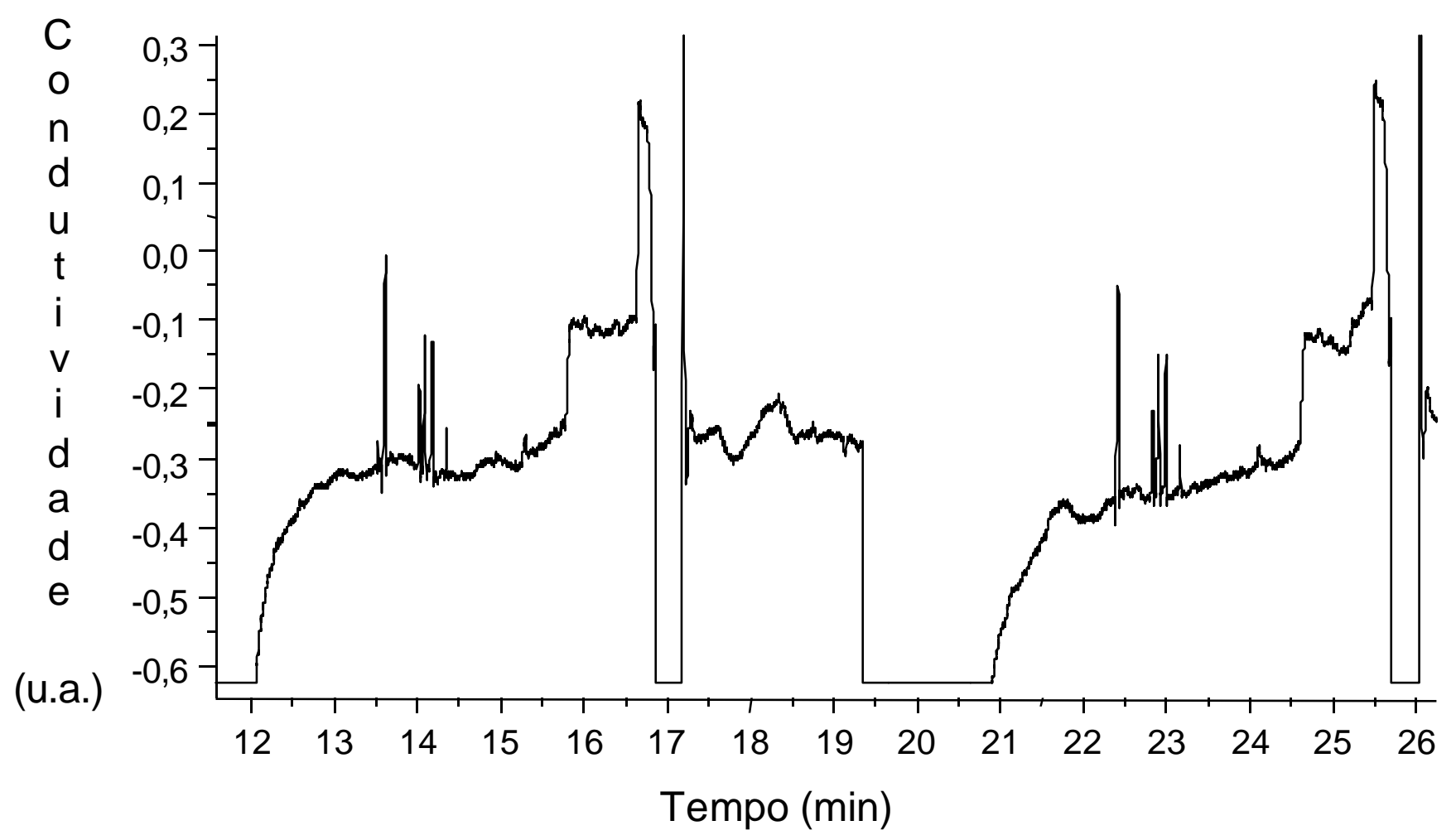

Figura 28 - Resultado de duas injeções sucessivas de uma amostra sintética: $\left[K^{+}\right]=100$ $\mu \mathrm{mol} / \mathrm{L} ;\left[\mathrm{Na}^{+}\right]=40 \mu \mathrm{mol} / \mathrm{L} ;\left[\mathrm{Ca}^{2+}\right]=80 \mu \mathrm{mol} / \mathrm{L} ;\left[\mathrm{Mg}^{2+}\right]=60 \mu \mathrm{mol} / \mathrm{L} ;\left[\mathrm{Li}^{+}\right]=40 \mu \mathrm{mol} / \mathrm{L} ;$ Tampão [HLac/His] $=20 \mathrm{mmol} / \mathrm{L}$; Potencial de Corrida=22 kV; Injeção Hidrodinâmica $-\Delta \mathrm{P}=11 \mathrm{~cm}$ de coluna d'água $\left(P_{\mathrm{amb}}-1080\right.$ Pascal); Tempo de injeção=20 s; $\phi \quad F I A=1,00 \mathrm{~mL} / \mathrm{min}$; Volume da alça de amostragem $=400 \mu \mathrm{L}$.

$\mathrm{Na}$ figura 29 é apresentado o resultado das corridas obtidas para separação dos cátions acima mencionados efetuando-se descarga acelarada do capilar (flush) mediante a aplicação de vácuo na extremidade final do capilar, de modo a remover mais rapidamente resíduo da amostra injetada juntamente com o plugue de água, possibilitando assim um ganho em freqüência analítica. 


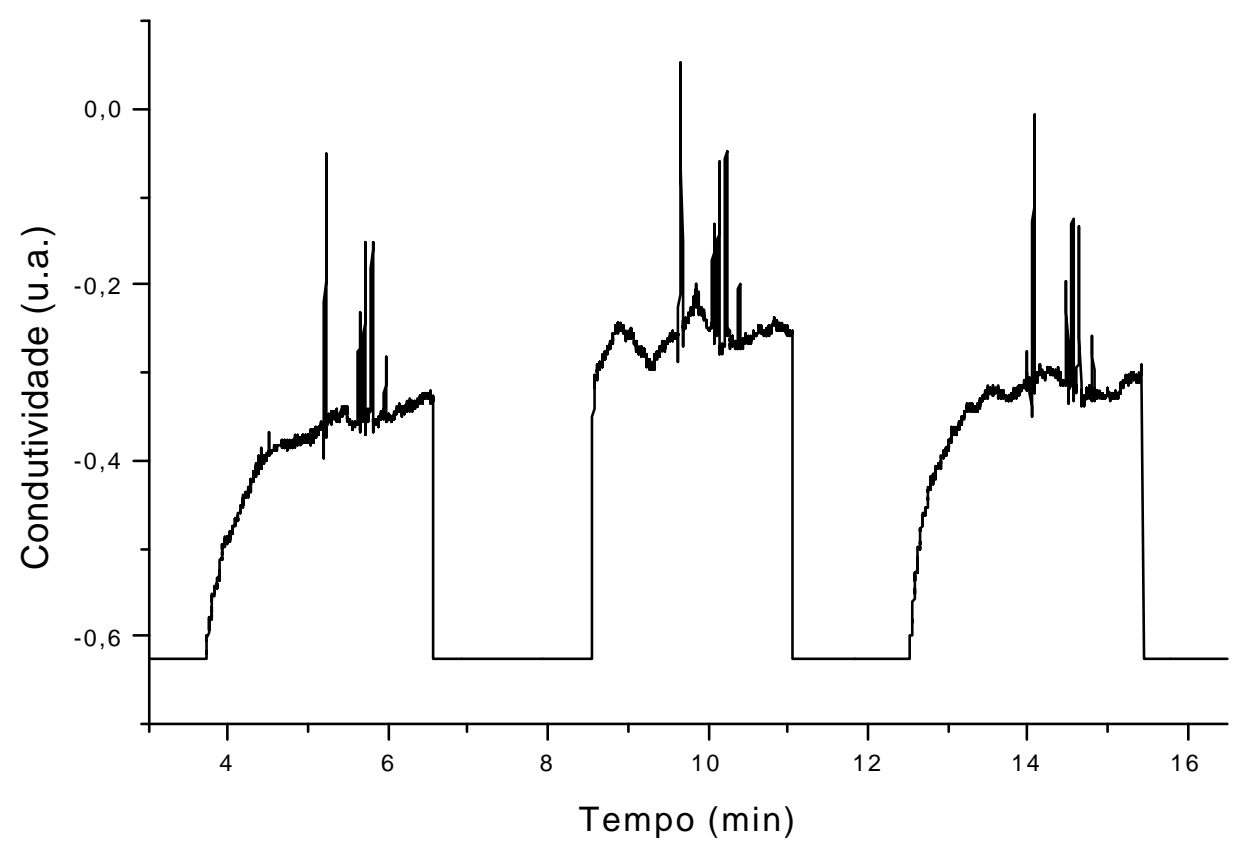

Figura 29 - Resultado de três injeções sucessivas de uma amostra sintética efetuandose descarga acelerada do capilar após ao termino da saída dos cátions: $\left[\mathrm{K}^{+}\right]=100 \mu \mathrm{mol} / \mathrm{L}$;

$\left[\mathrm{Na}^{+}\right]=40 \mu \mathrm{mol} / \mathrm{L} ;\left[\mathrm{Ca}^{2+}\right]=80 \mu \mathrm{mol} / \mathrm{L} ;\left[\mathrm{Mg}^{2+}\right]=60 \mu \mathrm{mol} / \mathrm{L} ;\left[\mathrm{Li}^{+}\right]=40 \mu \mathrm{mol} / \mathrm{L} ;$ Tampão [HLac/His] =20 mmol/L; Potencial de Corrida=22 kV; Injeção Hidrodinâmica - $\Delta \mathrm{P}=11 \mathrm{~cm}$ de coluna d'água $\left(P_{\mathrm{amb}}-1080\right.$ Pascal); Tempo de injeção $=20 \mathrm{~s} ; \phi \mathrm{FIA}=1,00 \mathrm{~mL} / \mathrm{min}$; Volume da alça de amostragem $=400 \mu \mathrm{L}$.

Para não ocorrer muita variação na força iônica dos diversos padrões injetados, a soluções que serviram de amostra foram feitas seguindo a tabela 2.

Tabela 2: Concentração dos cátions componentes de cada amostra sintética.

\begin{tabular}{|c|c|c|c|c|c|}
\hline Amostras & $\mathrm{K}^{+}(\mu \mathrm{mol} / \mathrm{L})$ & $\mathrm{Na}^{+}(\mu \mathrm{mol} / \mathrm{L})$ & $\mathrm{Mg}^{2+}(\mu \mathrm{mol} / \mathrm{L})$ & $\mathrm{Ca}^{2+}(\mu \mathrm{mol} / \mathrm{L})$ & $\mathrm{Li}^{+}(\mu \mathrm{mol} / \mathrm{L})$ \\
\hline Amostra 1 & 40 & 60 & 80 & 100 & 40 \\
\hline Amostra 2 & 100 & 40 & 60 & 80 & 40 \\
\hline Amostra 3 & 80 & 100 & 40 & 60 & 40 \\
\hline Amostra 4 & 60 & 80 & 100 & 40 & 40 \\
\hline
\end{tabular}


Cada amostra foi injetada 5 vezes e o cátion $\mathrm{Li}^{+}$foi utilizado como padrão interno. Os resultados das razões entre a altura dos picos dos cátions com o Lítio são apresentados na tabela 3.

Tabela 3: Razões entre as alturas dos picos dos cátions frente ao Lítio, com desvio padrão, $\mathrm{N}=5$.

\begin{tabular}{|c|c|c|c|c|c|}
\hline $\begin{array}{c}\text { Concentração } \\
\mu \mathrm{mol} / \mathrm{L}\end{array}$ & $\mathrm{K}^{+} / \mathrm{Li}^{+}$ & $\mathrm{Na}^{+} / \mathrm{Li}^{+}$ & $\mathrm{Ca}^{2+} / \mathrm{Li}^{+}$ & $\mathrm{Mg}^{2+} / \mathrm{Li}^{+}$ & $\mathrm{Li}^{+} / \mathrm{Li}^{+}$ \\
\hline 0 & 0 & 0 & 0 & 0 & 1,00 \\
\hline 40 & $(1,90 \pm 0,03)$ & $(1,35 \pm 0,02)$ & $(1,51 \pm 0,03)$ & $(1,42 \pm 0,02)$ & 1,00 \\
\hline 60 & $(2,84 \pm 0,05)$ & $(1,89 \pm 0,03)$ & $(2,27 \pm 0,04)$ & $(2,01 \pm 0,04)$ & 1,00 \\
\hline 80 & $(3,65 \pm 0,07)$ & $(2,61 \pm 0,05)$ & $(2,92 \pm 0,05)$ & $(2,61 \pm 0,05)$ & 1,00 \\
\hline 100 & $(4,48 \pm 0,09)$ & $(3,21 \pm 0,08)$ & $(3,50 \pm 0,07)$ & $(3,26 \pm 0,06)$ & 1,00 \\
\hline
\end{tabular}

Com isso podemos avaliar também a linearidade de resposta do sistema para a faixa de concentração escolhida para os cátions, na figura 30.

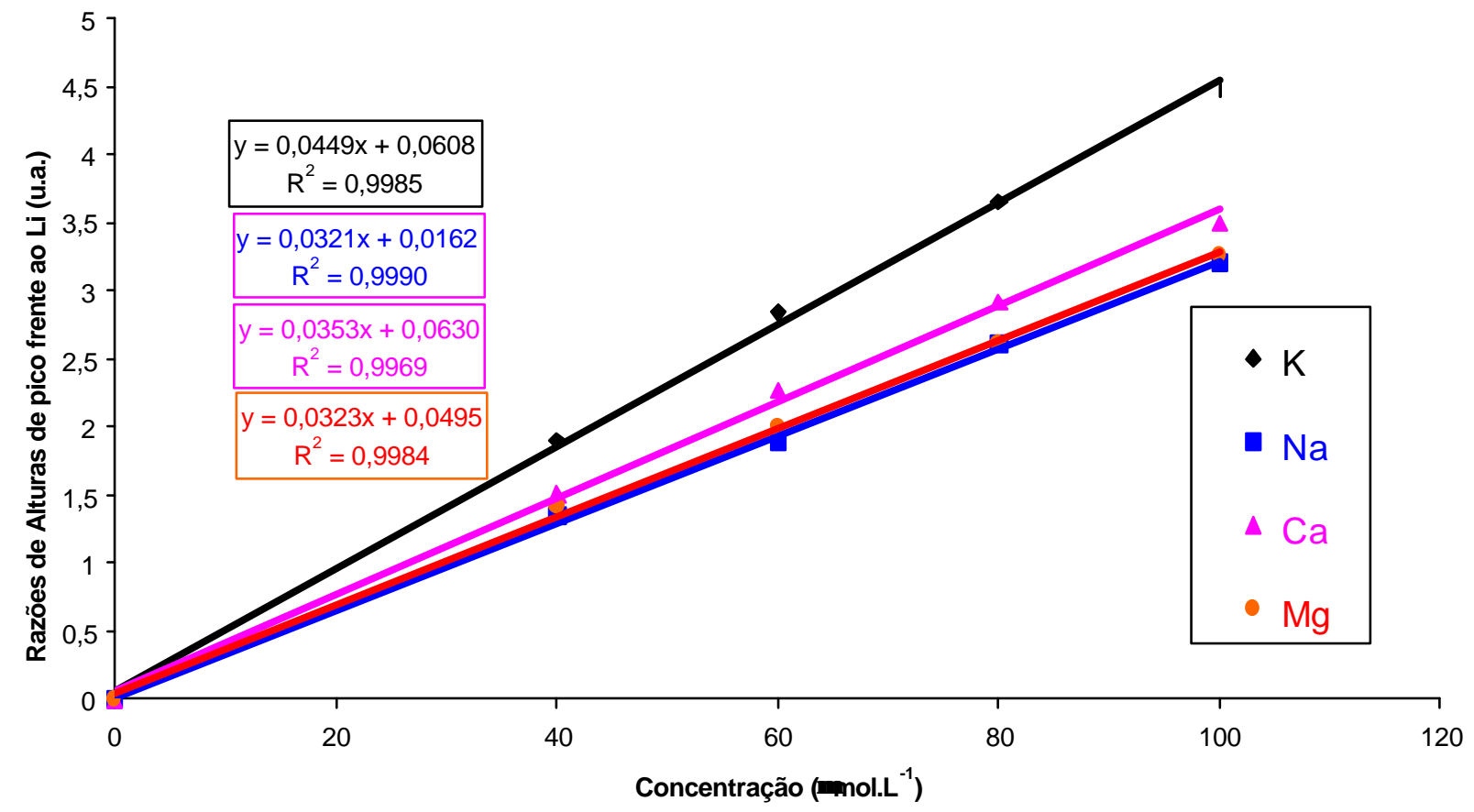

Figura 30 - Curvas de Calibração: Tampão [HLac/His] $=20 \mathrm{mmol} / \mathrm{L}$; Potencial de Corrida $=22 \mathrm{kV}$; Injeção Hidrodinâmica $-\Delta \mathrm{P}=11 \mathrm{~cm}$ de coluna d'água $\left(\mathrm{P}_{\mathrm{amb}}-1080\right.$ Pascal); Tempo de injeção $=20 \mathrm{~s}$; Volume da alça de amostragem $=400 \mu \mathrm{L} ; \phi \mathrm{FIA}=1,00 \mathrm{~mL} / \mathrm{min}$

Os coeficientes de correlação linear para cada curva de calibração, são apresentados na tabela 4 . 
Tabela 4: Coeficientes de correlação das curvas de calibração de cada cátion.

\begin{tabular}{|c|c|c|c|}
\hline $\mathrm{R}, \mathrm{K}^{+}$ & $\mathrm{R}, \mathrm{Na}^{+}$ & $\mathrm{R}, \mathrm{Ca}^{2+}$ & $\mathrm{R}, \mathrm{Mg}^{2+}$ \\
\hline 0,9992 & 0,9995 & 0,9984 & 0,9992 \\
\hline
\end{tabular}

Para efeito de comparação, avaliou-se também a área dos picos dos mesmos eletroferogramas. Os resultados das razões entre as áreas dos picos dos cátions com o Lítio são apresentados na tabela 5.

Tabela 5: Razões entre as áreas dos picos dos cátions frente ao Lítio, com desvio padrão, $\mathrm{N}=5$.

\begin{tabular}{|c|c|c|c|c|c|}
\hline $\begin{array}{c}\text { Concentração } \\
(\mu \mathrm{mol} / \mathrm{L})\end{array}$ & $\mathrm{K}^{+} / \mathrm{Li}^{+}$ & $\mathrm{Na}^{+} / \mathrm{Li}^{+}$ & $\mathrm{Ca}^{2+} / \mathrm{Li}^{+}$ & $\mathrm{Mg}^{2+} / \mathrm{Li}^{+}$ & $\mathrm{Li}^{+} / \mathrm{Li}^{+}$ \\
\hline 0 & 0 & 0 & 0 & 0 & 1,00 \\
\hline 40 & $(3,15 \pm 0,03)$ & $(1,61 \pm 0,02)$ & $(2,31 \pm 0,03)$ & $(1,73 \pm 0,02)$ & 1,00 \\
\hline 60 & $(4,31 \pm 0,05)$ & $(2,51 \pm 0,03)$ & $(3,34 \pm 0,04)$ & $(2,59 \pm 0,04)$ & 1,00 \\
\hline 80 & $(5,52 \pm 0,07)$ & $(3,32 \pm 0,05)$ & $(4,22 \pm 0,05)$ & $(3,47 \pm 0,05)$ & 1,00 \\
\hline 100 & $(6,98 \pm 0,09)$ & $(4,27 \pm 0,08)$ & $(5,70 \pm 0,07)$ & $(4,51 \pm 0,06)$ & 1,00 \\
\hline
\end{tabular}

Com isso podemos avaliar também a linearidade de resposta do sistema para a faixa de concentração escolhida para os cátions, ilustrada na figura 31.

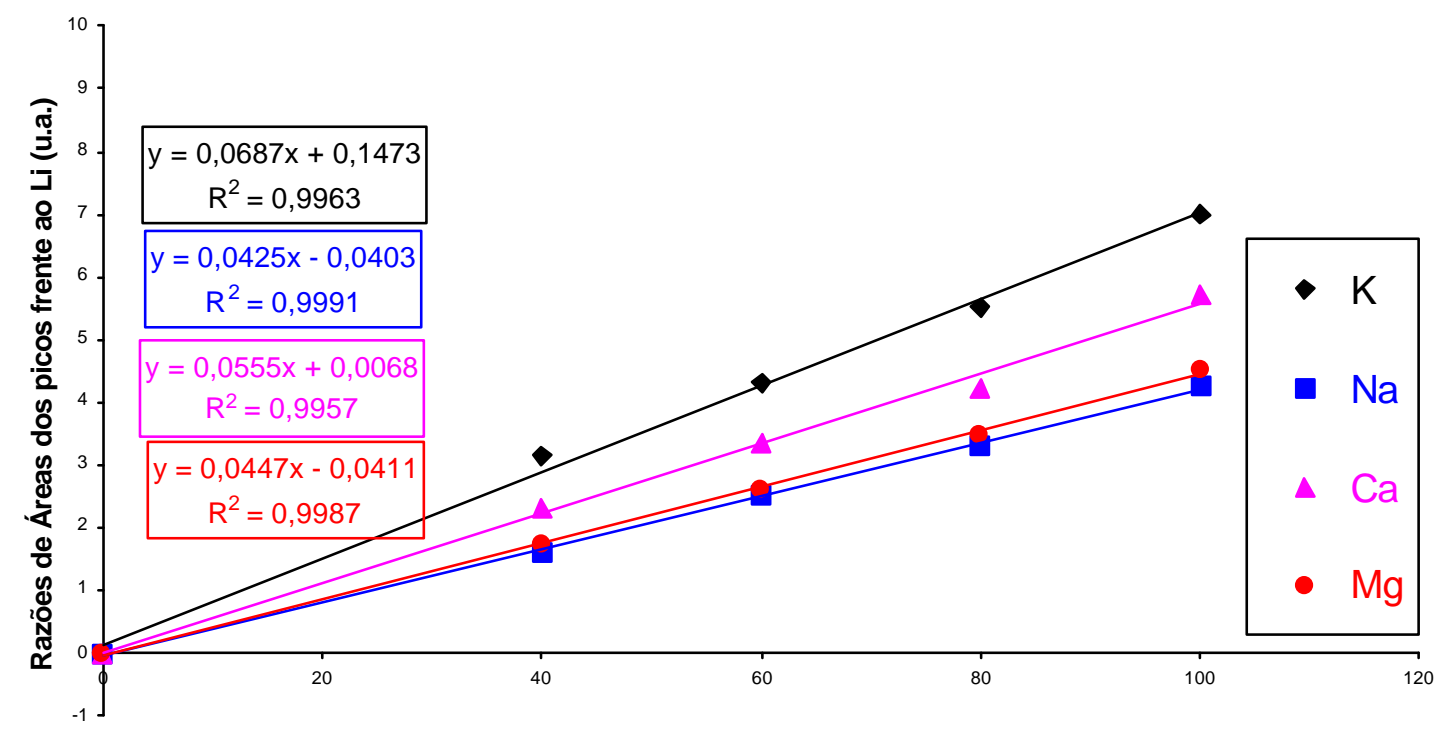

Concentração $\left(\mu \mathrm{mol} \cdot \mathrm{L}^{-1}\right)$

Figura 31 - Curva de Calibração com base na razão da área $\mathrm{M}^{\mathrm{n}} / \mathrm{Li}^{+}$: Tampão [HLac/His]=20 mmol/L; Potencial de Corrida=22 kV; Injeção Hidrodinâmica - $\Delta \mathrm{P}=11 \mathrm{~cm}$ de coluna d'água; Tempo de injeção $=20 \mathrm{~s}$; Volume da alça de amostragem $=400 \mu \mathrm{L} ; \phi$ $\mathrm{FIA}=1,00 \mathrm{~mL} / \mathrm{min}$. 
Os coeficientes de correlação linear para cada curva de calibração de áreas, são apresentados na tabela 6 .

Tabela 6: Coeficientes de correlação das curvas de calibração de cada cátion, com base na avaliação pela razão das áreas.

\begin{tabular}{|c|c|c|c|}
\hline $\mathrm{R}, \mathrm{K}^{+}$ & $\mathrm{R}, \mathrm{Na}^{+}$ & $\mathrm{R}^{+} \mathrm{Ca}^{2+}$ & $\mathrm{R}, \mathrm{Mg}^{2+}$ \\
\hline 0,9981 & 0,9995 & 0,9978 & 0,9993 \\
\hline
\end{tabular}

Comparação dos resultados obtidos com base nas razões de alturas e de áreas dos picos mostram que ambos os procedimentos evidenciam alta repetibilidade das medidas, sendo que $O$ DPR das quintuplicatas ficou, tipicamente, entre 1,5 e 2\% para a avaliação das alturas dos picos e entre 1 e 1,5\% para a avaliação das áreas, favorecendo o segundo procedimento. Os coeficientes de correlação foram igualmente bons por ambos os procedimentos mas, no caso particular do potássio, a avaliação com base na área resultou em reta de regressão com intersecção que se afastou um pouco mais de zero.

Com relação à repetibilidade da posição dos picos dos analitos, esta foi avaliada efetuando 20 injeções automáticas consecutivas, com aquisição dos eletroferogramas. Os resultados foram plenamente satisfatórios, como pode ser verificado na tabela 7 , observando a estabilidade da diferença do tempo de migração $t_{m}$ dos cátions mais lentos frente ao mais rápido, o $\mathrm{K}^{+}$.

Tabela 7: Tempos de migração dos cátions, $\mathrm{N}=20$.

\begin{tabular}{|c|c|c|c|c|c|}
\hline & $\mathrm{K}^{+}$ & $\mathrm{Na}^{+}$ & $\mathrm{Ca}^{2+}$ & $\mathrm{Mg}^{2+}$ & $\mathrm{Li}^{+}$ \\
\hline $\mathrm{t}_{\mathrm{m}}(\mathrm{s})$ & 39,9 & 63,7 & 67,7 & 72,7 & 82,4 \\
\hline $\mathrm{s}(\mathrm{s})$ & 0,3 & 0,4 & 0,4 & 0,5 & 0,6 \\
\hline $\mathrm{dpr}(\%)$ & 0,8 & 0,6 & 0,6 & 0,7 & 0,7 \\
\hline
\end{tabular}

Verifica-se, pois, que os dois parâmetros mais importantes extraídos dos eletroferogramas, a posição e a altura ou área (relativa) dos picos, podem ser obtidos com alta precisão com o sistema FIA-CE proposto. Este resultado favorável em relação à operação manual se deve, principalmente, à melhor repetibilidade de todas as etapas (do condicionamento à detecção), vez que são rigorosamente controladas pelo microcomputador. 
Por último, cabe mencionar que os aspectos mais essenciais do sistema foram testados trabalhando somente com injeção hidrodinâmica, por ser esta mais complexa e difícil de implementar. Não se prevê, contudo, dificuldades ou impedimentos para operação no modo de transferência eletrocinética mediante simples modificação do programa, consistindo em suprimir a aplicação de pressão reduzida pelo pressiostato e, em seu lugar, aplicar tensão apropriada durante período selecionável pelo operador.

Igualmente, há portas disponíveis na interface para comandar dispositivos adicionais do sistema FIA, selecionados do amplo repertório registrado na literatura internacional, sendo particularmente atraentes os que visam separação e/o pré-concentração de analitos. 


\section{CONCLUSÕES E PERSPECTIVAS}

O sistema se mostrou robusto, flexível e preciso. Diferentemente dos equipamentos comerciais de eletroforese capilar e/ou FIA, (que não permitem alterações de software ou hardware afora eventual escolha de opções dadas pelo fabricante), o acesso completo aos componentes mecânicos e eletrônicos, circuitos e programas do sistema construído permite não só a reprogramação de qualquer etapa como a expansões, reconfiguração e implementação dos procedimentos FIA que se fizerem necessários para diferentes aplicações.

O sistema apresentou uma excelente relação custo/beneficio em decorrência da escolha, em sua construção, de materiais econômicos e acessíveis com desempenho adequado. No caso de aplicações que exijam freqüente alternância entre a determinação de cátions e de ânions, resulta justificável a aquisição de fonte de alta tensão bipolar, de custo mais elevado, se bem que, para elevada demanda, possa ser preferível contar com dois sistemas FIA-CE independentes.

A freqüência analítica de 12 injeções por hora é bastante elevada, pois abrange não só a separação eletroforética de cátions de alta mobilidade iônica como todas as etapas acessórias, inclusive a descarga acelerada do capilar. Naturalmente, separações envolvendo espécies mais lentas ou por cromatografia capilar micelar eletrocinética (MEKC) poderão reduzir esta freqüência.

Pode-se observar também, limites de detecção similares e melhor repetibilidade da área, altura e posição dos picos (DPR<2,0\%) em comparação a CE praticada em equipamento de operação manual.

A implementação no sistema FIA-CE das duas formas de transferência (injeção) de amostra mais populares em CE - eletrocinética e hidrodinâmica -, a segunda com auxílio de um pressiostato, oferece nítida vantagem sobre sistemas mais simples, que dispõe somente de injeção eletrocinética.

O sistema automático de FIA-CE desenvolvido tem grande potencialidade e abre novas possibilidades de pesquisa, dada sua boa performance e facilidade de reconfiguração. Ao lado de procedimentos em fluxo usuais ou novos, 
conveniências como a adição em fluxo de padrão interno às amostras poderão vir a ser implementadas com facilidade. Na determinação de componentes diferindo largamente quanto à concentração, também pode ser explorado o perfil reprodutível de dispersão em torno do pico de amostra emergente do circuito FIA, para selecionar a diluição adequada na transferência à CE.

Visando funcionamento com menor supervisão, caberia adicionar um intercambiador de amostras a serem admitidas pelo circuito FIA, ou uma tubulação derivada do processo (em escala piloto ou industrial) que se deseja monitorar. Outro aperfeiçoamento consiste em implementar funções de diagnóstico de anormalidades, aproveitando-se sinais já disponíveis como temperatura no gabinete ou corrente que flui pelo capilar (permite, inclusive, detectar bolhas), comparação de eletroferogramas consecutivos quanto variações de linha base ou de posição do pico do padrão interno, adição de sensores de nível para os reservatórios, entre outros.

A adição de um segundo detector condutométrico sobreposto à interface FIA-CE facilitaria 0 acerto do sincronismo das operações durante a implementação de novos métodos. Seu uso rotineiro permitiria também compensar pequenas variações de vazão por acomodação dos tubos das bombas peristálticas e alertar quando estas se tornam excessivas. 
1. Hansen's Coprehensive Flow Injection Bibliography http://www.flowinjection.com/search.html.

2. Flow Analysis Database, $h$ ttp://www.fia.unf.edu/fad/fad.html.

3. Nóbrega, Joaquim A., Quim. Nova, 19 (1996), 684.

4. Aguiar, M.A.S.; Marquez, K.S.G.; Gutz, I.G.R.; Electroanal., 12 (2000)742.

5. De Donato A.; Pedrotti, J.J.; Gutz, I.G.R.; Electroanal., 11 (1999) 1124.

6. Dantoni, P.; Serrano, S.H.P.; Gutz, I.G.R.; Brett, A.M.O., Anal. Chim. Acta, 366(1998), 137.

7. Augelli, M.A.; Nascimento, V.B.; Pedrotti, J.J; Gutz, I.G.R; Angnes, L.A., The Analyst, 122 (1997) 843.

8. Pedrotti, J.J.; Angnes, L.; Gutz, I.G.R., Anal. Chim. Acta, 298 (1994) 393.

9. Gouveia, V.J.P.; Gutz, I.G.R.; Rubim, J.C., J. Electroanal. Chem., 371(1994) 37.

10. Tavares, Marina F.M., Quim. Nova, 19 (1996), 173.

11. Harris, D.C.; Análise Química Quantitativa; 5 ed. LTC Editora, Rio de Janeiro, 1999, 613.

12. Bier, M.; Theory, Methods and Applications; Academic Press Inc., New York, 1959.

13. Bard, A.J.; Faulkner, L.R.; Electrochemical Methods - Fundamentals and Applications; John Wiley; New York, 1980.

14. Zagatto, E. A. G.; Oliveira, C. C.; Collins, C. H., Quim. Nova, 22 (1999), 143.

15. Kuban, P.; Engström, A.; Olsson, J.C.; Thorsén, G.; Tryzell, R.; Karlberg, B., Anal. Chim. Acta, 337 (1997), 117.

16. Fang, Z, Anal. Chim. Acta, 400 (1999), 233.

17. Valcarcel, M.; Arce, L.; Rios, A.; J. Chromatogr. A., 924 (2001), 3.

18. Miranda, C. E. S.; Carrilho, E. et al., Quim. Nova, 25(2002),412.

19. Hogan, B.L.; Lunte, S.M.; Stobaugh, J.F.; Lunte, C.E.; Anal. Chem., 66(1994), 596. 
20. Chen, H.W.; Fang, Z.L., Anal. Chim. Acta, 355 (1997), 135.

21. Arce, L.; Ríos, A.; Valcárcel, M.; J. Chomatogr. A, 791 (1997) 279.

22. Kuban, P.; Arce, L.; Ríos, A.; Valcárcel, M.; Karlberg, B., Anal. Chim. Acta, 390 (1999), 39.

23. Chen, H.W.; Fang, Z.L., Anal. Chim. Acta, 376 (1998), 209.

24. Kuban, P.; Karlberg, B., Talanta, 45 (1998), 477.

25. Arce, L.; Ríos, A.; Valcárcel, M.; J. Chomatogr. A, 827 (1998) 113.

26. Lista, A.G.; Arce, L.; Rios, A. et al. Anal. Chim. Acta, 438 (2001) 315.

27. Tsuda, T. and Zare, R.N.; J. Chromatogr. A, 559 (1991), 103.

28. Kuban, P.; Pirmohammadi, R.; Karlberg, B., Anal. Chim. Acta, 378 (1999), 55.

29. Fracassi, J.A.; Lago, C., Anal. Chem., 70 (1998), 4339.

30. Fracassi, J.A.; Determinação Condutométrica Sem Contato (Oscilométrica) Para Eletroforese Capilar De Zona e Cromatografia Micelar Eletrocinética, Tese de doutoramento, IQ-USP, 2000.

31. Palgrossi, F.S.; Pedrotti, J.J.; Gutz, I.G.R., Quim. Nova, 24 (2001), 689. 


\section{Software}

Program EletroforeseCapilar_Praia;

\{- Ultima modificacao em 29/04/2002 - \}

Uses

DOS, CRT, EC, Graficos;

Var

Equip : CE;

W1, W2, W3, W4, W5, W6, W7, W8 : Janela;

Arq : Text;

Nome : String;

s,AuxNome : String[10];

Cont : Integer;

TempoMin, ATDouble, AtInj,TMaximo,

ITelaMax,DetTelaMax, i, v, temp, FundoEscala,

VDouble : Double ;

$\mathrm{v} 0$, t, ta, tb, tc : Word;

tempo0, tempoesp : LongInt;

Acao, ModoInjecao, Canal, Tecla,Tecla2 : Char;

Polaridade, G, GCorrente : Byte;

Function GetTempo2 : LongInt;

var hora, minuto, segundo, seg100 : Word;

Begin

GetTime(hora,minuto,segundo,seg100);

GetTempo $2:=$ LongInt(hora) $* 360000+\{3600$

$* 100\}$

LongInt(minuto) $* 6000+\{60 * 100\}$

LongInt(segundo) $* 100+$

LongInt(seg100) - tempoesp;

End;

Procedure ZeraCronometro2;

Begin

tempoesp := GetTempo2;

End;

Function GetTempo : LongInt;

var hora, minuto, segundo, seg 100 : Word;

Begin

GetTime(hora,minuto,segundo,seg100);

GetTempo := LongInt(hora) $* 360000+$ $\{3600 * 100\}$

LongInt (minuto) $* 6000+$

$\{60 * 100\}$

LongInt(segundo) $* 100+$

End;

LongInt(seg100) - tempo0;

Procedure ZeraCronometro;

Begin

tempo0 := GetTempo;

End;
BEGIN

$\mathrm{G}:=3 ; \quad \quad\{$ Ganho do conversor A/D $\}$

GCorrente $:=4 ; \quad\{$ Ganho leitura de corrente $\}$

TMaximo $:=20.0 ;\{$ Tempo Max. de tela em min. $\}$

ITelaMax $:=20.0 ;\{$ Fundo de escala - janela de corente\}

DetTelaMax := 4095.0;

\{ Fundo de escala - janela do detector \}

Case $\mathrm{G}$ of

$0:$ FundoEscala $:=5.0$

$1:$ FundoEscala $:=2.5$

$2:$ FundoEscala $:=1.25$

3 : FundoEscala $:=0.625$;

$4:$ FundoEscala $:=0.3125$;

end;

Repeat

ClrScr;

TextColor(LightRed);

WriteLn(' ***** Programa de Aquisicao de Dados

Para FIA-CE de Praia *****');

WriteLn;

WriteLn('Escolha a Opcao : ');

WriteLn;

TextColor(10);Write('I');TextColor(LightRed);WriteLn ('niciar Aquisicao');

TextColor(10);Write('P');TextColor(LightRed);WriteL $\mathrm{n}($ 'arametros');

TextColor(10);Write('L'); TextColor(LightRed);WriteL n('impar Capilar');

TextColor(10);Write('S');TextColor(LightRed);WriteL n('air');

NormVideo;

Tecla $:=$ UpCase(ReadKey);

Case Tecla of

'P' : Begin

Repeat

ClrScr;

TextColor(LightRed);

WriteLn(' *** Parametros *** ');

WriteLn;WriteLn;

TextColor(10);Write('G');TextColor(LightRed);WriteL n('anho,', \{',G,'\}');

TextColor(10);Write('T');TextColor(LightRed);WriteL n('empo de tela maximo',' \{',TMaximo:2:0,'\}');

TextColor(10);Write('C');TextColor(LightRed);WriteL n('orrente maxima (tela)'); 
TextColor(10);Write('R'); TextColor(LightRed); WriteLn('esposta maxima do detector'); TextColor(10);Write('V');TextColor(LightRed);Wr iteLn('oltar');

Tecla2 := UpCase(ReadKey);

Case Tecla2 of

'G' : Begin

WriteLn('Entre com o valor do

ganho (0 a 4)');

$\operatorname{ReadLn}(\mathrm{G})$

End;

' $\mathrm{T}$ ' : Begin

WriteLn('Entre com o valor do

tempo de tela maximo');

ReadLn(TMaximo);

End;

'C' : Begin

WriteLn('Entre com o valor da

corrente maxima (em microamperes)');

ReadLn(ITelaMax);

End;

'R' : Begin

WriteLn('Entre com o valor

maximo de resposta do detector (4095 maximo)');

ReadLn(DetTelaMax);

End;

'V': ;

end;

Until Tecla2 = 'V';

NormVideo;

End;

'L' : Begin

ClrScr;

WriteLn('Espere confortavelmente

enquanto o progama realiza a limpeza do sistema');

WriteLn;

Equip.Iniciar;

With Equip do

WriteLn('Tempo estimado para o Termino:

35 minutos');

WriteLn('Aguarde');

WriteLn;

Equip.BombaLig('C');

WriteLn('Limpando Sistema FIA com

$\mathrm{NaOH}$ );

TempoMin $:=0$;

tempoesp : $=0$;

ZeraCronometro2;

Repeat

TempoMin :=

$1.0 *($ GetTempo2/(100*60));

Until (TempoMin >=2);

Equip.BombaDes;

Equip.VacuoLig;

WriteLn('Limpando Capilar com $\mathrm{NaOH}^{\prime}$ );

TempoMin : $=0$;

tempoesp $:=0$;
ZeraCronometro2;

Repeat

TempoMin $:=1.0 *($ GetTempo2/(100*60));

Until (TempoMin >=5);

Equip.VacuoDes;

Equip.BombaLig('B');

WriteLn('Limpando Sistema FIA com H2O');

TempoMin $:=0$;

tempoesp $:=0$;

ZeraCronometro2;

Repeat

TempoMin := 1.0*(GetTempo2/(100*60));

Until (TempoMin >=2);

Equip.BombaDes;

Equip.VacuoLig;

WriteLn('Limpando Capilar com H2O');

TempoMin $:=0$;

tempoesp : $=0$;

ZeraCronometro2;

Repeat

TempoMin := 1.0*(GetTempo2/(100*60));

Until (TempoMin >=12);

Equip.VacuoDes;

Equip.BombaLig('A');

WriteLn('Condicionando Sistema FIA com Tampao');

TempoMin :=0;

tempoesp $:=0$;

ZeraCronometro2;

Repeat

TempoMin := 1.0*(GetTempo2/(100*60));

Until (TempoMin >=2);

Equip.BombaDes;

Equip.VacuoLig;

WriteLn('Condicionando Capilar com

Tampao');

TempoMin := 0;

tempoesp $:=0$;

ZeraCronometro2;

Repeat

TempoMin := 1.0*(GetTempo2/(100*60));

Until (TempoMin >= 12);

Equip.VacuoDes;

Equip.Finalizar;

End;

'S' : Begin

End;

'I' : Begin

tempo0 $:=0$

\{ --------Inicia Interface PCL---------- $\}$

Equip.Iniciar;

$\mathrm{ClrScr}$;

\{ -------Entrada de Dados-------------- $\}$

Write('Nome do arquivo: ');

Readln(Nome);

AuxNome := Nome;

AuxNome := Concat(AuxNome,'.dat'); 
Nome :=

Concat('c: \BP\dados\',Nome,'.dat');

Assign(arq,Nome);

Rewrite(Arq);

WriteLn;

WriteLn('Alta Tensao aplicada ? (Maximo de $29.0 \mathrm{kV}$ ) : ');

ReadLn(ATDouble);WriteLn;

WriteLn('Polaridade :');

WriteLn('(0) - Negativa');

WriteLn('(1) - Positiva');

ReadLn(Polaridade);

WriteLn;

WriteLn('Escolha a opcao de injecao :');

WriteLn;

WriteLn('G - Gravidade');

WriteLn('E - Eletrocinetica');

WriteLn('N - Sem injecao');

Repeat

ModoInjecao := Upcase(ReadKey);

Case ModoInjecao of

'G' : Begin

WriteLn;

Write('Tempo de Injecao ? (em

segundos): ')

$\operatorname{ReadLn}(\mathrm{t})$;

end;

'E' : Begin

WriteLn;

Write('Tempo de Injecao ? (em

segundos): ');

$\operatorname{ReadLn}(\mathrm{t})$;

Write('Alta tensao de injecao?

$(\mathrm{em} \mathrm{kV)}:$ ');

ReadLn(AtInj);

end;

'N' : WriteLn;

end;

Until (ModoInjecao = 'G') or

$($ ModoInjecao $=$ 'E') or $($ ModoInjecao $=$ 'N');

WriteLn;

Write('Tempo de Preenchimento da alca

de amostragem? (em segundos): ');

ReadLn(ta);

Write('Tempo para amostra chegar a

interface FIA-CE ? (em segundos) : ');

$\operatorname{ReadLn}(\mathrm{tb})$;

Write('Tempo para limpeza do percurso

FIA ? (em segundos): ');

ReadLn(tc);

WriteLn;

WriteLn('Tecle <ENTER> para iniciar aquisicao');

ReadLn;

tempo0 :=0;

TempoMin $:=0$;

tempoesp $:=0$;
Equip.BombaDes;

\{
ModoGrafico;
Cor(10);
W1.Init(1, 1, 479, 256, 0.0, 0.0, TMaximo, 4095.0, 4);

W1.TextoXY(410,5,'Detector');

W2.Init(1, 276, 479, 478, 0, 0.0, TMaximo,

50.0, 4);

W2.TextoXY(410,5,'Corrente');

With W3 do

Begin

Init(501, 1, 638, 478, 0.0, 0.0, 10.0, 10.0, 4);

TextoXY(50, 5, 'Parametros');

TextoXY(5, 50, 'i :'); TextoXY(100, 50,

'uA');

TextoXY(5, 100, 'v:'); TextoXY(100, 100,

'kV');

TextoXY(5, 150, 'T:'); TextoXY(100, 150,

'oC');

TextoXY(5, 200, 't:'); TextoXY(100, 200,

'min');

TextoXY(5, 250, 'Det:');

TextoXY (5, 450, AuxNome);

Case ModoInjecao of

'N' : TextoXY(5,300,'Sem Injecao');

'E' : Begin

TextoXY (5,300,'Eletro');

$\operatorname{Str}(\mathrm{t}: 2, \mathrm{~s})$;

TextoXY(5,315,s);TextoXY(50,315,'s');

Str(ATInj:2:1,s);

TextoXY(5,330,s);TextoXY(50,330,'kV');

End;

'G' : Begin

TextoXY (5,300,'Gravidade');

$\operatorname{Str}(\mathrm{t}: 2, \mathrm{~s})$;

TextoXY $(5,315, \mathrm{~s}) ; \operatorname{TextoXY}\left(50,315\right.$, ,'s'); $^{\prime}$ TextoXY(5,330,'Pressao'); End;

End;

End;

Equip.SetAT(ATDouble,Polaridade);

Equip.EnableAT;

ZeraCronometro;

ZeraCronometro2;

Acao := 'N';

Canal $:=$ 'A';

\{-------- Inicia Aquisicao de dados ------------- $\}$

With Equip do

Repeat

49 
TempoMin $:=1.0 *($ GetTemp o/(100*60));

TempoSeg $:=1.0 *($ GetTempo2/100);

LeCorrente(GCorrente,i,Polaridade);

LeTemp(temp);

LeAT(v);

If KeyPressed Then

Begin

Acao := UpCase $(\operatorname{ReadKey})$;

tempoesp : $=0$;

TempoSeg $:=0$;

ZeraCronometro2;

end;

If Acao $=$ 'A' Then

Begin

Canal := 'A';

Equip.AmosLig(Canal);

TempoSeg $:=0$;

tempoesp $:=0$;

ZeraCronometro2;

Acao := 'B';

end;

If $($ Acao $=$ 'B' $)$ and $($ TempoSeg $>=$ ta $)$

Then

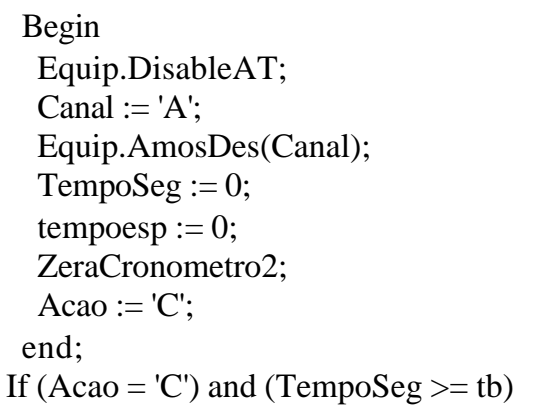

Then
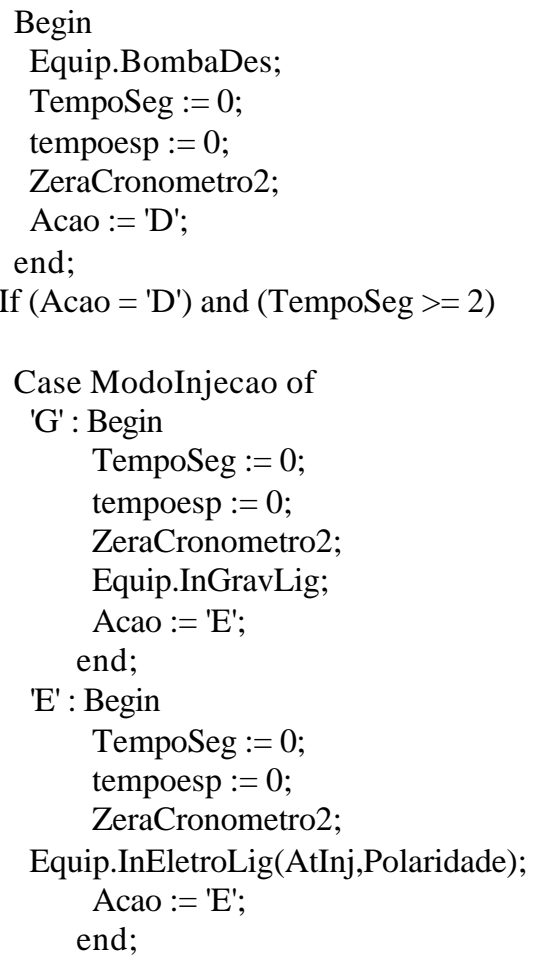

'N' : Begin

TempoSeg : $=0$;

tempoesp $:=0$;

ZeraCronometro2;;

Acao := 'E';

end;

end;

If $($ Acao $=$ 'E') and $($ TempoSeg $>=t)$ Then

Case ModoInjecao of

'G' : Begin

Equip.InGravDes;

TempoSeg $:=0$;

tempoesp $:=0$;

ZeraCronometro2;

Acao := 'F';

end;

'E' : Begin

Equip.InEletroDes;

TempoSeg $:=0$;

tempoesp : $=0$;

ZeraCronometro2;

Acao := 'F';

end;

'N' : Begin

TempoSeg : $=0$;

tempoesp $:=0$;

ZeraCronometro2;

Acao := 'F';

end;

end;

If $($ Acao $=$ 'F' $)$ Then

Begin

Canal := 'A';

Equip.BombaLig(Canal);

Acao := 'G';

end;

If $($ Acao $=$ 'G') and $($ TempoSeg $>=$ tc $)$ Then

Begin

Equip.BombaDes;

Equip.SetAT(ATDouble,Polaridade);

Equip.EnableAT;

TempoSeg : $=0$;

tempoesp $:=0$;

Acao := 'N';

end;

VDouble := ( $2 * \mathrm{v} 0 *$ FundoEscala/4095)-

FundoEscala;

WriteLn(arq,TempoMin:6:4,' ',VDouble);

With W1 do

Begin

Init(1, 1, 479, 256, 0.0, 0.0, TMaximo,

DetTelaMax, 4);

Ponto(TempoMin,v0,15);

Done;

End;

With W2 do 


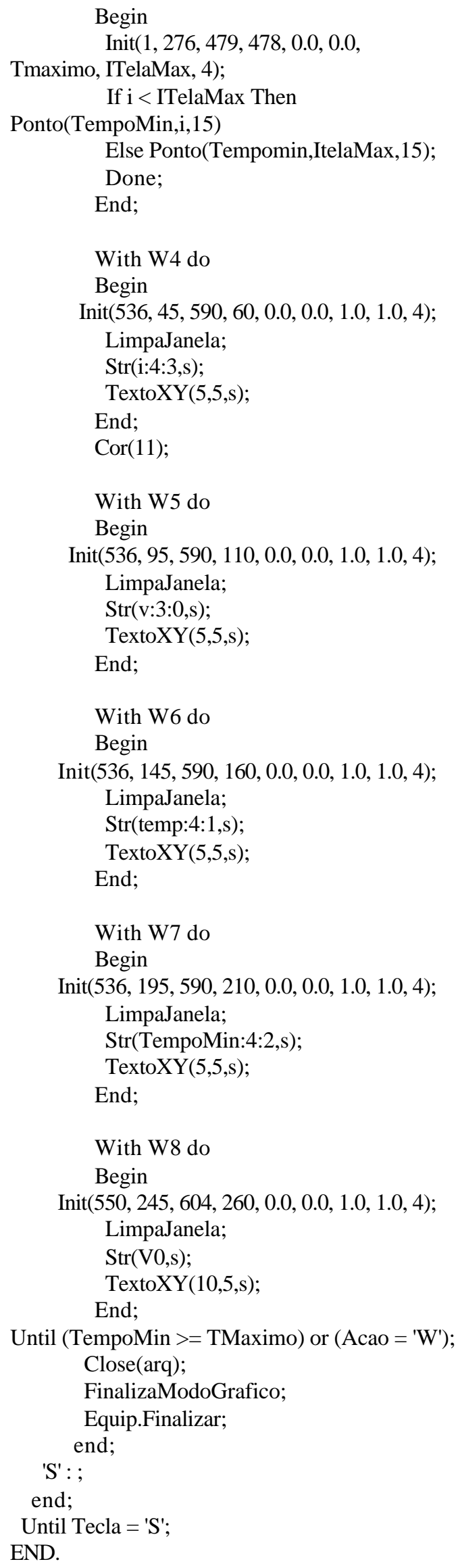

With W8 do

Begin

Init(550, 245, 604, 260, 0.0, 0.0, 1.0, 1.0, 4);

LimpaJanela;

Str(V0,s);

TextoXY $(10,5, \mathrm{~s})$;

End;

Until $($ TempoMin $>=$ TMaximo $)$ or $($ Acao $=$ 'W');

Close(arq);

FinalizaModoGrafico;

Equip.Finalizar; end;

'S' : ;

end;

Until Tecla = 'S';

END. 
Procedure CE.VacuoLig;

Unit EC;

Interface

Uses Dos, Crt, \{Printer, \} PCL;

Type $\mathrm{CE}=$ Object

Cartao : PCL711;

Indice : Byte;

Constructor Iniciar;

Destructor Finalizar;

Procedure VacuoLig;

Procedure VacuoDes;

Procedure AmosLig(Canal : Char);

Procedure AmosDes(Canal : Char);

Procedure BombaLig(Canal : Char);

Procedure BombaDes;

Procedure InGravLig;

Procedure InGravDes;

Procedure InEletroLig(AT : Double; Pol : Byte);

\{ AT UltraVolt \}

Procedure InEletroDes; \{ AT UltraVolt \}

Procedure LeTemp(var t : Double);

Procedure LeDetector(var Det : Word; Ganho :

Byte);

Procedure SetAT(Tensao : Double; Polaridade :

Byte); $\{$ AT UltraVolt $\}$

Procedure LeAT(var AT : Double); \{ AT

UltraVolt \}

Procedure LeCorrente(Ganho : byte; var i :

Double; Polaridade : byte); \{ AT UltraVolt \}

Function LeCanal7(Ganho : Byte) : Word;

Procedure EnableAT;

Procedure DisableAT;

\{Private

end;

Procedure Espera(TEspera : Real); \{ TEspera em segundos $\}$

type

Vetor $=$ array $[1 . .8]$ of Integer;

const

DOutPut: Vetor $=((1),(5),(4),(6),(2),(10),(8),(9))$;

implementation

Constructor CE.Iniciar;

Begin

Cartao.Init(0);

Indice $:=1$;

Cartao.DigOut $\left(0,{ }^{\prime}{ }^{\prime}\right)$;

Cartao.DigOut(0,'M');

End;

Destructor CE.Finalizar;

Begin

Cartao.Done;

End;

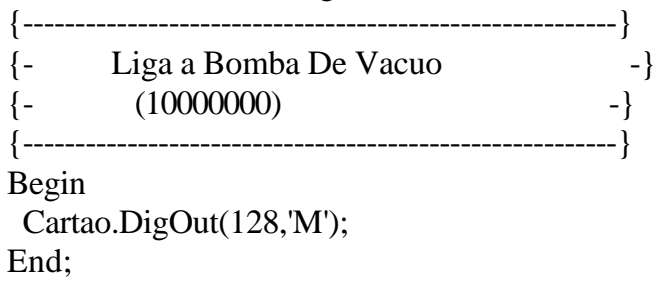

Procedure CE.VacuoDes;

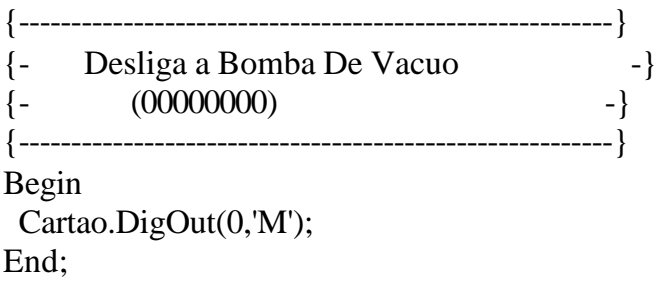

Procedure CE.AmosLig(Canal : Char);

$\left.\begin{array}{ccc}\{--- & \text { Liga o Injetor para Preenchimento } & - \\ \{- & \text { da alca de amostragem } & - \\ \{- & \text { e liga Bomba e abre o canal 1(A) } & - \\ \{- & \text { ou 2(B) ou 3(C) ou 4(D) } & -\end{array}\right\}$

Begin

Case Canal of

'A' : Begin

Cartao.DigOut(14,'M');

end;

'B' : Begin

Cartao.DigOut(22,'M');

end;

'C' : Begin

Cartao.DigOut(38,'M');

end;

'D' : Begin

Cartao.DigOut(70,'M'); end;

End;

End;

Procedure CE.AmosDes(Canal : Char);

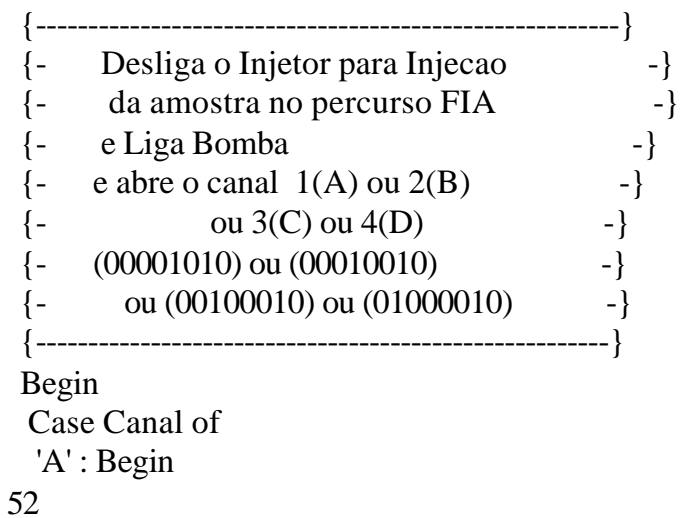


Cartao.DigOut(10,'M');

end;

'B' : Begin

Cartao.DigOut(18,'M');

end;

'C' : Begin

Cartao.DigOut(34,'M');

end;

'D' : Begin

Cartao.DigOut $\left(66, \mathbf{M}^{\prime}\right)$; end;

End;

End;

Procedure CE.BombaLig(Canal : Char);

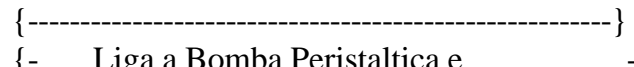

$\{-\quad$ Liga a Bomba Peristaltica e $\quad-\}$

$\{-\quad$ e abre o canal 1(A) ou 2(B) $\quad-\}$

$\{-\quad$ ou 3(C) ou 4(D) $\quad-\}$

$\{-\quad(00001010)$ ou $(00010010) \quad-\}$

$\{-\quad$ ou $(00100010)$ ou $(01000010) \quad-\}$

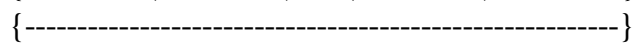

Begin

Case Canal of

$$
\begin{aligned}
& \text { 'A' : Begin } \\
& \text { Cartao.DigOut(10,'M'); } \\
& \text { end; }
\end{aligned}
$$

'B' : Begin

Cartao.DigOut(18,'M');

end;

' $\mathrm{C}$ ' : Begin

Cartao.DigOut(34,'M');

end;

'D' : Begin

Cartao.DigOut $\left(66,{ }^{\prime} \mathbf{M}^{\prime}\right)$; end;

End;

End;

Procedure CE.BombaDes;

\{------------------------------------------------------------ $\}$

\{- Desliga a Bomba Peristaltica - $\}$

\{- Deixando todos canais fechados (00000000) -

\{--------------------------------------------------------- $\}$

Begin

Cartao.DigOut $\left(0,{ }^{\prime} \mathbf{M}^{\prime}\right)$;

End;

Procedure CE.InGravLig;

\{--------------------------------------------------------- $\}$

\{- Desliga a Bomba Peristaltica e - $\}$

$\{$ - Liga a valvula de Injecao Gravitacional -

$\left\{\begin{array}{lll}\text { - } & (00000001) & -\}\end{array}\right.$

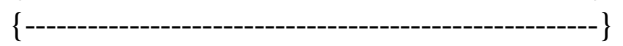

Begin

Cartao.DigOut(1,'M');

End;

Procedure CE.InGravDes;

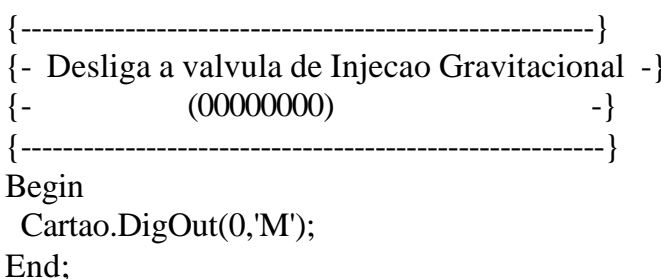

Procedure CE.InEletroLig(AT : Double; Pol : Byte);

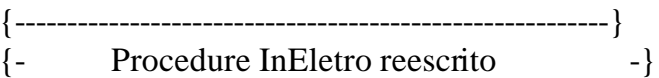

\{- para operar com a fonte de AT UltraVolt. - $\}$

$\{-\quad$ AT : Potencial aplicado; $\quad-\}$

$\{$ - Pol : Polaridade da fonte : 0-Neg, 1-Pos; - -

$\{-\quad-\}$

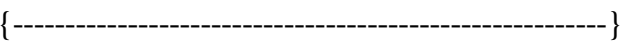

Begin

SetAT(AT,Pol);

EnableAT;

End;

Procedure CE.InEletroDes;

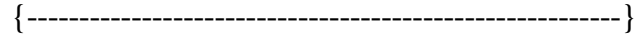

\{- $\quad$ Procedure InEletroDes reescrito $\quad-\}$

\{- para desligar a fonte de AT UltraVolt. $\quad-\}$

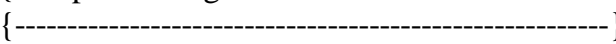

Begin

DisableAT;

End;

Procedure CE.LeTemp(var t : Double); $\{\mathrm{t}$ em oC $\}$ Begin

Cartao.SetCanal(3);

Cartao.SetGanho(3);

$\mathrm{t}:=0.0305^{*}$ Cartao.ADAvg(5000) - 62.5; \{ Com

curva de calibracao em 31/01/01 \}

$$
\left\{\mathrm{T}=0.0305^{*} \mathrm{~W}-62.5\right\}
$$

$\{$ Ajuste antigo $\}\left\{\mathrm{t}:=25.0^{*}(\operatorname{ADAvg}(50)-\right.$

2047)/1024.5;

End;

Procedure CE.LeDetector(var Det : Word; ganho :

Byte);

Begin

Cartao.SetCanal(6);

Cartao.SetGanho(Ganho);

Delay(1);

Det $:=$ Cartao.ADAVg(5000);

End;

Procedure CE.SetAT(Tensao : Double; Polaridade : Byte);

\{-------------------------------------------------------

$\{-\quad$ Procedure SetAT reescrito $\quad-\}$

\{- para operar com a fonte AT UltraVolt. $\quad-\}$

$\{-\quad$ AT : Potencial aplicado; -$\}$

$\{-$ Polaridade da fonte (fixa) : 0- Neg, 1- Pos; - $\}$

$\{-\quad-\}$ 


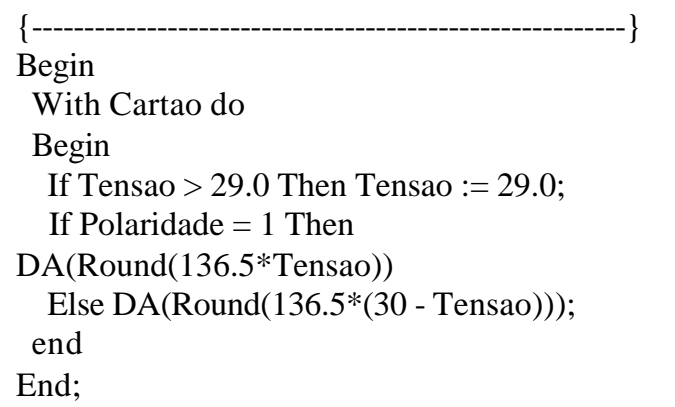

Procedure CE.LeAT(var AT : Double);

$\{-\quad$ Procedure LeAT reescrito -$\}$

$\{-\quad$ para operar com a fonte UltraVolt -$\}$

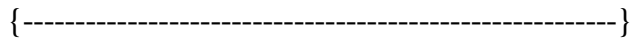

Begin

Cartao.SetCanal(2);

Cartao.SetGanho(4);

AT $:=0.01960 *($ Cartao.ADAvg(100)) - 39.6; \{

$\mathrm{AT}$ em kV \}

\{ Com curva de Calibracao em 12/07/2001 \}

$\{\mathrm{AT}:=128.4 * \mathrm{~V}-0.5\}$

End;

Procedure CE.LeCorrente(Ganho : byte; var i : Double; Polaridade : byte);

$\left\{\begin{array}{l}\{-\quad \text { Procedure LeCorrente reescrito } \\ \{-\quad \text { para operar com a fonte UltraVolt. } \\ \left\{---{ }_{-}-\right.\end{array}\right.$

Begin

Cartao.SetCanal(5);

Cartao.SetGanho(Ganho);

Case Ganho of

$0:$ i $:=0.17462 *($ Cartao.ADAvg(100)-2047.5);

$1: \mathrm{i}:=0.08731 *($ Cartao.ADAvg(100)-2047.5);

$2:$ i $:=0.04366 *($ Cartao.ADAvg(100)-2047.5);

$3: \mathrm{i}:=0.02183^{*}($ Cartao.ADAvg(100)-2047.5);

4 : i := 0.01091*(Cartao.ADAvg(100)-2047.5);

end;

$\{$ If Polaridade $=1$ Then $\mathrm{i}:=\mathrm{i}\}$

\{ Else $\mathrm{i}:=-\mathrm{i} ; \quad\}$

End;

Function CE.LeCanal7(Ganho : Byte) : Word;

Begin

Cartao.SetCanal(7);

Cartao.SetGanho(Ganho);

LeCanal7 := Cartao.ADAVg(200);

End;

Procedure CE.EnableAT;

Begin

Cartao.DigOut(1,'L');

End;

Procedure CE.DisableAT;
Begin

Cartao.DigOut(0,'L');

End;

Procedure Espera(TEspera : Real); $\{$ TEspera em segundos $\}$

var

t1, t2 : LongInt;

Hours, Minutes, Seconds, HundredSeconds : Word;

Dt : Real;

Begin

TEspera $:=$ TEspera $* 100$;

GetTime(Hours, Minutes, Seconds,

HundredSeconds);

$\mathrm{t} 1:=$ LongInt(Hours) $* 360000+\{3600 * 100\}$

LongInt(Minutes) $* 6000+\{60 * 100\}$

LongInt(Seconds) $* 100+$

LongInt(HundredSeconds);

Repeat

GetTime(Hours, Minutes, Seconds,

HundredSeconds);

t2 $:=$ LongInt(Hours) $* 360000+\{3600 * 100\}$

LongInt(Minutes) $* 6000+\{60 * 100\}$

LongInt(Seconds) $* 100+$

LongInt(HundredSeconds);

Dt $:=1.0 *(\mathrm{t} 2-\mathrm{t} 1)$;

Until Dt >= TEspera;

End;

var

regs : Registers;

Begin

regs.dx :=0;

regs.ah $:=1$;

intr (23, regs);

End. 


\section{Unit PCL;}

$\left.\begin{array}{lll}\{ & & \\ \{ & \text { Esta Unit possui os procedimentos para } & \\ \{ & \text { controle da Placa A-8111 } & \} \\ \{ & \text { Placa multifuncional 12-bit } & \} \\ \{ & \text { Entrada e Saída Digitais } & \} \\ \{ & \text { Conversor Analógico/Digital } & \} \\ \{ & \text { Conversor Digital /Analógico } & \end{array}\right\}$

interface

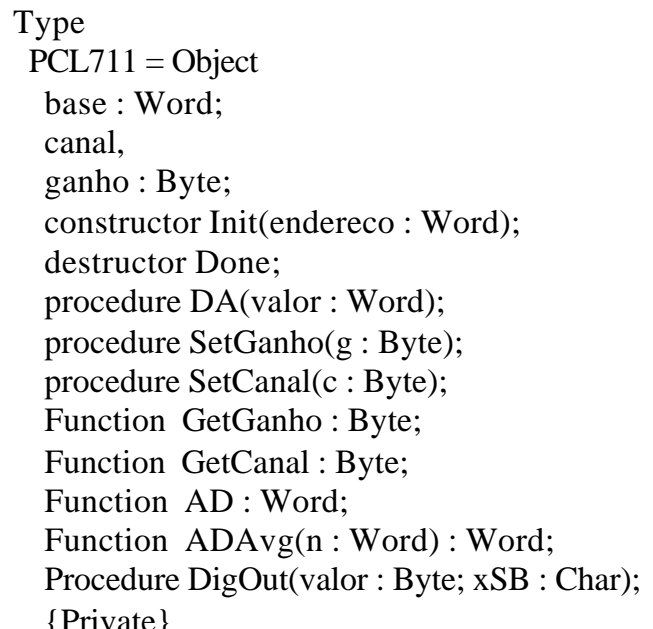

end;

implementation

Constructor PCL711.Init(endereco : Word);

Begin

If endereco $\langle>0$ then base $:=$ endereco else base

$:=\$ 220$

SetGanho(0);

SetCanal(0);

End;

Destructor PCL711.Done;

Begin

$\mathrm{DA}(0)$;

$\operatorname{DigOut}\left(0, \mathrm{~L}^{\prime}\right)$;

$\operatorname{DigOut}\left(0, \mathrm{M}^{\prime}\right)$;

End;

Procedure PCL711.DA(valor : Word);

Begin

PortW[base + 4] := valor;

End;

Procedure PCL711.SetGanho(g : Byte);

Begin ganho :=g;

Port[base + 9] := ganho;

End;

Function PCL711.GetGanho : Byte;

Begin

GetGanho := ganho;

End;

Procedure PCL711.SetCanal(c : Byte);

Begin

canal $:=\mathrm{c}$;

Port[base + 10] := canal;

End;

Function PCL711.GetCanal : Byte;

Begin

GetCanal := canal;

End;

Function PCL711.AD : Word;

var lixo : Word;

Begin

Port[base + 12] := 0;

lixo := lixo + 0;

While $(($ Port $[$ base +5$]$ and \$10 $)=\$ 10)$ do;

$\mathrm{AD}:=$ PortW[base +4$]$ and $\$ 0 F F F$;

End;

Function PCL711.ADAvg(n : Word) : Word; var i : Word;

soma : LongInt;

Begin

soma $:=0$;

For $\mathrm{i}:=1$ to $\mathrm{n}$ do soma $:=$ soma $+\mathrm{AD}$

ADAvg := soma div $n$;

End;

Procedure PCL711.DigOut(Valor : Byte; xSB : Char);

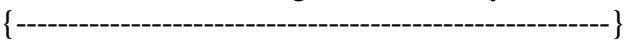

$\{-\quad$ Coloca um valor na saida digital. $\quad-\}$

\{- $\quad$ xSB se refere aos bytes LSB e MSB. - $\}$

$\{-\quad$ se $\mathrm{xSB}=\mathrm{L}, \mathrm{o}$ LSB sera atualizado, -$\}$

$\{-\quad$ se $\mathrm{xSB}=\mathrm{M}$ o MSB sera atualizado. $\quad-\}$

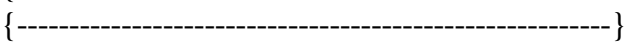

Begin

If $(\mathrm{xSB}=$ 'L')or(xSB = 'l') then Port[Base + 13] :=

Valor; $\{$ LSB $\}$

If $(\mathrm{xSB}=$ 'M')or(xSB = 'm') then Port[Base + 14] :=

Valor; $\{\mathrm{MSB}$ \}

End;

End. 


\section{Unit Graficos;}

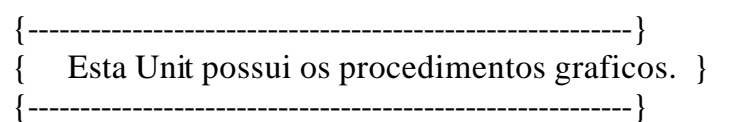

Interface

Uses Graph;

Type Janela $=$ Object

$\mathrm{X} 1, \mathrm{X} 2, \mathrm{Y} 1, \mathrm{Y} 2$ : Word;

FatorX, FatorY,

RX1, RX2, RY1, RY2 : Double;

Constructor Init(TelaX1, TelaY1, TelaX2,

TelaY2 : Word;

RealX1, RealY1, RealX2, RealY2 :

Double; cor: Byte);

Destructor Done;

Procedure SetRangeX(RealX1, RealX2 :

Double);

Procedure SetRangeY(RealY1, RealY2 :

Double);

Procedure Ponto(RealX, RealY : Double; Cor : Byte);

Procedure Linha(RealX1, RealY1, RealX2,

RealY2 : Double; Cor : Byte);

Procedure LinhaPara(RealX, RealY : Double;

Cor : Byte);

Procedure MovePara(RealX, RealY : Double);

Procedure SetCor(Cor : Byte);

Procedure TextoXY(TelaX, TelaY : Word; s :

String);

Procedure TextoRealXY(RealX,RealY :

Double ; s : String);

Procedure LimpaJanela;

\{Private

End;

Procedure ModoGrafico;

Procedure FinalizaModoGrafico;

Procedure Cor(Cor : Word);

Implementation

Procedure ModoGrafico;

Var

GD,GM : Integer;

Begin

$\mathrm{GD}:=$ Detect;

InitGraph(GD,GM,'c:Itpl');

if GraphResult <> grOk then Halt(1);

End;

Procedure FinalizaModoGrafico;

Begin

CloseGraph;

End;
Procedure Cor(Cor : Word);

Begin

SetColor(Cor);

End;

Constructor Janela.Init(TelaX1, TelaY1, TelaX2, TelaY2: Word;

RealX1, RealY1, RealX2, RealY2 :

Double;

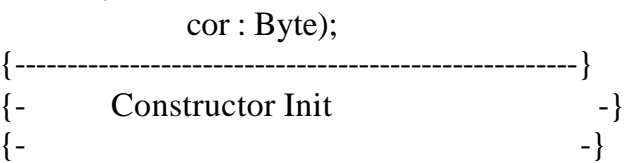

\{- Define um ViewPort com as coordenadas - $\}$

\{- de tela de entrada, ajusta as -$\}$

\{- coordenadas a um range $\mathrm{X}$ e $\mathrm{Y}$ definido -

\{- por parametros de entrada e -

\{- desenha uma moldura em torno da janela -$\}$

\{- com cor definida pelo parametro -$\}$

$\{$ - de entrada. Clip : ClipOn.

$\{-$

\{- Parametros - TelaX1, TelaX2 : X inicial -

\{- e final, coordenadas de tela - -

\{- TelaY1, TelaY2: Y inicial e final, " " " $\quad-\}$

\{- RealX1, RealX2 : Range X -

\{- RealY1, RealY2: Range Y -

$\{-\quad$ Cor : Cor da moldura da janela -$\}$

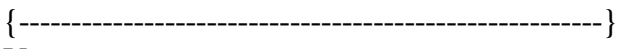

Var

CorAntiga : Byte;

Begin

CorAntiga := GetColor;

$\mathrm{X} 1:=$ TelaX1; X2 := TelaX2; Y1 := TelaY1; Y2 :=

TelaY2;

RX1 := RealX1; RX2 := RealX2; RY1 := RealY1;

$\mathrm{RY} 2:=$ RealY2

FatorX :=(X2-X1)/(RX2-RX1);

FatorY := (0-(Y2-Y1)/(RY2-RY1));

SetViewPort(0,0,GetMaxX,GetMaxY,ClipOn);

SetColor(Cor);

Rectangle(Pred(TelaX1), Pred(TelaY1),

Succ(TelaX2), Succ(TelaY2));

SetViewPort(TelaX1, TelaY1, TelaX2, TelaY2,

ClipOn);

SetColor(CorAntiga);

End;

Destructor Janela.Done;

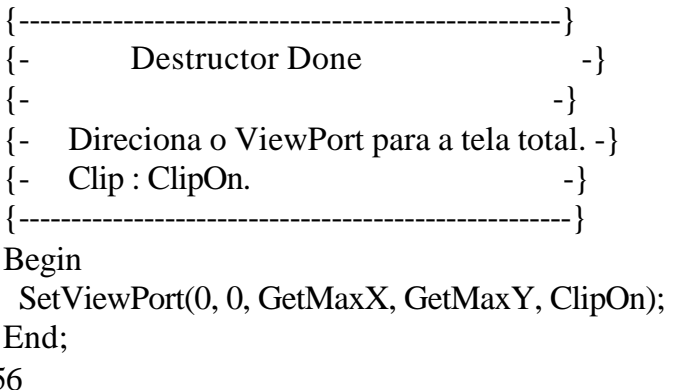


Procedure Janela.SetRangeX(RealX1, RealX2 : Double);

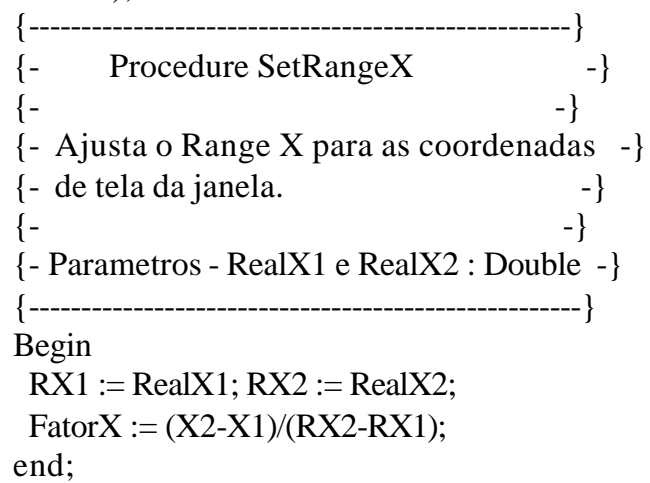

Procedure Janela.SetRangeY(RealY1, RealY2 : Double);

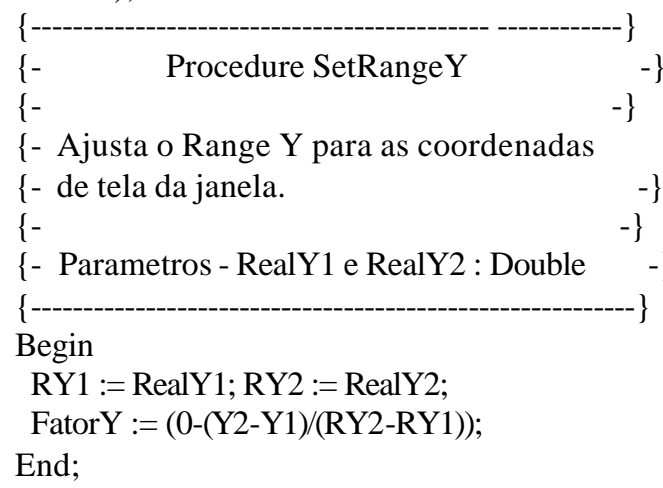

Procedure Janela.Ponto(RealX, RealY : Double;
Line(Px1,Py1,Px2,Py2);

MoveTo(Px2,Py2);

End;

Procedure Janela.LinhaPara(RealX, RealY : Double;

Cor: Byte);

Var

Px, Py : Word;

Begin

Px := Round(FatorX*(RealX-RX1) + 0);

Py := Round(FatorY*(RealY-RY1) +(Y2-Y1));

SetColor(Cor);

LineTo(Px,Py);

End;

Procedure Janela.MovePara(RealX, RealY : Double);

Var

Px, Py : Word;

Begin

Px := Round(FatorX*(RealX-RX1) + 0);

Py := Round(FatorY*(RealY-RY1) + (Y2-Y1));

MoveTo(Px,Py);

End;

Procedure Janela.SetCor(Cor : Byte);

Begin

SetColor(Cor);

End;

Procedure Janela.TextoXY(TelaX, TelaY : Word; s : String);

Begin

OutTextXY(TelaX,TelaY,s);

End;

Procedure Janela.TextoRealXY(RealX, RealY :

Double ; s : String);

Var

Px, Py : Word;

Begin

Px := Round(FatorX*(RealX-RX1) +0);

Py := Round(FatorY*(RealY-RY1) +(Y2-Y1));

OutTextXY(Px,Py,s);

End;

Procedure Janela.LimpaJanela;

Begin

SetViewPort(X1,Y1,X2,Y2,ClipOn);

ClearViewPort;

End;

End. 


\section{Currículum vitae}

\section{FABIANO SOUZA PALGROSSI}

Rua Izabel Ocaso $\mathrm{n} \stackrel{\circ}{ }$. 30 - Jardim Silveira

Barueri - SP CEP: 06433-240

Brasileiro, Solteiro, 26 anos

CRQ: 4145877 - 4ํㅡㄹ região

beirut6@yahoo.com

Tel: (11) 9199 - 3899

(11) $4162-1341$

\section{I - FORMAÇÃO}

Bacharelado em Química

Instituto de Química - Universidade de São Paulo

Ano de Conclusão: 2000

Licenciatura em Química

Faculdade de Educação - Universidade de São Paulo

Ano de Conclusão: 2000

Mestrado em Química Analítica Instrumental

Instituto de Química - Universidade de São Paulo

Ano de Conclusão: 2002

\section{II - EXPERIÊNCIA PROFISSIONAL}

Cargo: Químico Responsável

Local: Coalhobrás I. C. de Prod. Químicos Ltda. - Carapicuíba / Tel. 4187-3470

Período: Outubro de 2002 até a presente data.

Cargo: Professor de Ensino Médio

Local: E.E. Jardim Paulista - Barueri / Tel. 4194-0430

Período: Fevereiro de 1999 - Fevereiro de 2000

Cargo: Professor de Ensino Médio

Local: E.E. Prof ${ }^{a}$ Alayde D. C. Macedo - Barueri / Tel. 4194-0002

Período: Fevereiro de 1996 - Fevereiro de 2000

Cargo: Estagiário

Local: Laboratório de Automação e Instrumentação Analítica

Instituto de Química - USP / Tel. 3091-3781

Período: Agosto de 1996 - Julho de 2000

Cargo: Técnico Eletrônico de Manutenção

Local: Eletrônica Tele-Video / Barueri - SP

Período: Janeiro de 1992 - Dezembro de 1995 


\section{III - HABILIDADES}

Análises clássicas (Titulações, Gravimetria) e Análises instrumentais:

\begin{tabular}{|c|c|}
\hline CE, FIA. & $\begin{array}{l}\text { Construção de equipamentos e } \\
\text { desenvolvimento de métodos. }\end{array}$ \\
\hline $\begin{array}{c}\text { IC, HPLC, CG, MS, Espectrofotometria UV- } \\
\text { Vis, Calorimetria, Refratometria, } \\
\text { Polarimetria e Análises Eletroquímicas } \\
\text { (Polarografia, Eletrogravimetria, } \\
\text { Condutometria, Potenciometria,Voltametria, } \\
\text { Amperometria e Coulometria). }\end{array}$ & $\begin{array}{l}\text { Desenvolvimento de métodos, } \\
\text { assistência técnica. }\end{array}$ \\
\hline $\begin{array}{l}\text { Absorção Atômica, Fotometria de Chama, } \\
\text { Análise Térmica(TG e DTG), Colorimetria, } \\
\text { Fluorimetria e IMS. }\end{array}$ & $\mathrm{C}$ \\
\hline
\end{tabular}

\section{IV - INFORMÁTICA}

Bons conhecimentos em informática (Windows 3.11 e 95/8, Dos, LINUX, Internet Explorer, Netscape Navegator e Comunicator, HTML, Word, Access, PowerPoint, Excel, Origin, MathCad, Corel Draw, Gimp, Photoshop, Paint, Turbo C++, Pascal, Quick-Basic, Hp-VEE, Chemwin, Hiperchem e Matemathica).

\section{V - ELETRÔNICA}

Conhecimentos em elétrica, eletrônica e microeletrônica: planejamento, desenvolvimento, construção e manutenção de circuitos analógicos, circuitos digitais, automação de sistemas eletro-mecânicos, circuitos A/D e D/A, portas lógicas, montagem SMD, corrosão química de placas de circuito impresso.

\section{VI - MECÂNICA}

Conhecimentos em Qualidade Total (ISO NBR 9000), Mecânica de Precisão e Hidráulica: Torno, Fresadora, Furadeira de Bancada, Lixadeira, Relógio Apalpador, Paquímetro, Micrômetro, Mesa XY, Soprador Térmico, Maçarico, Serra circular, Fita e Tico-tico.

\section{VII - CURSOS EXTRACURRICULARES}

"Técnicas Básicas de Vendas" IPEB - São Paulo

"Preparo de Amostras" Departamento de Química - UFSCar.

"Tópicos Especiais em Biogeoquímica" Departamento de Química - UFSCar.

"Metodologia de Análise de Plantas" Congresso Brasileiro de Química - UFMA.

"Fundamentos e Aplicações em Química Forense" Congresso Brasileiro de Química, CBQ - UFMA, São Luís/MA.

"Introdução à análise por injeção em fluxo" CBQ - USP - SP.

"IX Curso de Primeiros Socorros" Escola de Enfermagem - USP. 


\section{VIII - LÍNGUAS}

Inglês Instrumental - Centro de Línguas da Faculdade de Filosofia, Letras e Ciências Humanas da Universidade de São Paulo(FFLCH-USP).

\section{IX - PARTICIPAÇÕES EM CONGRESSOS}

- Flow Analysis 9, Australia, 2003.

- 8. ${ }^{\circ}$ SIICUSP, Campus São Carlos, USP, São Carlos, 2000.

- XVISQ, IQ, USP, São Paulo, 1999.

- 7. SICUSP, Poli, USP, São Paulo, 1999.

- 4th. Latin-American Synposium on Biomedical, Biopharmaceutical and Industrial Aplications of Capillary Eletrophoresis, IQ - USP, São Paulo,1998.

- XXXVIII CBQ, ABQ / UFMA, São Luís, 1998.

- XIV SQ, IQ, USP, São Paulo, 1997.

- XXXVI CBQ, ABQ / IQ / IEA - USP, 1996.

\section{X - PUBLICAÇÕES}

- "Injetor Multicanal com Válvulas de Estrangulamento para Análise em Fluxo" Palgrossi, F.S.; Pedrotti, J.J.; Gutz, I.G.R., Química Nova, 24 (2001), 689.

\section{XI - OUTROS}

Trabalho Voluntário: Chefe de Tropa Escoteira no Grupo Escoteiro Bandeirantes, 310GE, Rua Recanto Infantil, 120 - Jd. Reginalice - Barueri - SP

Período: Fevereiro de 2001 até a presente data. 